\title{
WestVirginiaUniversity
}

THE RESEARCH REPOSITORY @ WVU

Graduate Theses, Dissertations, and Problem Reports

2007

\section{Evaluation of longwall face support hydraulic supply systems}

Ted M. Klemetti II

West Virginia University

Follow this and additional works at: https://researchrepository.wvu.edu/etd

\section{Recommended Citation}

Klemetti, Ted M. II, "Evaluation of longwall face support hydraulic supply systems" (2007). Graduate Theses, Dissertations, and Problem Reports. 4312.

https://researchrepository.wvu.edu/etd/4312

This Thesis is protected by copyright and/or related rights. It has been brought to you by the The Research Repository @ WVU with permission from the rights-holder(s). You are free to use this Thesis in any way that is permitted by the copyright and related rights legislation that applies to your use. For other uses you must obtain permission from the rights-holder(s) directly, unless additional rights are indicated by a Creative Commons license in the record and/ or on the work itself. This Thesis has been accepted for inclusion in WVU Graduate Theses, Dissertations, and Problem Reports collection by an authorized administrator of The Research Repository @ WVU. For more information, please contact researchrepository@mail.wvu.edu. 


\title{
Evaluation of Longwall Face Support Hydraulic Supply Systems
}

\author{
Ted M. Klemetti II \\ Thesis Submitted to the \\ College of Engineering and Mineral Resources \\ at West Virginia University \\ in partial fulfillment of the requirements \\ for the degree of \\ Master of Science \\ in \\ Mining Engineering \\ Syd S. Peng, Ph.D., Chair \\ Keith A. Heasley, Ph.D. \\ Yi Luo, Ph.D. \\ Thomas Barczak, Ph.D. \\ Department of Mining Engineering \\ Morgantown, WV \\ 2007
}

Keywords: Longwall Mining, Shields, Supports, Hydraulic Supply System, Setting Pressure

Copyright 2007 Ted M. Klemetti II 


\title{
ABSTRACT \\ Evaluation of Longwall Face Support Hydraulic Supply Systems
}

Ted M Klemetti II

\begin{abstract}
With increases in panel size and production levels in longwall mining, the hydraulic flow rates required to allow the shields to keep pace with the mining operations have substantially increased. The panel size and production increases have also increased the hydraulic supply system's pressure losses. To quantitatively evaluate the possible design changes to the hydraulic supply system, a practical and accurate method of evaluating potential hydraulic supply systems for the shields is needed. This thesis endeavors to develop a method to evaluate the effects on pressure and flow rate from changes in a hydraulic supply system and to determine the necessary design specifications of the system to supply a specific flow at a specific pressure at a particular mine site. An initial model was developed and shows great promise; however, additional field and laboratory testing are needed to calibrate the model for use in the design of hydraulic supply systems.
\end{abstract}




\section{ACKNOWLEDGMENTS}

I would like to extend sincere thanks to my committee chair, Dr. Syd Peng, for his guidance and understanding during the hours he devoted to helping me complete this thesis. I would also like to thank the other members of my committee, Dr. Keith Heasley, Dr. Li Yuo, and Dr. Thomas Barczak for their wisdom, advice, assistance, and support.

I would also like to thank the folks from DBT and Foundation Coal for their assistance and time. Specifically, Dan Lincoski, Peter Zhang, Jack Trackemas from Foundation Coal for their support and guidance.

I am grateful to the many people who supported and encouraged me during the completion of this thesis. First, I would like to thank my family and friends who have given me moral support and encouragement throughout my graduate studies. I am indebted to my mother, Elyce Biddle, for teaching me that with hard work and determination I can accomplish the goals that I have sought.

Without the help of all these folks, this thesis would not have been possible. 


\section{TABLE OF CONTENTS}

Page

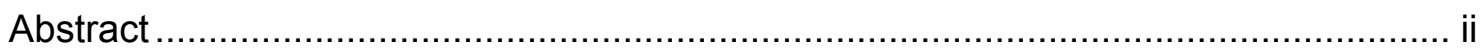

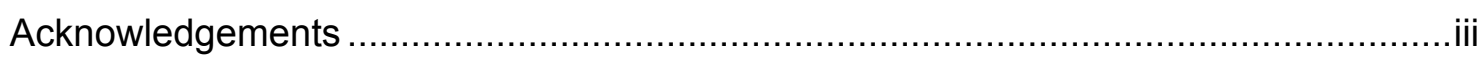

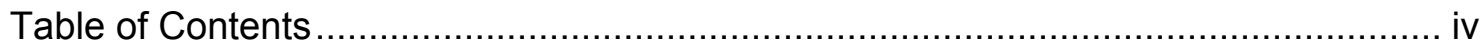

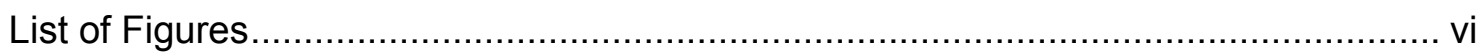

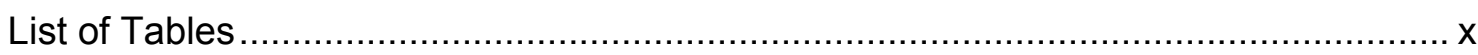

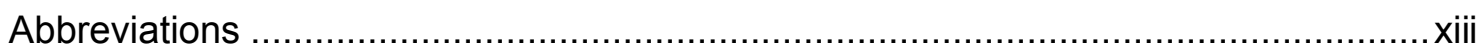

CHAPTER 1 - INTRODUCTION .................................................................... 1

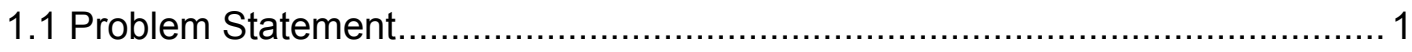

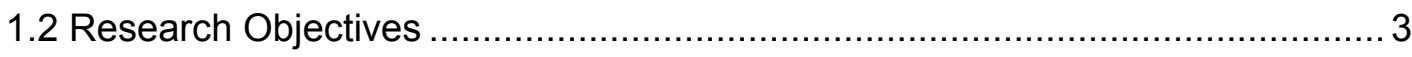

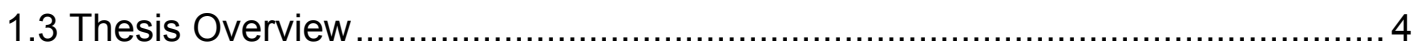

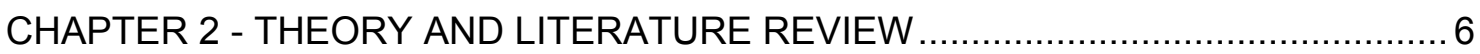

2.1 Longwall Mining Description \& Terminology ........................................... 6

2.2 Longwall Face Support Systems ......................................................... 10

2.3 Importance of Proper Setting Pressure and Flow Rate ............................... 19

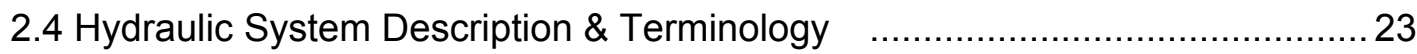

2.5 Fluid Mechanics of Hydraulic Supply Systems.......................................... 32

2.6 Previous Works in Hydraulic Supply Systems........................................... 43

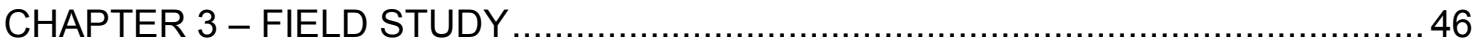

3.1 Information Required from Mine Site .................................................... 46

3.2 Field Site Hydraulic System and Operating Procedures ............................. 48

3.3 Location and Description of Instrumentation ............................................... 54

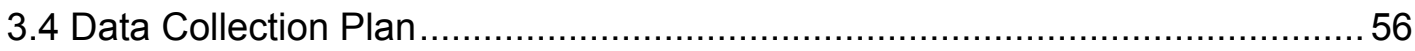

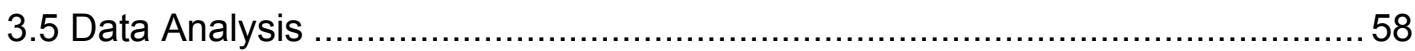

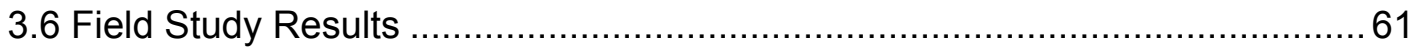

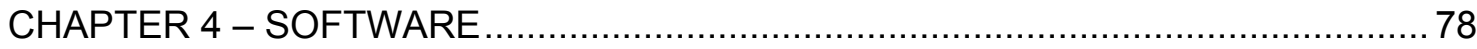

4.1 Critical Evaluation of Software ............................................................... 78

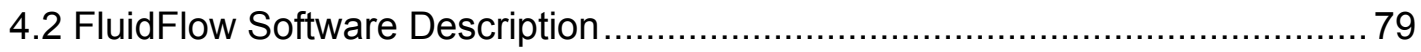

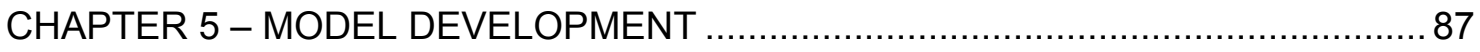

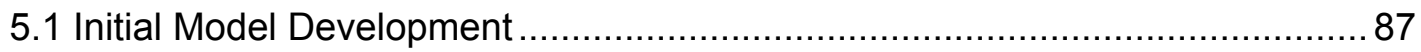

5.1.1 Initial Inputs from Previous Research......................................... 87

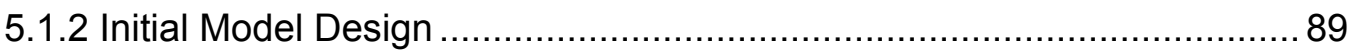




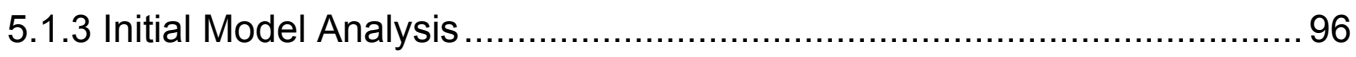

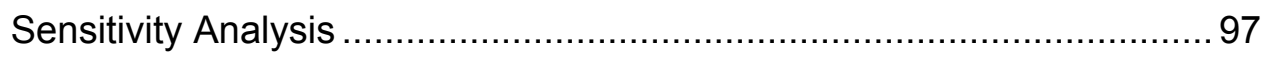

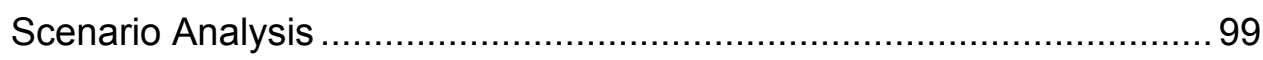

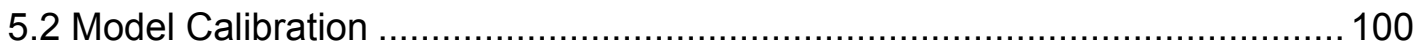

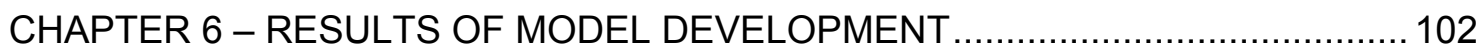

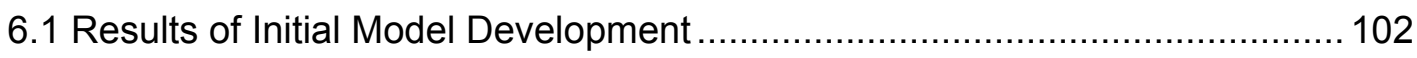

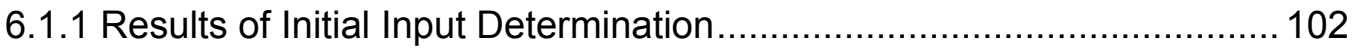

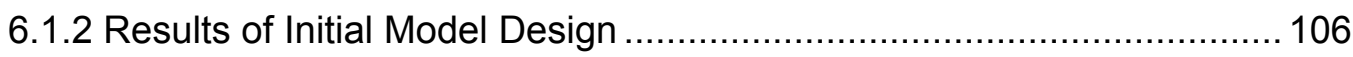

6.1.3 Results of Initial Model Analysis ...................................................... 107

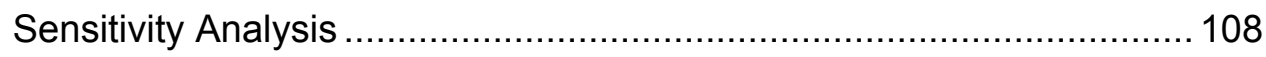

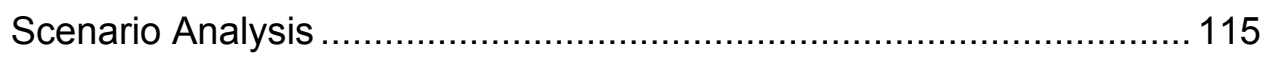

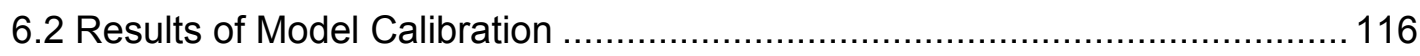

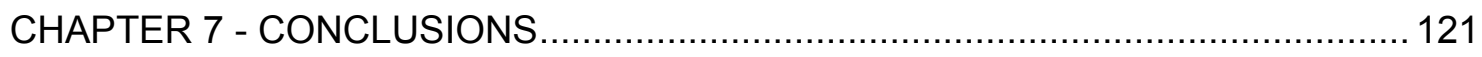

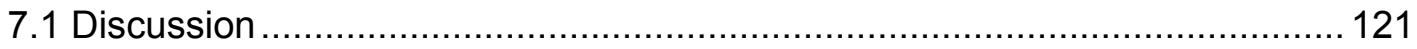

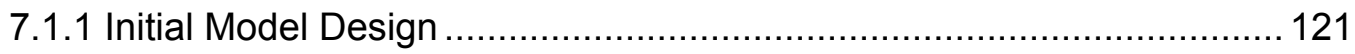

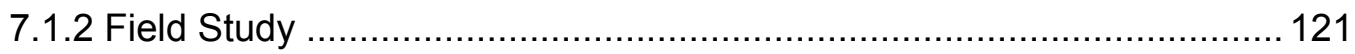

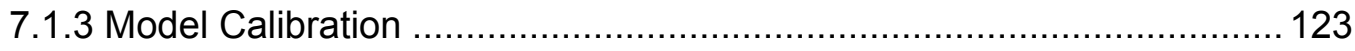

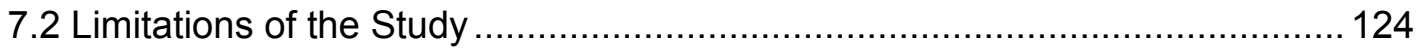

7.3 Future Research and Model Enhancements ........................................... 126

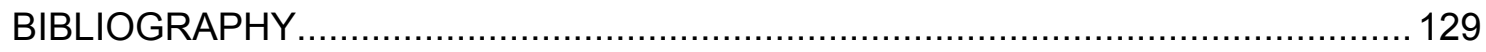

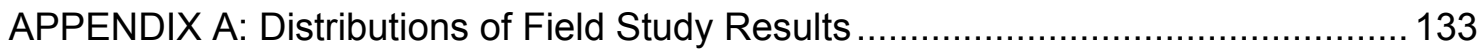

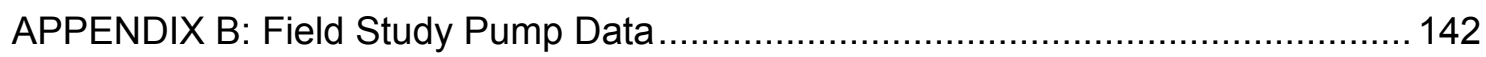




\section{LIST OF FIGURES}

Page

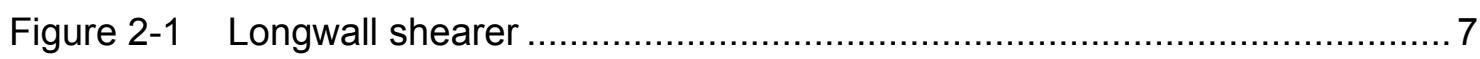

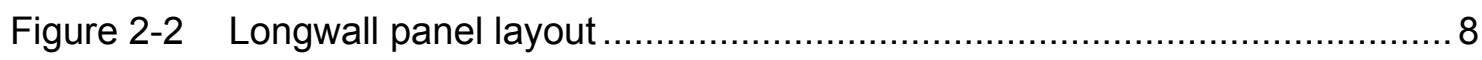

Figure 2-3 Depiction of frames and chocks ..................................................... 11

Figure 2-4 Depiction of shields and chock shield..............................................11

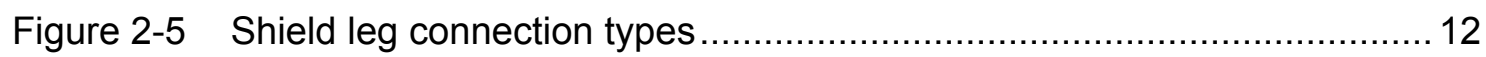

Figure 2-6 Components of a modern shield .......................................................... 14

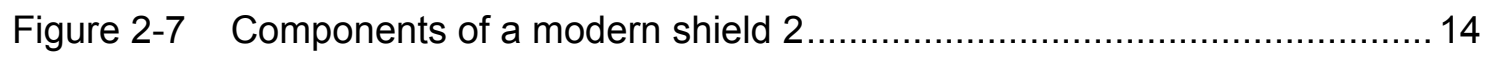

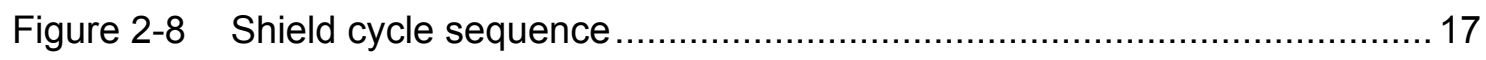

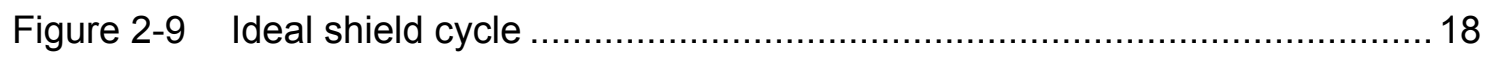

Figure 2-10 A sample schematic of longwall hydraulic system................................2 24

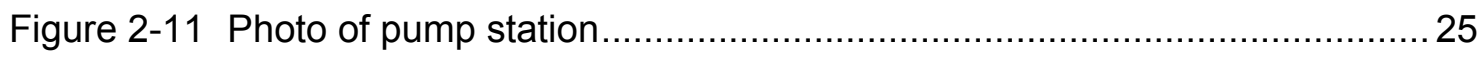

Figure 2-12 Sample positive displacement pump curve ………......................... 26

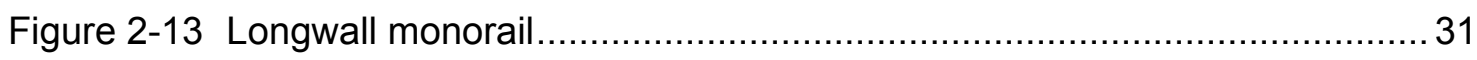

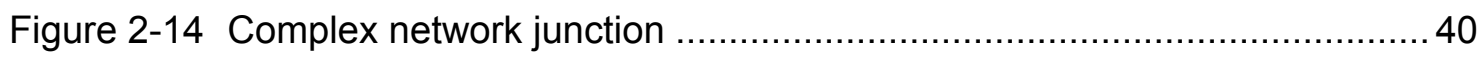

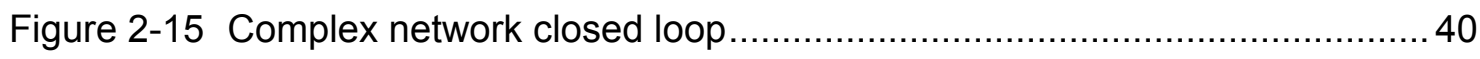

Figure 2-16 Depiction of the first network equation ........................................... 41

Figure 2-17 Depiction of the second network equation......................................... 42

Figure 3-1 Longwall hydraulic system layout ....................................................52

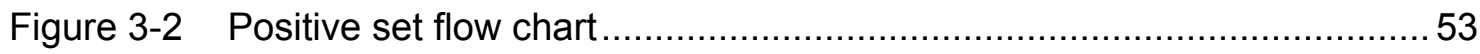

Figure 3-3 Photo of pressure transducer …………............................................ 55

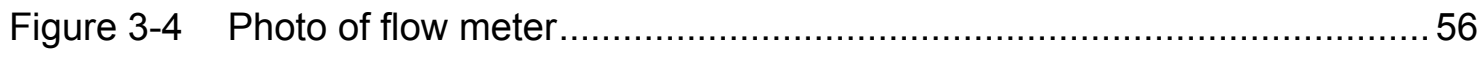

Figure 3-5 Depiction of the setting pressure determination algorithm .....................60 


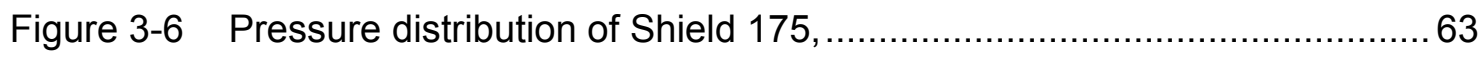

May 11 2007, 12:00 a.m. to May 12 2007, 8:00 a.m.

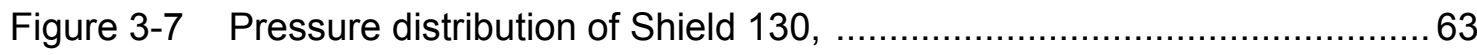

May 11 2007, 12:00 a.m. to May 12 2007, 8:00 a.m.

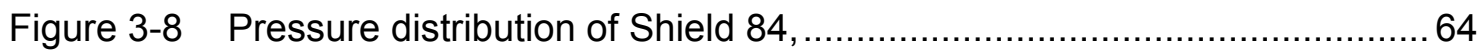

May 11 2007, 12:00 a.m. to May 12 2007, 8:00 a.m.

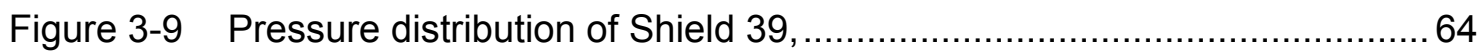

May 11 2007, 12:00 a.m. to May 12 2007, 8:00 a.m.

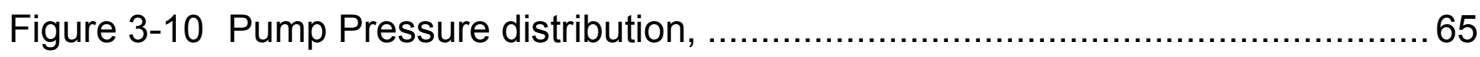

May 11 2007, 12:00 a.m. to May 12 2007, 8:00 a.m.

Figure 3-11 Flow distribution Flow 2, 65

May $112007,12: 00$ a.m. to May 12 2007, 8:00 a.m.

Figure 3-12 Flow distribution Flow 1, 66

May 11 2007, 12:00 a.m. to May 12 2007, 8:00 a.m.

Figure 3-13 Pressure distribution of Shield 175, 66

May 12 2007, 4:00 p.m. to May 13 2007, 11:59 p.m.

Figure 3-14 Pressure distribution of Shield 130, 67

May 12 2007, 4:00 p.m. to May 13 20007, 11:59 p.m.

Figure 3-15 Pressure distribution of Shield 84, 67

May 12 2007, 4:00 p.m. to May 13 2007, 11:59 p.m.

Figure 3-16 Pressure distribution of Shield 39, 68

May 12 2007, 4:00 p.m. to May 13 2007, 11:59 p.m.

Figure 3-17 Pump Pressure distribution, 68 May 12 2007, 4:00 p.m. to May 13 2007, 11:59 p.m.

Figure 3-18 Flow distribution Flow 2, 69

May 12 2007, 4:00 p.m. to May 13 2007, 11:59 p.m.

Figure 3-19 Flow distribution Flow 1, 69 May 12 2007, 4:00 p.m. to May 13 2007, 11:59 p.m.

Figure 3-20 Setting pressure across face, May 11 2007, 8 a.m. to 4 p.m. 71 vii 
Figure 3-21 Setting pressure across face, May 13 2007, 8 a.m. to 4 p.m. 71

Figure 3-22 Pump output just prior to power station move ............................... 73

Figure 3-23 Pump output just after power station move ................................. 74

Figure 3-24 Depiction of time delay across the face ...................................... 76

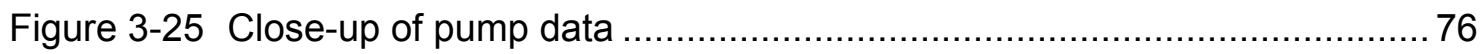

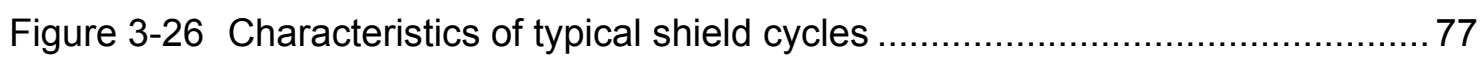

Figure 4-1 Sample display from FluidFlow, add components to library .................. 82

Figure 4-2 Sample display from FluidFlow, default component function ................. 83

Figure 4-3 Sample display from FluidFlow, add component function ..................... 84

Figure 4-4 Sample display from FluidFlow, solve function............................... 85

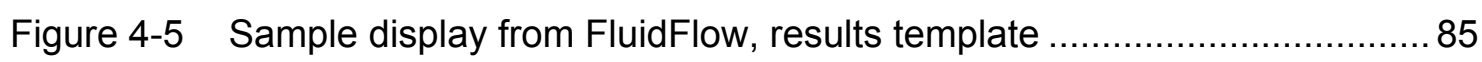

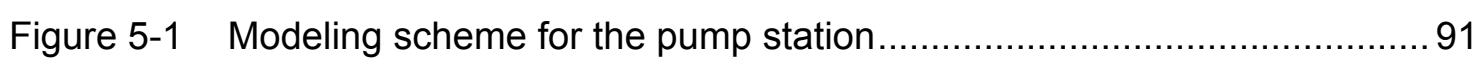

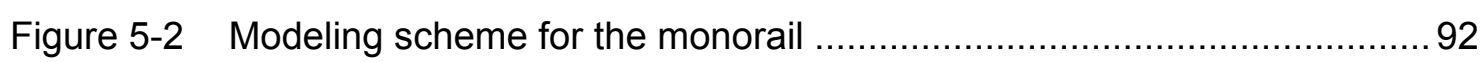

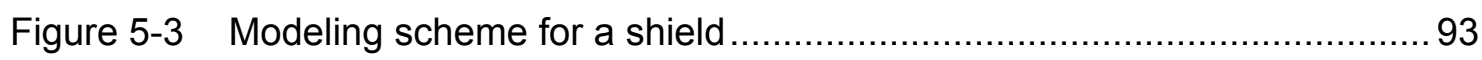

Figure 5-4 Initial model with panline potential pressure loss ............................ 94

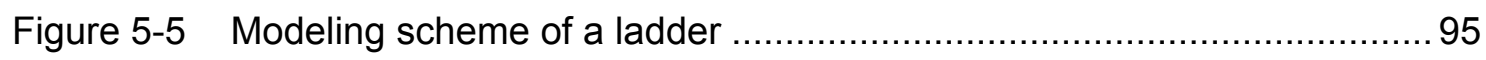

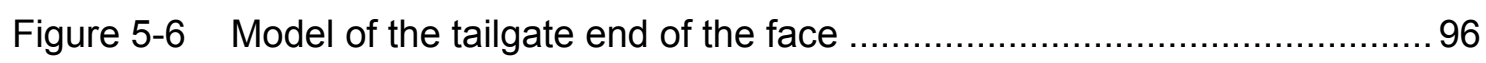

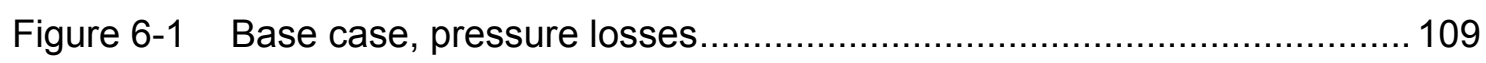

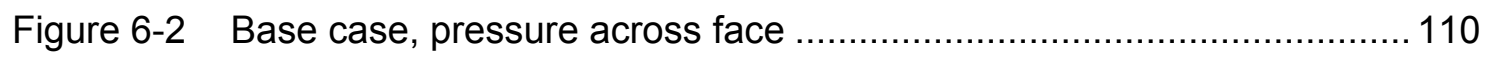

Figure 6-3 Variation of pressure losses due to filter changes ........................... 111

Figure 6-4 Variation of pressure losses due to flow rate................................... 112

Figure 6-5 Variation of pressure across face due to pump pressure .....................113

Figure 6-6 Variation of pressure losses due to roughness coefficients ................ 114

Figure 6-7 Variation of pressure across face due to scenarios........................... 115

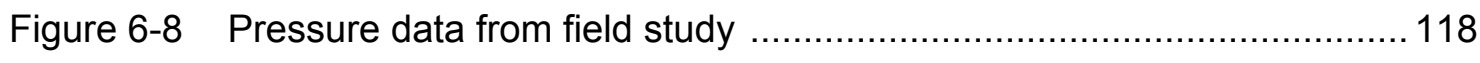


Figure 6-9 Pressure data from field study, second sample .......................... 119

Figure 6-10 Pressure data from field study, third sample .............................. 120

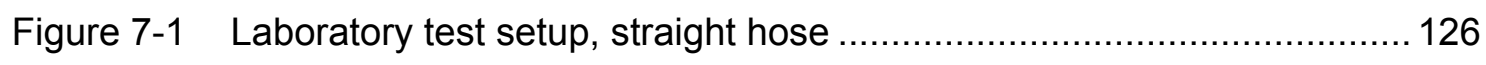

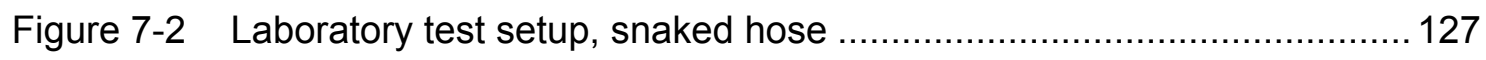




\section{LIST OF TABLES}

\section{Page}

Table 2-1 Hazen-Williams coefficients for some common materials ...................... 37

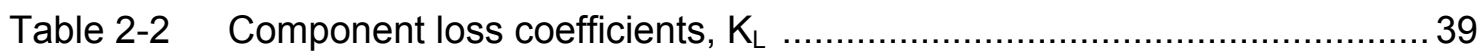

Table 3-1 Central Tendency of Pump Flow \& Pressure, ................................... 61 May $11,2007,12: 00$ a.m. to $8: 00$ a.m.

Table 3-2 Central Tendency of Pump Flow \& Pressure, ................................... 62 May $13,2007,12: 00$ a.m. to 8:00 a.m.

Table 4-1 Critical evaluation of existing software ............................................ 79

Table 5-1 Darcy-Weisbach roughness coefficients ...................................... 88

Table 6-1 Roughness coefficient existing cases ....................................... 103

Table 6-2 Roughness coefficient hand calculations using existing cases ............ 104

Table 6-3 Roughness coefficient FluidFlow calculations using existing cases...... 105

Table 6-4 Typical longwall pump station output........................................ 106

Table $6-5 \quad$ Calibration input information .................................................... 116

Table 6-6 Measured pressure changes in the face hoses ........................... 117

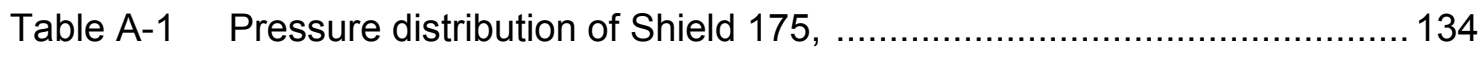
May 11 2007, 12 a.m. to May 12 2007, 8 a.m.

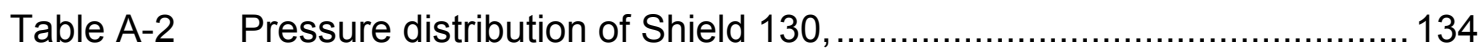
May 11 2007, 12 a.m. to May 12 2007, 8 a.m.

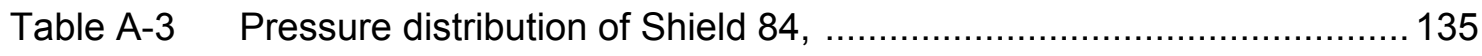
May 11 2007, 12 a.m. to May 12 2007, 8 a.m.

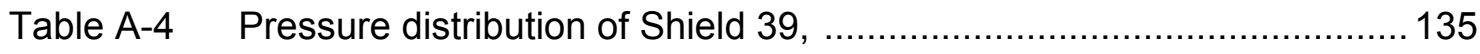
May 11 2007, 12 a.m. to May 12 2007, 8 a.m. 
Table A-5 Pump pressure distribution,

May 11 2007, 12 a.m. to May 12 2007, 8 a.m.

Table A-6 Flow distribution Flow 2,

May 11 2007, 12 a.m. to May 12 2007, 8 a.m.

Table A-7 Flow distribution Flow 1, 137

May 112007,12 a.m. to May 12 2007, 8 a.m.

Table A-8 Pressure distribution of Shield 175, 138

May 12 2007, 4 p.m. to May 13 2007, 11:59 p.m.

Table A-9 Pressure distribution of Shield 130, 138

May 12 2007, 4 p.m. to May 13 2007, 11:59 p.m.

Table A-10 Pressure distribution of Shield 84, 139 May 122007,4 p.m. to May 13 2007, 11:59 p.m.

Table A-11 Pressure distribution of Shield 39, 139

May 12 2007, 4 p.m. to May 13 2007, 11:59 p.m.

Table A-12 Pump pressure distribution, 140

May 12 2007, 4 p.m. to May 13 2007, 11:59 p.m.

Table A-13 Flow distribution Flow 2, 141

May 12 2007, 4 p.m. to May 13 2007, 11:59 p.m.

Table A-14 Flow distribution Flow 1, 141

May 12 2007, 4 p.m. to May 13 2007, 11:59 p.m.

Table B-1 Central tendency of pump flow \& pressure, 143

May 112007,12 a.m. to 8 a.m.

Table B-2 Central tendency of pump flow \& pressure, 143 May 112007,8 a.m. to 4 p.m. 
Table B-3 Central tendency of pump flow \& pressure, 143 May 112007,4 p.m. to $11: 59$ p.m.

Table B-4 Central tendency of pump flow \& pressure, 144 May 122007,12 a.m. to 8 a.m.

Table B-5 Central tendency of pump flow \& pressure, 144 May 12 2007, 8 a.m. to 4 p.m.

Table B-6 Central tendency of pump flow \& pressure, 144 May 122007,4 p.m. to $11: 59$ a.m.

Table B-7 Central tendency of pump flow \& pressure, 145 May 132007,12 a.m. to 8 a.m.

Table B-8 Central tendency of pump flow \& pressure, 145 May 13 2007, 8 a.m. to 4 p.m.

Table B-9 Central tendency of pump flow \& pressure, 145 May 13 2007, 4 p.m. to 11:59 p.m. 


\section{ABBREVIATIONS}

$$
\begin{aligned}
& \text { psi - pounds per square inch } \\
& \text { in - inch } \\
& \mathrm{ft} \text { - feet } \\
& \text { gpm - gallons per minute, US } \\
& \text { I/min - liters per minute } \\
& \mathrm{ft} / \mathrm{s}^{2} \text { - feet per second squared } \\
& \mathrm{m} / \mathrm{s}^{2} \text { - meter per second squared } \\
& \mathrm{mm} \text { - millimeter } \\
& \text { gal - gallon } \\
& \mathrm{L} \text { - length } \\
& \text { D - diameter } \\
& \text { Q - flow rate } \\
& \Delta \mathrm{P} \text { - pressure loss } \\
& \varepsilon / D \text { - roughness coefficient } \\
& \text { HFA - hydraulic fluid additive } \\
& \text { AFC - armored face conveyor } \\
& \text { ID - inner diameter } \\
& \text { FM - flow meters } \\
& \text { PT - pressure transducers }
\end{aligned}
$$




\section{CHAPTER 1: INTRODUCTION}

\subsection{PROBLEM STATEMENT}

Although coal mining has been ongoing for centuries, longwall mining technology was first introduced in the United States in the early 1960's. Adapted from methods used in other countries, this new methodology was initially met with mixed acceptance. In order for longwall mining to be adopted in the U.S., it had to be efficient, safe, and cost effective. To meet these goals, drastic changes from the original longwall mining systems were necessary. Some of the more substantial changes needed were the use of retreat mining, bleeder entries, and modified support and mining systems. Until these changes were implemented, the majority of underground coal production in the U.S. followed traditional mining practices, instead of the more efficient longwall-mining methodology. When modification to established longwall methods were implemented to accommodate these improved technologies and procedures, considerable increases in coal production and significant reductions in workforce size were realized. As a function of these and other factors, the physical size of mines has enlarged over time. Today, following thirty years of longwall mining evolution, the method has received widespread acceptance, and currently nearly $52 \%$ of all underground coal mined in the U.S. utilizes the longwall mining method (Peng, 2006, pg 13).

With the increases in panel size and production levels in longwall mining, the hydraulic flow rates required to allow the shields to keep pace with the mining operations have substantially increased. The panel size and production increases have also increased the hydraulic supply system's pressure losses. Striving to operate at maximal efficiency, 
the hydraulic systems should have undergone substantial changes in their designs to maintain the setting pressure with the increased speed of the modern longwall mining systems and to accommodate the increased flow demands with resultant increases in pressure loss.

There have been a few completed studies that show possible methods of updating the hydraulic supply system in order to meet these new demands. Some of the recommendations include larger supply hoses, more flow pathways, and even switching to pipes rather than hoses. Although all of these methods are capable of raising the available flow without significant loss of pressure, very little research has been done on the exact effects of these changes in practice. Although the mining industry has done little research on the fluid dynamics of the hydraulic supply systems, several other industries have done exhaustive studies on similar hydraulic systems. Much of this research has focused on the pressure losses associated with pipes, hoses, tubes and various other components of hydraulic systems.

In order to quantitatively evaluate the possible design changes available to the hydraulic supply system, a practical and accurate method of evaluating potential hydraulic supply systems is needed. This thesis intends to develop a method that will evaluate the effects on pressure and flow rate from varying operational and design aspects of a hydraulic supply system. The goal is to determine a site specific system design to supply a required flow at a required operating pressure. 


\subsection{RESEARCH OBJECTIVES}

The primary goal is to develop a method to evaluate the longwall support hydraulic system. Since fluid dynamics is not a new field and there have been various hydraulic networks in operation for years, many methods of evaluating such a network have been developed. There are both numerical and graphical methods of solving the network flow problems. These methods can be solved by hand, but are tedious and time consuming. Thus for this application, it is beneficial to use a computer program that can perform the calculations much faster. This program would need to be compliant with the fluid dynamic laws associated with the existing hydraulic supply system as well as capable of evaluating proposed changes. In order to facilitate the primary goal, this research will adopt a computerized flow network applications program that has been developed for use in other industries. This research has three main objectives.

The first objective is to determine an appropriate software program that is capable of modeling the existing longwall face support hydraulic supply system. This program must be capable of including changes in inputs as the hydraulic system changes to insure that the appropriate setting pressure and required flow is delivered to the shields.

The second objective is to adapt the software program to replicate the components of the longwall hydraulic supply system. This will require conceptualizing the longwall shield so that it can be translated for use in the software program. Consideration of the complexity of the hydraulic supply system, combined with limitations of the data collected from the field site, must be considered in determining any modifications of the hydraulic supply system as represented in the software program. 
The last objective is to demonstrate the capability and validity of the chosen software program by evaluating an existing hydraulic system at an operational mine. The developed model will be calibrated with physical flow and pressure measurements from the mine. This calibration will lead to accurate values for critical input parameters such as coefficients of friction and relative roughness coefficients for the hydraulic supply system employed by the longwall face supports. These values can then be used to evaluate alternative designs with either the same or different software in order to insure the proper setting pressure is realized at the face supports.

The end result of this thesis work will be a methodology utilizing a pre-existing software program that will be able to model varying hydraulic systems to insure that the appropriate flow and pressures can be delivered when needed to the longwall face supports.

\subsection{THESIS OVERVIEW}

This study is presented in seven chapters; the first being the introduction. The following paragraphs briefly describe the remaining chapters.

A literature review and discussion of background information and theories related to fluid mechanics is contained in Chapter 2. This chapter discusses longwall mining description and terminology, face support system description, longwall hydraulic supply system descriptions, and relevant fluid mechanic theories. A review of the literature 
summarizing previous studies on the evaluation of hydraulic supply systems in mining is also found in this chapter.

The field study is presented in Chapter 3, which includes a description of the information required from the mine site, the field site's hydraulic system and operating procedures, and the location and description of the instrumentation used at the site. The data collection plan and the data analysis are also included in this chapter. The final portion of Chapter 3 provides the results of the field study work.

Chapter 4 presents a description of FluidFlow, the software used in this thesis, and describes the method of inputting system components into the software.

Chapter 5, Model Development, presents the methods involved in the initial model design, beginning with presentation of the method for determining the initial inputs, derived from prior research findings. The chapter finishes with an analysis of the initial model. The analysis section also includes the methods to conduct sensitivity and scenario analyses. Model calibration is described in Section 5.2.

The results from the initial model development are found in Chapter 6, with specific sections on what inputs were used, the initial model design, and the initial model analysis. The chapter is completed with the results from the model calibration.

The final chapter, Chapter 7, presents conclusions, discusses the limitations of the study, and presents potential future research. 


\section{CHAPTER 2: THEORY AND LITERATURE REVIEW}

\subsection{LONGWALL MINING DESCRIPTION \& TERMINOLOGY}

Much of mining terminology is unique to the industry. "Inby" and "outby" are two key terms that are used in all underground mining and should be defined at the earliest opportunity for purposes of clarity. Inby is any area that is further from the shaft or mine exit, whereas outby is any area which is closer to the shaft.

Additionally, many other coal mining specific terms are defined by industry practice and nomenclature, especially those dealing with the equipment and methods used in longwall coal mining. A more detailed understanding of the terminology and procedures used in longwall mining is beneficial to the understanding of the importance of proper shield hydraulic supply system pressures. A better understanding of longwall mining will also facilitate the dissemination of the results from this study. The remainder of this section provides definitions of key terms and methods associated with longwall mining.

Longwall mines in the U.S. have traditionally used two basic types of mining methods. The first type, named the room \& pillar method, utilizes the continuous miner. This method is used to develop the entries around the longwall panels as well as all the other entries throughout the mine. The second method is the actual longwall face mining that is commonly referred to as mechanized longwall mining. Mechanized longwall mining utilizes a shearer or plow, hydraulic roof supports, an armored face conveyor (AFC), and belt conveyor. The hydraulic supports assist in holding up the roof and in advancing the AFC and are numbered, beginning with one and running sequentially, from headgate to 
tailgate. The AFC is used to move the mined coal away from the coal face to the gate road as well as a platform for the shearer or plow to ride on. The shearer or plow is used to remove the coal in passes. Typical passes for the shearer remove slabs of coal some 36-42 in deep, 5-12 ft tall, and 600-1,450 ft long, as seen in Figure 2-1.

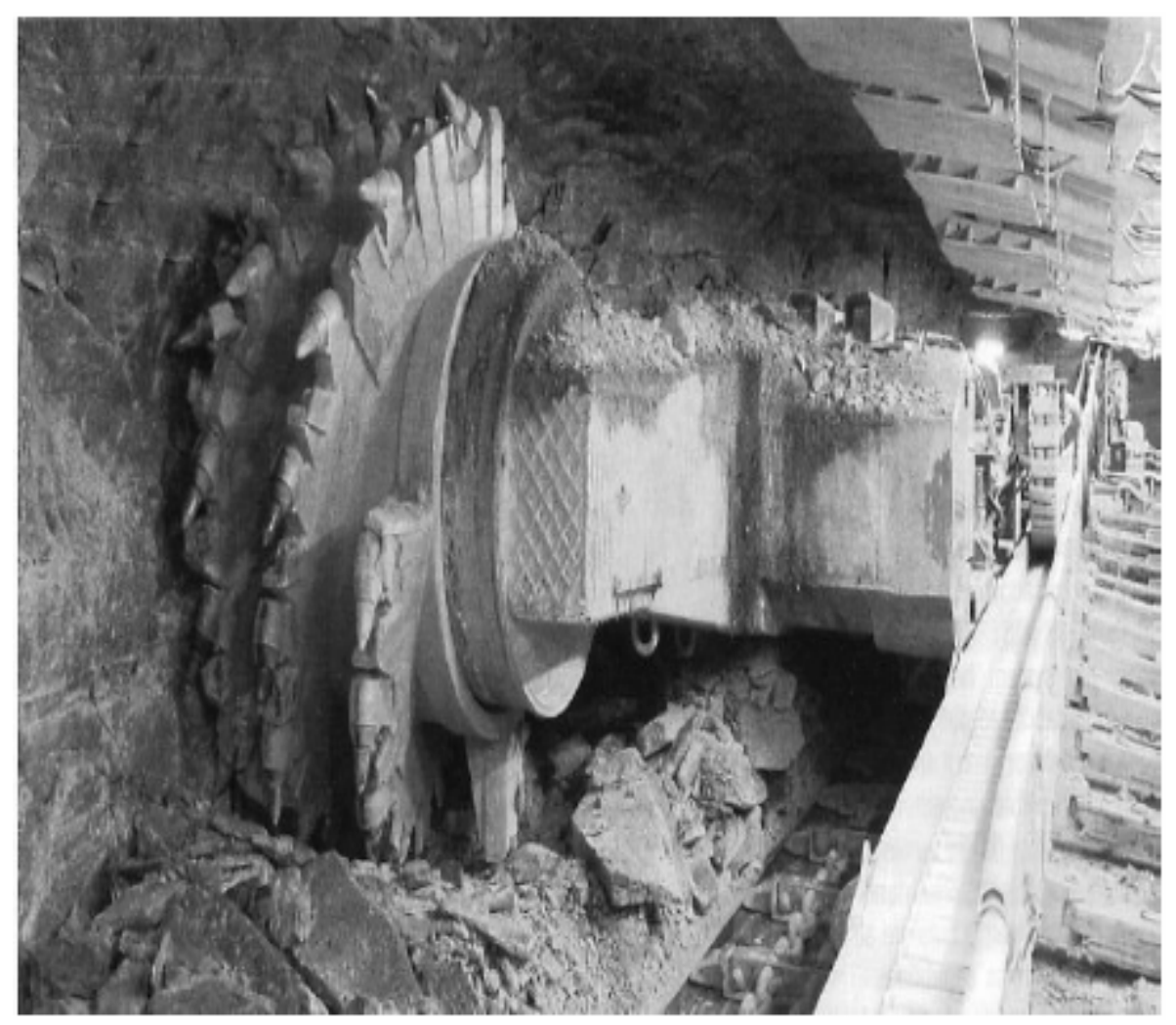

Figure 2-1, Longwall shearer (Source: Peng, 2006)

Although there are other methods used throughout the world, the U.S. uses a retreat method for longwall mining (Figure 2-2). In the retreat method, longwall mining begins at the bleeder entries and proceeds toward the main entries, or moves from inby to outby. The main entries, or mains/submains, stem from the shaft and progress out toward the property boundaries. Off the mains, development sections or entries are driven. These entries, often referred to as gate roads, run parallel to the longwall panel length. Once 
these entries reach the intended panel length, bleeder entries are driven to connect the two gate roads on either side of the future longwall panel. Bleeder entries, which are unique to the U.S., are entries used at the back side of the longwall panel to allow for ventilating the gob. As seen in Figure 2-2, the panel is surrounded by the main, development, and bleeder entries.

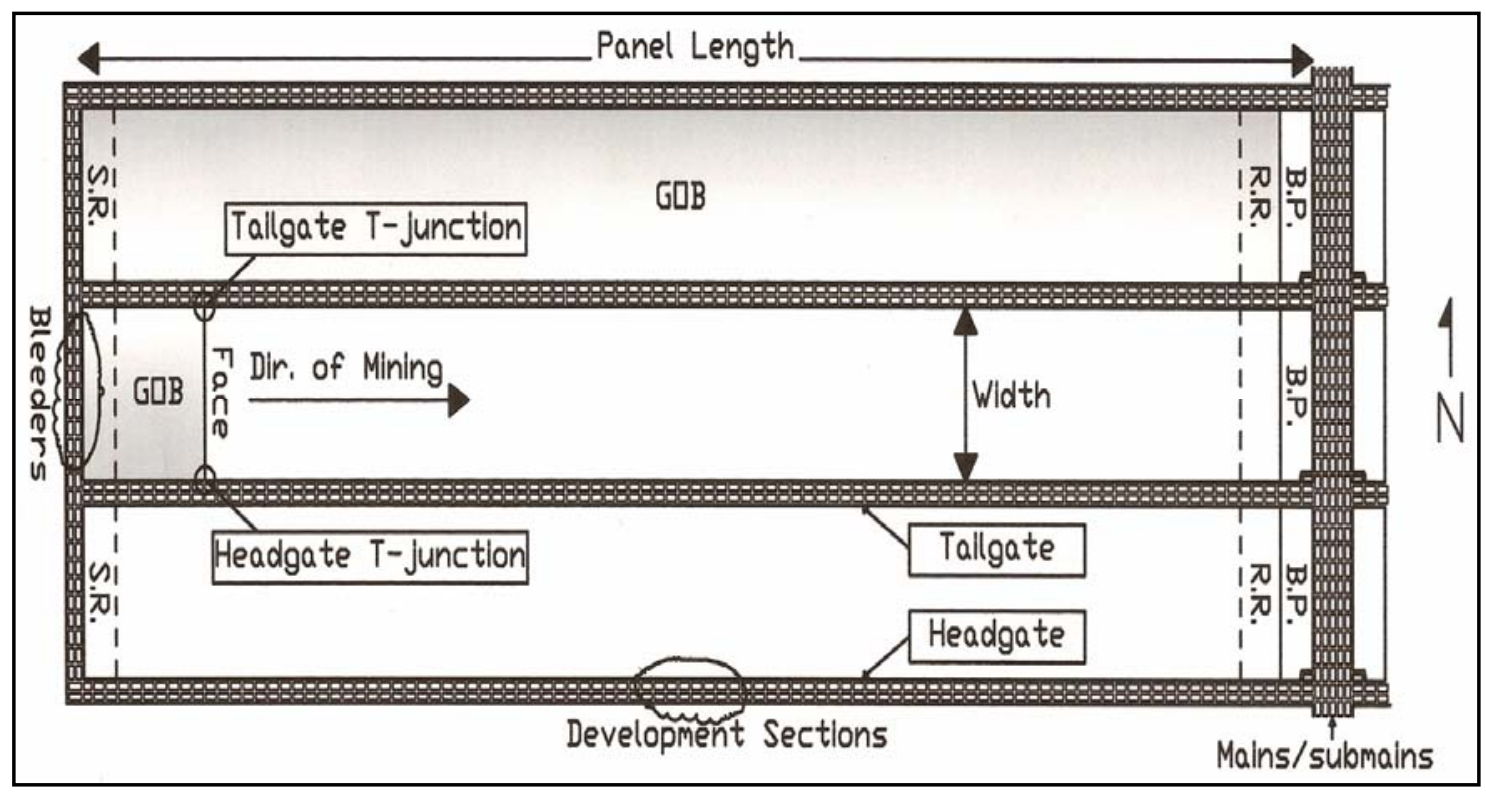

Figure 2-2, Longwall panel layout

Generally mining in the U.S. begins at the bleeder entry end; a set up room (S.R.) is driven in the panel to allow for the placement of the mining machinery. Upon completion of the panel, a recovery room (R.R.) is erected to allow the longwall face equipment to be moved to the next panel's S.R. The longwall panel recovery ends at the barrier pillar (B.P.) which is at the main side of the panel. The barrier pillar is used to insure that the coal extraction does not cause failure in the mains that are used throughout the life of the mine.

Parallel to the mining direction there is the gob side and the face side. The gob is the area which has caved behind the shields after the coal has been removed and the 
shields have advanced. Perpendicular to the mining direction there is the headgate and tailgate side. The headgate is the entry on the side that typically does not have a gob adjacent to it and always contains the "services." The services are the electrical supply, equipment supply road, the conveyor belt, the intake ventilation, and the water supply. The tailgate is typically the side which was the previous panel's headgate and is now adjacent to the gob.

In longwall mining the face coal is cut by either a shearer loader or plow. The shearer usually rides on the panline of an AFC. The AFC sits on the floor parallel to the faceline. Two self-contained electric motors on each end of the machine pull the shearer. The motors turn sprocket wheels that run on a track, which is positioned on the gob side of the chain conveyor. As a result, the AFC is utilized as a track to move the shearer on, and also serves as a guide to hold the plow in place. There are two drums mounted on the face side of the shearer, one at each end. These drums are similar to those used in a continuous miner but are larger in diameter and narrower in width. Ranging arms hydraulically adjust the cutting position of a drum. The rotating torque available at the axis of the drum provides the cutting force. The shearer makes a cut, or web, approximately 30 to 46 in wide. The shearer cuts from one end of the face to the other. The shearer is typically moving at the fastest speed when it is around the center of the face. When the shearer is close to the ends of the face it must slow down to allow for sumping and other issues with shield advance and panline snaking (Peng, 2006). 


\subsection{LONGWALL FACE SUPPORT SYSTEMS}

Modern longwall mining employs self-advancing hydraulic powered supports (which will simply be called powered supports in this book) at the face area. The support not only holds up the roof, pushes the face chain conveyor (AFC), and advances itself, but also provides a safe environment for all associated mining activities. (Peng, 1984, pg 144)

At the time this quotation was made about hydraulic supports, there were several types of face supports in general use. The primary types were frame, chock, chock shield, and shield, as seen in Figures 2-3 and 2-4 (Peng, 2006). All types utilized hydraulic cylinders to produce the supporting force necessary to hold the roof. The frame is essentially two independent props. With the addition of a solid canopy, causing the two props to act in unison, the support is classified as a chock. With the addition of a caving shield, the support becomes a shield. Furthermore, there are several different classifications of each type of face supports. "Since a powered support consists of four major components (i.e., canopy, caving shield, hydraulic legs or props, and base plate), the ways by which they are interrelated are used for classification" (Peng, 1984). 


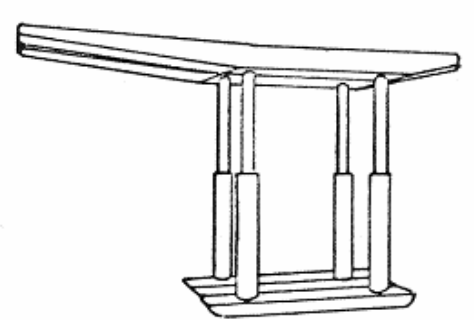

Dual-frame support unit

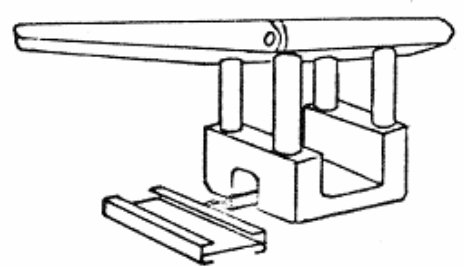

Four-leg chock

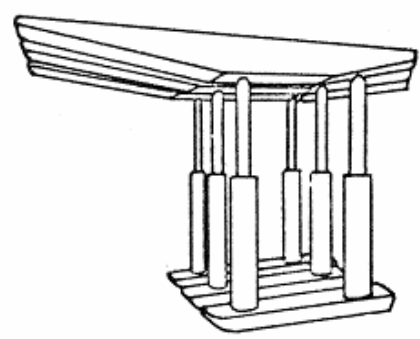

Triple-frame support unit

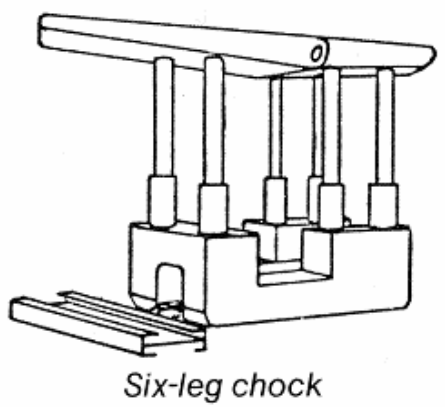

Figure 2-3, Depiction of frames and chocks (Source: Peng, 1984)
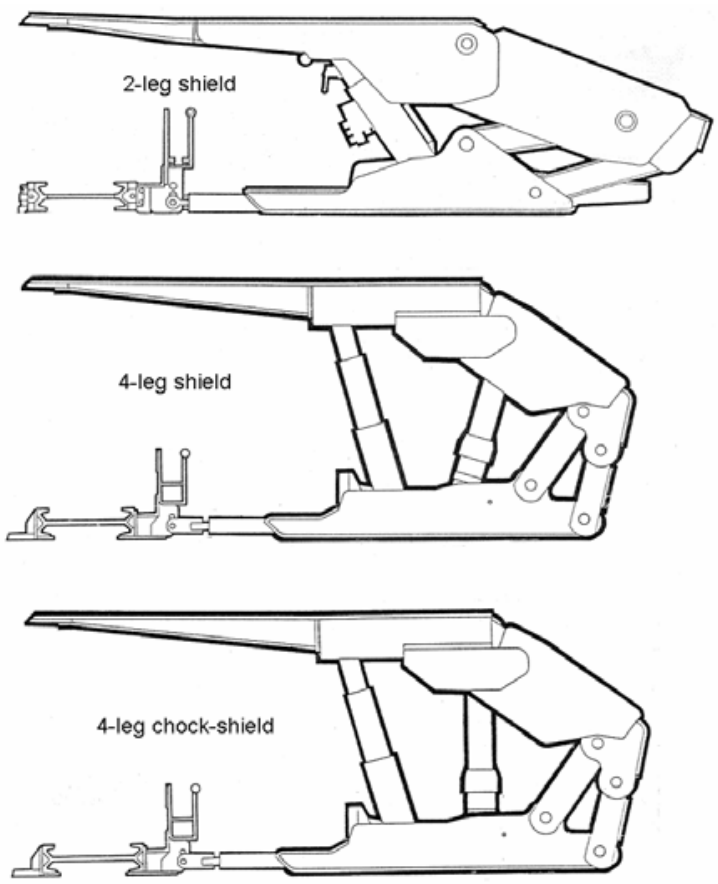

Figure 2-4, Depiction of shields and chock shield (Source: Peng, 1984)

The only type of face support currently used today in the U.S. is the modern shield. During the evolution of the shield, numerous shield models were developed using 
different combinations of each of the four major components named above. The number of hydraulic legs has ranged from 4 to 2 , with 2 being solely used today. The second major variation is the placement or connection points of the legs. Leg connections include canopy, caving shield, hinge, vertical and parallel, V-shaped, and X-shaped, as seen in Figure 2-5.

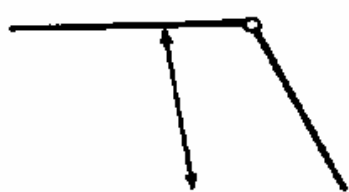

A. Canopy connection, $F$

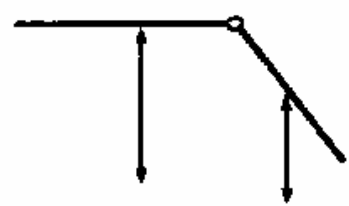

D. Vertical parallel, U

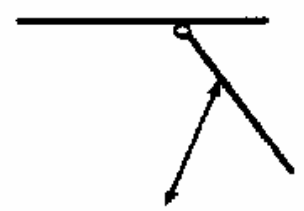

B, caving shield connection, $G$

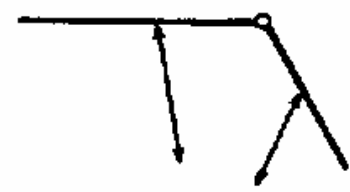

E. $v$-shaped, $v$

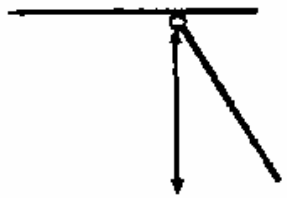

c. Hinge connection, $\mathbf{H}$

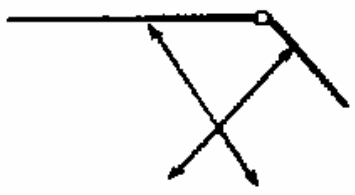

F. X-shaped, $X$

Figure 2-5, Shield leg connection types (Source: Peng, 1984)

The third major variation is the path that the canopy tip follows. The three varieties of the path are the lemniscate, caliper, and ellipse. The other two major improvements or changes to the shield over time have been the addition of lemniscate links and a stabilizing ram. The lemniscate model is now dominating the market because of its ability to allow vertical movement in the canopy tip only during normal operating conditions (Peng, 2006). 
Today's shields use some of the most advanced, cutting edge technology. The major components of the shields, as seen in Figures 2-6 and 2-7 (Peng, 2006), are described in the following list:

1. Canopy - the load bearing unit which contacts the roof.

2. Base - the load bearing unit which transfers the roof stress to the floor.

3. Caving shield - designed to make the shield kinematically stable, is used to resist horizontal forces, and prevent the caved rock fragments from getting into the face area.

4. Lemniscate assembly - a set of four strong steel plates welded into box section of appropriate length and placement geometry to allow the shield's tip to move up and down more or less vertically within a certain range of mining height.

5. Hydraulic legs - double acting cylinders intended to transmit the hydraulic pressure into supporting power.

6. Tilt cylinder (stabilizing ram) - used to control the canopy when the shield is away from the roof or being set against the roof. It ensures that the canopy attitude remains parallel to the base.

7. Double acting rams - used to pull the shield forward and push the pan forward.

8. Relay bar - used to span the pan to shield so that when lifting the shield the base is above the floor.

9. Base lifting device - cylinder which is actually used to raise the toes or front section of the base to facilitate moving the shield forward especially in soft floor conditions.

10. Hydraulic control system - an electrohydraulic system that controls the flow of hydraulic fluid into and out of cylinders that control the operation of the shield. 


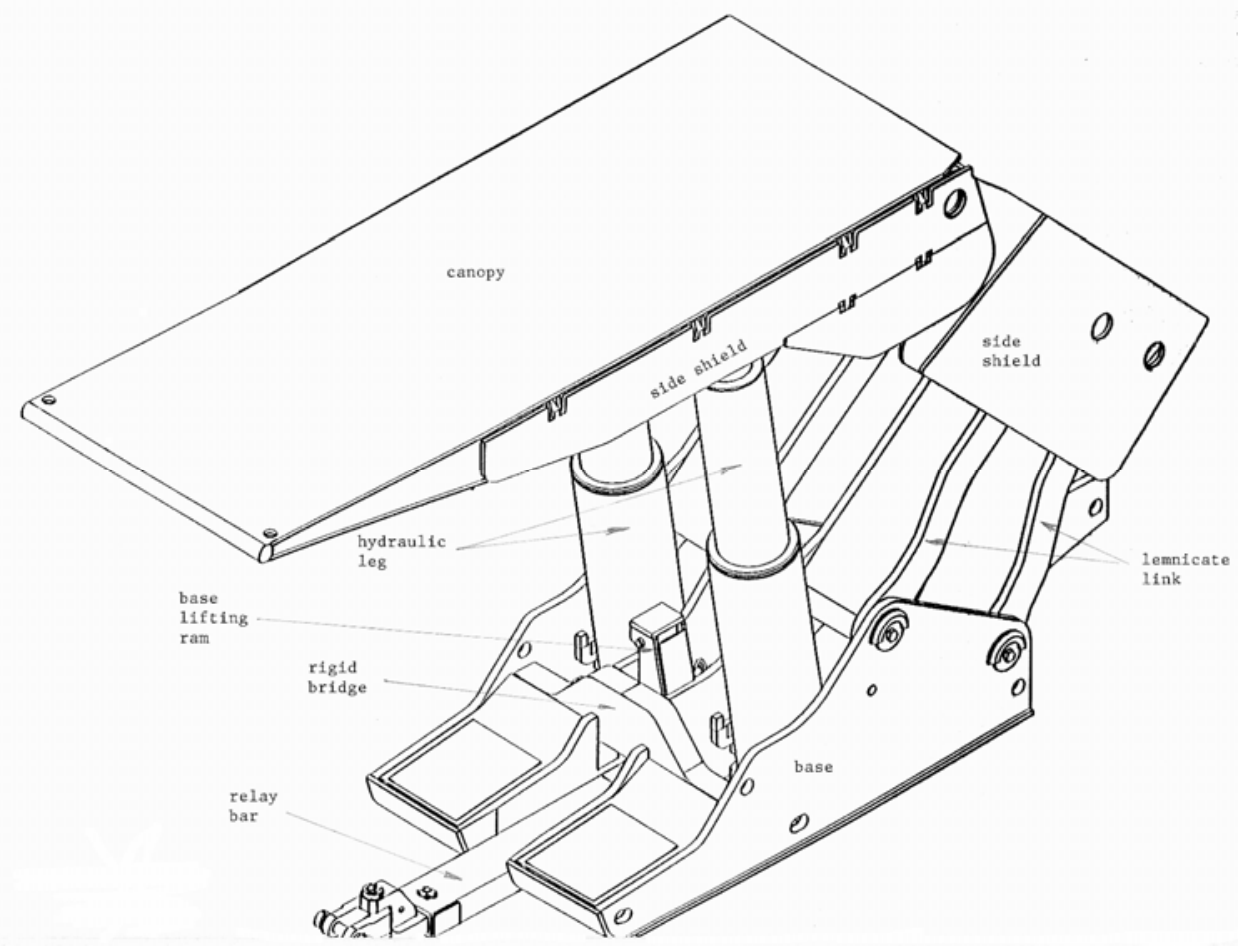

Figure 2-6, Components of a modern shield (Source: Peng, 1984)

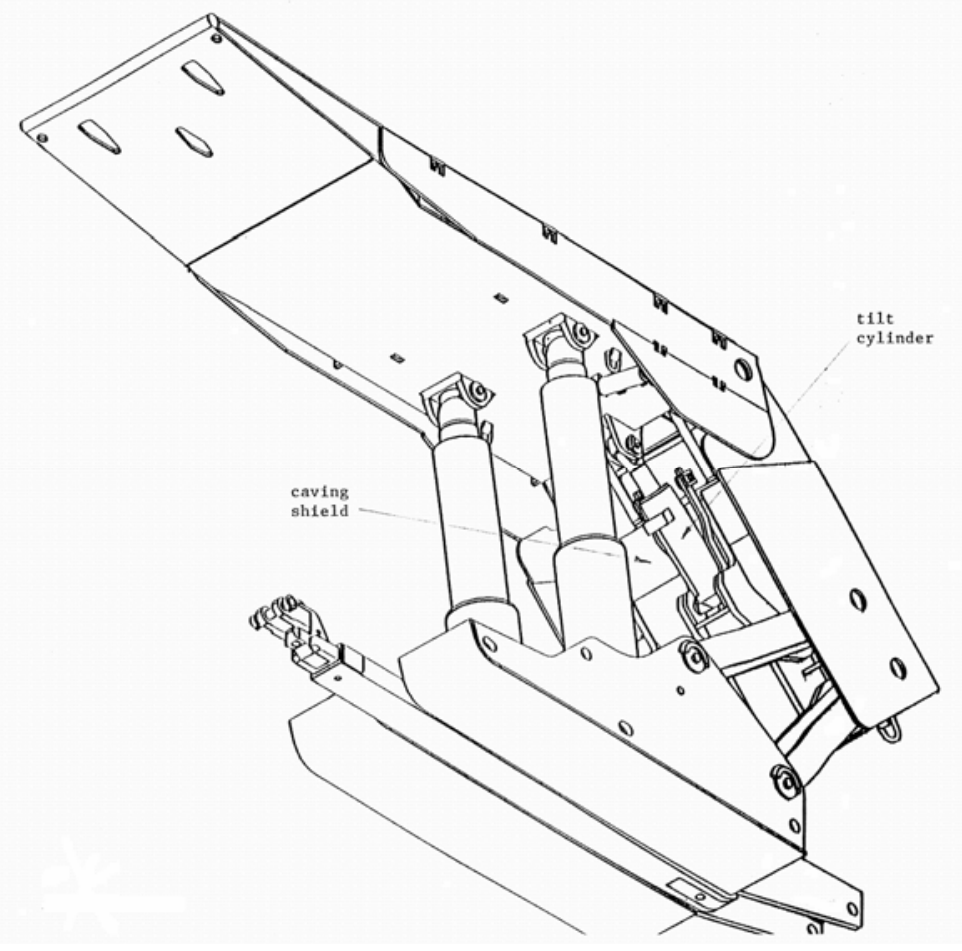

Figure 2-7, Components of a modern shield 2 (Source: Peng, 1984) 
In order to maintain a safe and productive environment during mining, all of the components of the shield must function properly.

Now that the major components within a modern shield have been described, details of the hydraulic system within the shield shall be discussed. The shield supports the mine roof by hydraulic power. This power is transmitted to the base and canopy of the shield through the hydraulic leg cylinders and the stabilizing ram. The stabilizing ram is used to maintain a horizontal canopy attitude and also applies a slight horizontal force to the canopy. The lemniscate assembly allows the forces to be transferred to the canopy and base while maintaining horizontal stability. Without the lemniscate assembly, the shield would be free to rotate forward and backward.

Although the lemniscate assembly and stabilizing ram play a major role in allowing the shield to do its job, the main roof support work is done by the two hydraulic leg cylinders. Typically, these are inclined, double-acting, two-staged cylinders. The inclination provides for a greater working height and larger active horizontal force. Double-acting simply means that the cylinders are hydraulically extended and contracted. Two-staged cylinders have two cavity areas-one inside the other, each with an independent piston. This allows for lower closed height to facilitate transportation of the shield. These cylinders are fueled by a valve bank that is controlled by the electrohydraulic control system. The electrohydraulic control system replaces the manual control systems previously used to control the hydraulic fluid flow. The electrohydraulic control system consists of a bank of valves which are electronically controlled by a microprocessor. The hydraulic system controlled by a microprocessor is capable of automatically 
advancing shields in groups or individually as well as pushing the sections of conveyor pans forward. The processor is preprogrammed with numerous cutting and advancing control algorithms that allow for a fully automated mining system, but can also be manually controlled with a remote or at the shield control unit itself.

The shields are operated in a cycle that occurs during the shearer's cut. This cycle is approximately one hour long. The shield is set against the roof for the large majority of this cycle. The supporting resistances of the hydraulic legs keep the canopy of the shield set tightly against the immediate roof strata when in normal supporting condition. The advancing of the shield is a much smaller portion of the shield cycle. The sequence of the shield cycle can be seen in Figure 2-8. The advance for modern longwall faces is usually around 6 seconds. The shield advances when the leading drum of the shearer cuts and passes several additional shield units. The shield advance begins with the shield legs lowering 2 to 4 in (Figure 2-8B) and then the double-acting advancing ram is extended, which pulls the shield forward the distance of the width of the cut (Figure 2-8C \& D). The position of the conveyor panline is held steady by the advancing rams' forces against the shields, which are set on both sides of the shield to advance. The shield is reset against the roof when it has advanced the desired distance (Figure 2-8E). The conveyor is pushed forward by extending the advancing ram of the shield (Figure 2-8F). At this point, the system is ready to make the next cut. Since the shield advance is directly linked to the shearer position, the speed at which the shearer traverses the face affects the flow rate required to set the shields. The faster the shearer is moving, the faster the shields need to be set (Peng, 2006). 

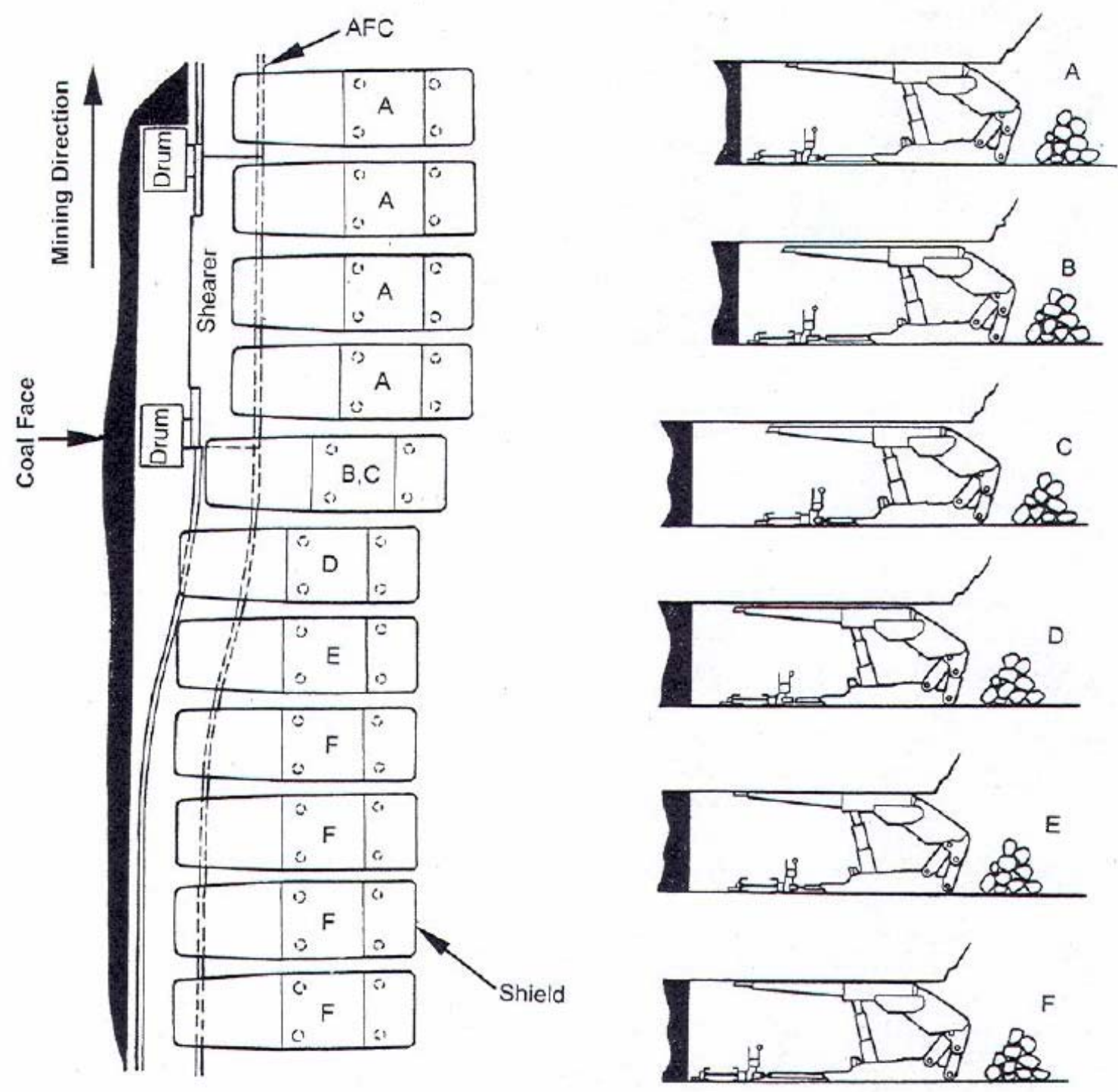

Figure 2-8, Shield cycle sequence (Source: Peng, 1984)

The shield cycle can also be represented by the leg pressure measurements. This is illustrated in Figure 2-9, along with the changes of the leg cylinder volume associated with the shield cycle. The thinner red line represents the pressure in the leg cylinder and the thicker blue line represents the volume of the leg cylinder during a typical shield cycle. The shield is first lowered, which is represented from point A to B in Figure 2-9. The advancing of the shield is represented by point B to $C$. The setting of the shield is 
represented by point $C$ to $D$. The rest of the figure represents the portion of the cycle while the shield is set against the roof.

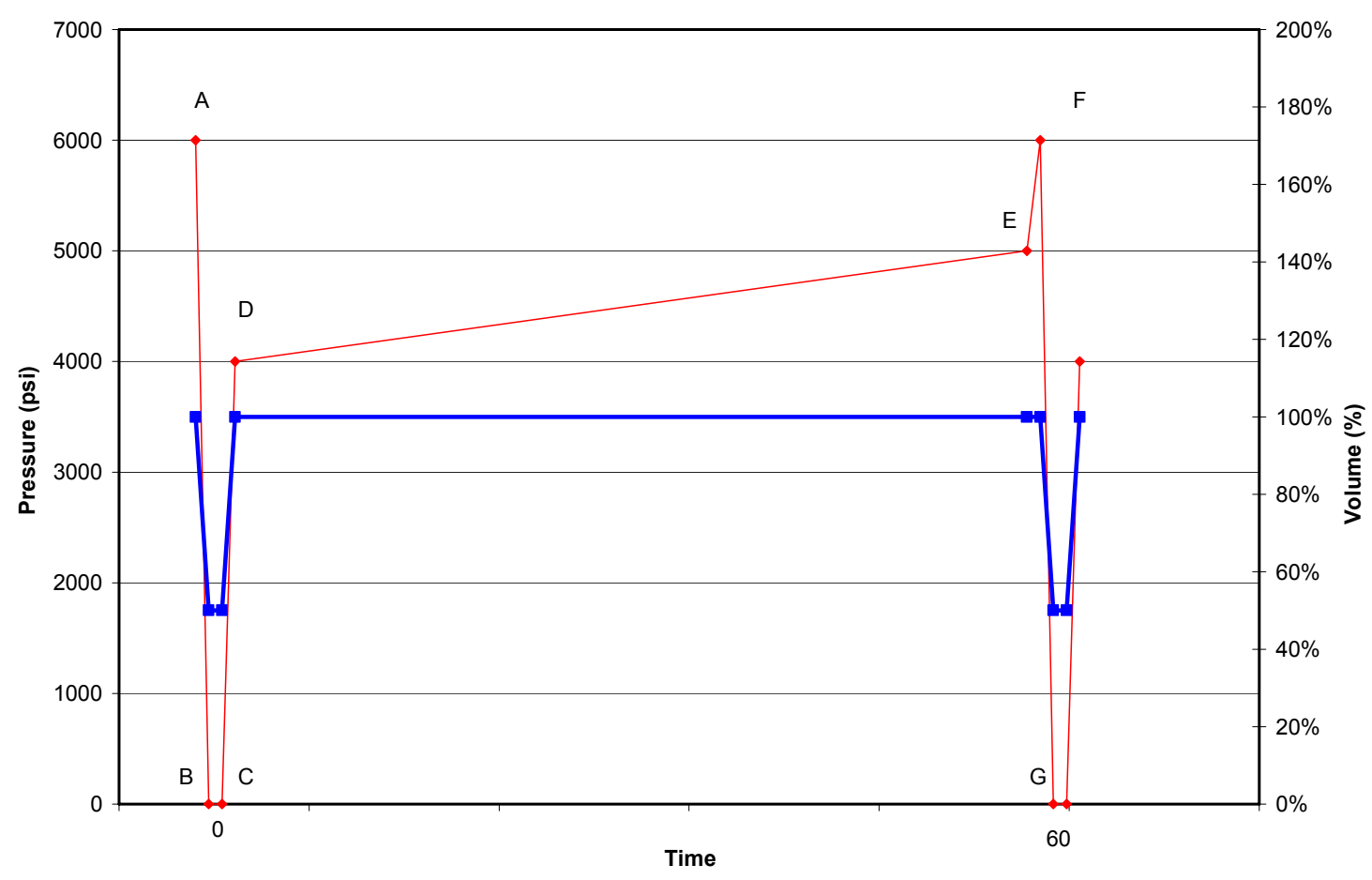

Figure 2-9, Ideal shield cycle

The most relevant item pertaining to a flow/pressure study of longwall face supports is the concepts of setting pressures and setting load density. The setting pressure is the pressure in the shield's legs at the time of the shield setting against the mine roof and floor. The setting load density is the support load at the time of the setting divided by roof area supported before the support is advanced. The setting pressure is determined by the pump pressure, the flow rate, and the hydraulic supply system components. During the setting of a shield, the fluid enters the leg cylinders rapidly initially and slows down dramatically as the support canopy is raised to roof contact. As the flow rate decreases, the system pressure increases, allowing the shield's setting pressure to be higher. 


\subsection{IMPORTANCE OF PROPER SETTING PRESSURE AND FLOW RATE}

During the mid-1970's, Bates, in his position as the head of the Mining Investigations Branch of the National Coal Board Mining Research and Development Establishment (MRDE) in England, was conducting research to determine the strata-support interaction and the optimal face roof support characteristics. The relative importance of setting pressure for the successful deployment of hydraulic shields was established in the following quotation: "The basic concept put forward is that the most important function of powered supports is to provide an adequate and consistent setting load density" (Bates, 1978). This suggests that although the yield load, structural stability, and geometric design of shields are very important, the setting pressure is the most important specification for a shield. His professional judgment as to the importance of setting pressure was accepted throughout the mining-engineering community and the industry. It continues to be accepted at this time as the most significant factor in successful shield deployment.

Ensuring that the shield is set at the proper setting pressure is a primary concern for roof stability. Because roof stability impacts both the safety of the miners and the production of the longwall face, maintaining good roof conditions and limiting convergence are very important. Not only does the setting pressure affect production from a strata control perspective, but it can also impact the speed with which the shearer may be run. The faster the shearer is running and the more the shields move, the larger the pressure losses and the greater the demand of the hydraulic supply system will be, thus lowering the setting pressure along the face. 
The first area of concern is the strata control impact of proper setting pressure from a safety perspective. This assures that the shield applies an active roof support load. Without this active support load being applied, flaking, sloughing, spalling, and roof caving are possible. All of these are considered serious conditions and can cause both injuries and production slowdowns. There are two distinctly different results from an improper setting pressure that are caused by either too low or too high of a setting pressure.

With a setting pressure that is too low, there is a greater chance of roof failures, which can include catastrophic failures. The 1983 work of Gupta and Farmer, clearly demonstrated the impact of low setting pressure. They found that increased setting pressures and the resulting increase in setting load density reduced face spalling, roof flaking, and convergence. Furthermore, they found that increasing setting pressure reduced the frequency of roof cavities and face spalling. They concluded that increases in support setting load density were responsible for reducing average roof to floor convergence over the supported face area, reducing lateral expansion of the coal face into the working area, reducing the extent of roof cavity formations, and reducing the extent of face spalling. Finally, through inspection of roof deformations, they concluded that "increases in support load density changed the vertical strain pattern immediately above the supports from an uneven compression zone with a tension zone ahead of the supports, to an evenly distributed compression zone over the supported area." In addition to this work, numerous other research efforts showed similar findings. (Ashwqin 
and Campbell, 1970; Bates, 1978; Graham, 1978; Price and Pickering, 1981; Gupta and Farmer, 1982; Gupta and Farmer, 1985; Trueman et al., 2005)

Another area of concern is the case of too high of a setting pressure. "Too high a support loading may in fact do more harm than good, especially when applied near the waste edge of a weak roof' (Wilson,1964). When the setting pressure is too high, the roof may be damaged by the force applied in setting. This can cause small roof falls and poor canopy roof contact. Peng and Chiang (1983) specifically state that "lower setting resistance allows the roof to settle which can contribute to ultimate caving." This statement by Peng and Chiang suggests that too high of a setting pressure can lead to problems with the caving behind the shield, causing an increased load on the face. This can ultimately lead to shields that cannot be moved or lowered. In addition to potential roof damage, the high pressures can expose the supports to excessive stress that leads to wear and tear (Trueman et al., 2005).

The other area of concern is the effect of the setting pressure on production. Price and Pickering (1981) found that when higher setting pressure and/or positive set valves were utilized, not only were the roof condition improved, but productivity increased. Conversely, Trueman, et al. (2005) found that "low set pressures and associated rapid roof movement and unraveling of the strata may eventually lead to roof cavities and potential production delays."

When a higher setting pressure is required, the speed of the shearer must be slower or more shields must be set and advanced at the same time. In other words, if the 
production levels need to increase, then either the setting pressure must be lowered or the flow rate must be raised. Since these two variables are not independent, they both must be considered together when looking at the desired production rates.

As with the setting pressure delivered by the hydraulic supply system, the flow rate also has an impact on both strata control and production. The only effect that the flow rate would have on the strata control would be the inability of the shields to set and advance quickly enough to keep pace with the shearer and to avoid time dependent failure of the roof. Since the shields require a specific amount of hydraulic fluid to set and advance, then the amount of fluid delivered by the hydraulic system must be considered. One of the most important elements to good roof control is the time that the roof is unsupported after it is exposed. As the time delay for resetting the supports increases, the potential for roof failures becomes much greater. Thus, the hydraulic supply system must also be evaluated for its ability to deliver sufficient flow to support the operational conditions on the longwall face. Research findings in the 1978 Bates work provide support to these concepts.

They showed that while people believed that they were consistently achieving optimum setting pressures, the actual setting pressured measured covered a wide range down to as low as $20 \%$ of optimum in a random pattern across the coalface. Setting pressures were not only low but also inconsistent. The reason for this situation was the inadequacy of the hydraulic power supply and distribution systems feeding the supports and a failure to recognize in their design the problems which arise from simultaneous demand on a common supply system by several operators (Bates, 1978, pg 682)

The flow rates' effect on production is the same as the setting pressures effect on production. This is due to the direct link between setting pressure and flow rate, which will be discussed in detail in Section 2.5. 
In summary, the hydraulic system characteristics must be known to design and maintain hydraulic power systems that will insure that required setting pressures on the shield supports are achieved.

\subsection{HYDRAULIC SYSTEM DESCRIPTION \& TERMINOLOGY}

The hydraulic supply system for a longwall face is large, complex, and extremely dynamic. A sample schematic of a longwall hydraulic system is presented in Figure 2-10. A brief overview of the components comprising the system will provide the necessary background for this thesis. A longwall hydraulic supply system consists of a fluid source, storage tanks, pump station, fluid conduits, connections, and filters. The most complex part of a longwall hydraulic supply system is the pump station, either centralized or decentralized. A centralized pump station is one that supplies all the hydraulic power for the longwall face/s in one location. Conversely, a decentralized pump station is a group of pumps that supply the hydraulic power simultaneously. 


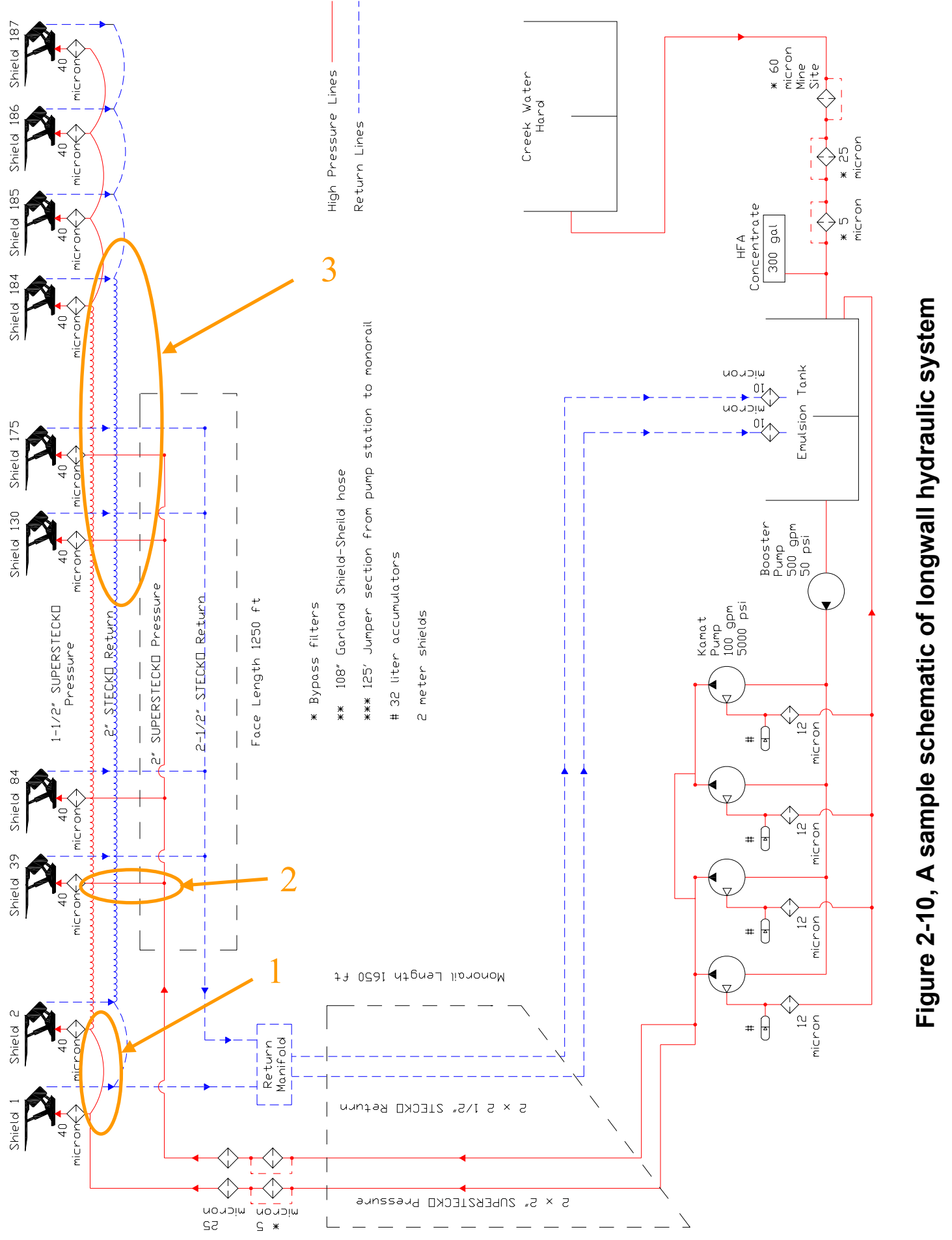

24 
A pump station is comprised of several smaller components and is tasked with developing the desired flow and pressure to the longwall shields. Figure 2-11 is a photo of a pump station. The basic components of the pump station are pumps, accumulators, filters, fluid conduits, various connections, a mobile cart containing all the components, and an electronic control system. Generally, within a pump station there are several pumps each with a capacity of $80-125 \mathrm{gpm}$ at $4,200-5,000$ psi. Typically, one pump is constantly operating; when the flow demand exceeds its capacity or the pressure drops too much ( $300 \mathrm{psi})$, the next pump begins operating. This cycle continues until all the pumps in the pump station are operating. Conversely, a pump will stop operating when it is no longer needed because of pressure increases or flow demand drops.

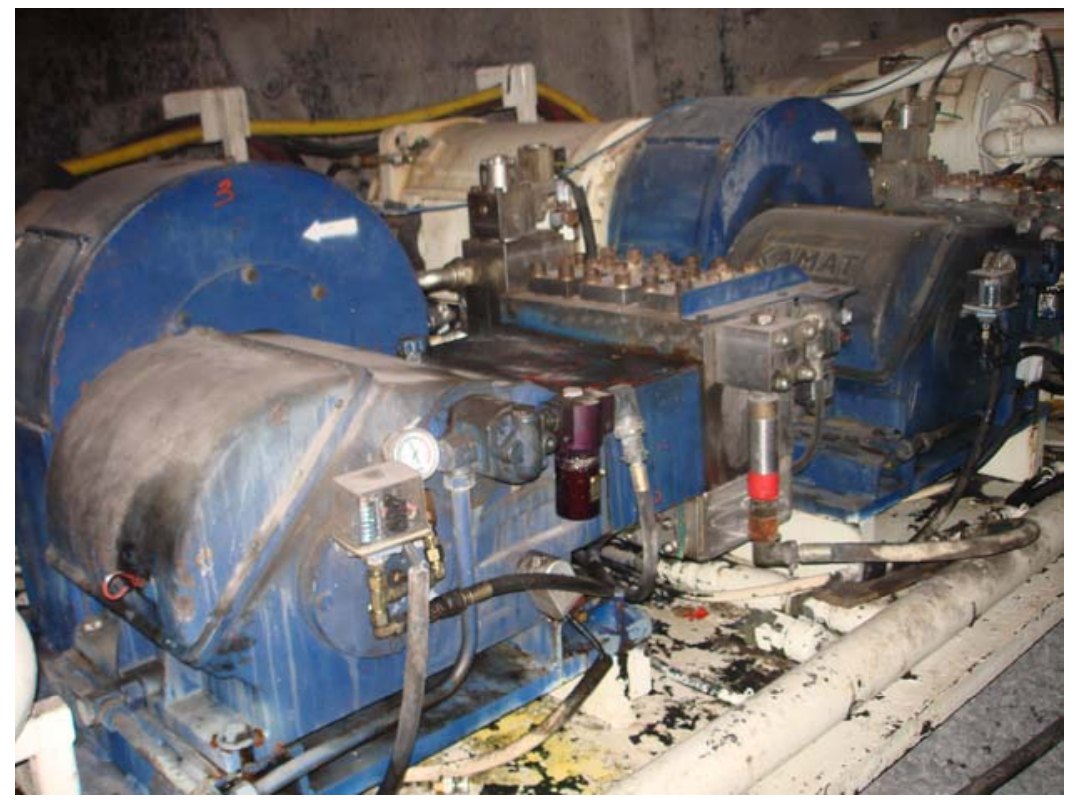

Figure 2-11, Photo of pump station

The first component of a pump station to be discussed is the pump. The hydraulic supply systems in longwall mining generally use positive-displacement reciprocating pumps, which are typically triple-plunger-type pumps. A positive-displacement pump is one that 
provides a set displacement, or flow rate, per revolution. Thus, the speed of the motor determines the flow rate. A reciprocating pump draws fluid into the plunger under suction during the intake stroke and discharges the fluid under positive pressure during the discharge stroke. As a result of this cycle, the discharge flow is pulsating. Figure 2-12 shows a typical performance chart for a triple-plunger, positive-displacement reciprocating pump. The blue dotted line is the actual curve with slippage and leakage, whereas the red line is the ideal curve.

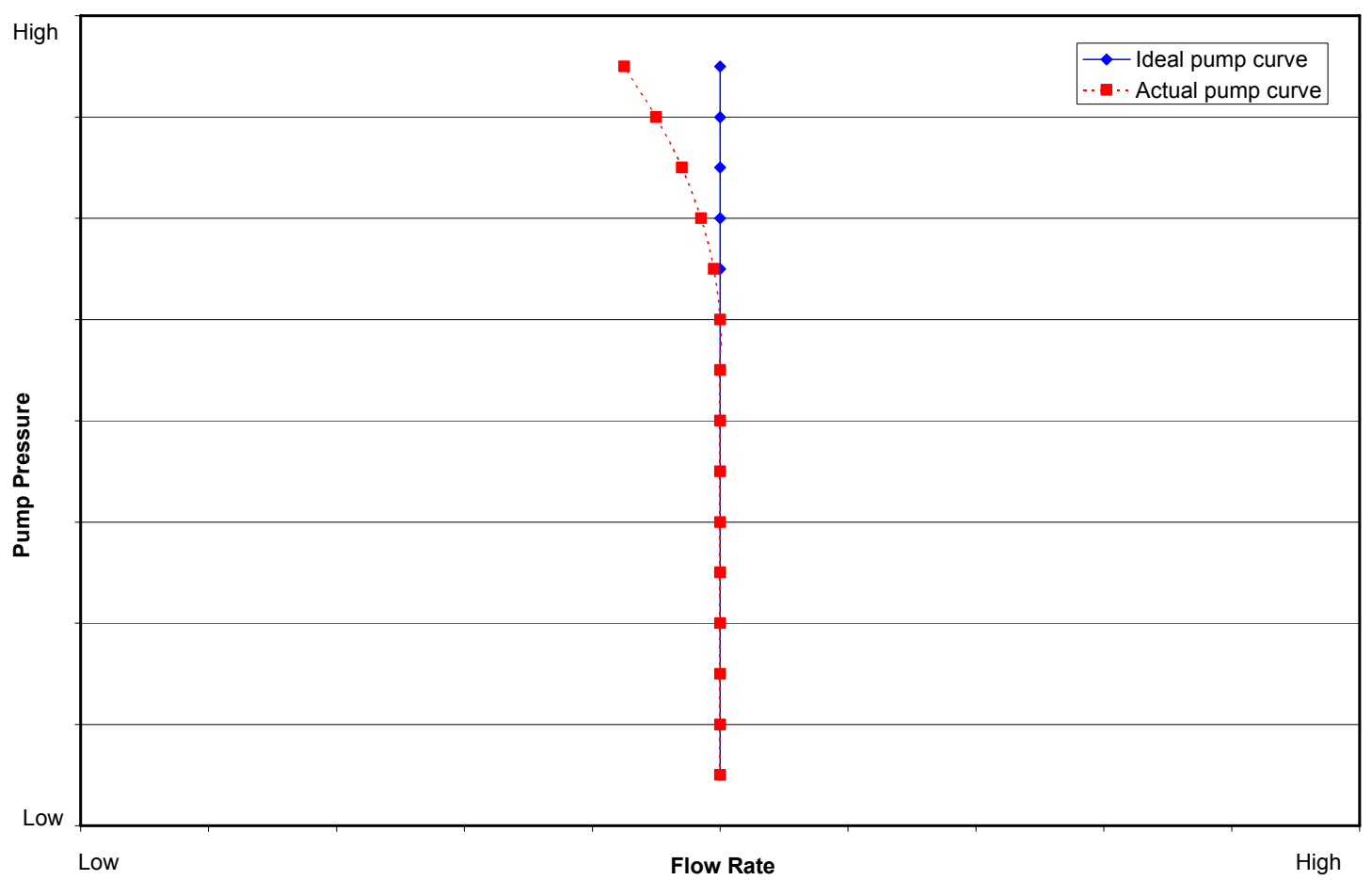

Figure 2-12, Sample positive displacement pump curve

Another component of the pump station is the accumulator. The accumulator holds reserve fluid at system pressure to provide or absorb momentary flow fluctations. An accumulator can serve as an auxiliary power source, pulsation damper, fluid dispenser, suction stabilizer for pumps, leakage-makeup source, or thermal expansion volume 
compensator. Typically, there is an accumulator associated with each pump in the pump station.

The next component of the pump station is the filter. The pump station uses filters to insure that the fluid returning to the emulsion tank is filtered after contact with the internal walls of the pumps and accumulators in the pump station. These filters are typically in the $5-60$ micron range of filtration size. The filters in the pump station are usually non-bypass filters that have a replaceable element. Some systems use bypass filters with a back flushing system and a permanent filtration element.

The next component of the pump station is the fluid conduit. The most common fluid conduits used in the pump station are Stecko hoses. Stecko hoses are flexible rubber hoses with operating pressures in excess of 5,000 psi. There are two major types: the Super-Stecko and the Regular-Stecko hose, which are designed to accept high pressure flow and return pressure flow, respectively. Some pump stations have short sections of pipes where appropriate.

The next components of the pump station are the connections. The typical connections in the pump station are tees and elbows. The tees are used to connect the multiple pumps to one flow line. The elbows are used for tight bends when the flow direction must be changed. These components lead to some pressure losses within the pump station. Some of the other connections used are valves. They serve the additional purpose of controlling the flow rate and direction of flow. 
The next component of the pump station is the mobile platform. This platform is used to store all the components of the pump station in one organized location and allow the pump station to move from one location to another as the longwall face is mined. The ability to move the pump station is extremely important due to the speed with which the modern mechanized longwall advances.

The last component of the pump station is the electronic control system. This system is used to control when each pump is running and how much power these pumps are getting. It is capable of utilizing almost any algorithm to control the flow of the pump station. The typical control scheme is based on pressure exiting the pump station. Typically, when the flow leaving the pump station drops $300 \mathrm{psi}$, another pump begins operating. Conversely, when the pressure of the fluid leaving the pump station exceeds 4,900 psi, another pump is shut off.

Now that the pump station has been described, the rest of the longwall hydraulic supply system will be described. Many of the additional components of the hydraulic supply system are the same as the components of the pump station. These components include fluid conduits, connections, and filters.

As mentioned previously in reference to the pump station, the Stecko hose, a highpressure-capable hose, is widely used as a conduit for hydraulic fluid. As mentioned, there are two major different types the Super-Stecko and the Regular-Stecko hose, for high pressure and return pressure applications, respectively. Some longwall mines 
have begun using pipes in the monorail and panlines, as they reduce the pressure losses in the system.

Like the pump station, the hydraulic supply system uses several types of connections: Tees and elbows are also used in the hydraulic supply system. Line connections are additionally used to connect the sections of hoses or pipes used in the system. These allow the fluid conduits to be stored and transported in much smaller volumes. The hydraulic supply system also uses manifolds throughout the system. There are numerous pieces of equipment that need hydraulic power. The pump station also uses valves to control the flow rate and direction of flow.

Another component of the hydraulic system is the filter. The filters in the hydraulic system are used to insure that the other components are not damaged by particles common to hydraulic fluid. These filters are typically in the 5-60 micron range of filtration size. There are several different types of filters used in longwall hydraulic supply systems. Some of these are bypass, non-bypass, back flushing, and replaceable element filters. A bypass filter has the ability to continue to supply fluid even if the filter needs to be replaced or cleaned.

The longwall hydraulic supply system as contains a fluid source. Typically these fluid sources are either a natural water source or public water supply. The natural sources commonly used are ponds, lakes, rivers, creeks, and reservoirs. The fluid source used is typically one that is abundant and close to the mine site. Some longwall mines have even used old abandoned mines that have flooded. 
The last major component of a longwall hydraulic supply system is a storage tank. The system typically requires at least two storage tanks. One tank is used to store the HFA and is typically much smaller than the other tank. The other tank is used as an intermediate water storage location.

Now that the system components have been described, some of the common terminology will be described. The fluid conduit system has several different configurations. The first is the monorail, which is the conduit system that connects the longwall face to the pump station, as seen in Figure 2-13. This monorail expands and contracts to allow fewer power moves. When the monorail is snaked, meaning that it is fully contracted, (sometimes referred to as coiled or contracted), it is positioned for further expansion and movement. The next fluid conduit system component is the face area, where fluid is transported from the headgate to the tailgate. Face areas are generally employ three configurations: (1) garland-shaped hoses from shield to shield, (2) straight hose line along the AFC with a crossover connection to each shield, and (3) two hose lines in a ring main system, as seen in Figure 2-10. The garland-shaped hoses are typically smaller diameter hoses. The straight hose line along the AFC is referred to as the panline hose. A ring main system is one that has both the garlandshaped hoses and the hose along the panline. The crossover connection is commonly referred to as a ladder. U.S longwall faces use as few as zero and as many as 1 ladder every 10 shields. 


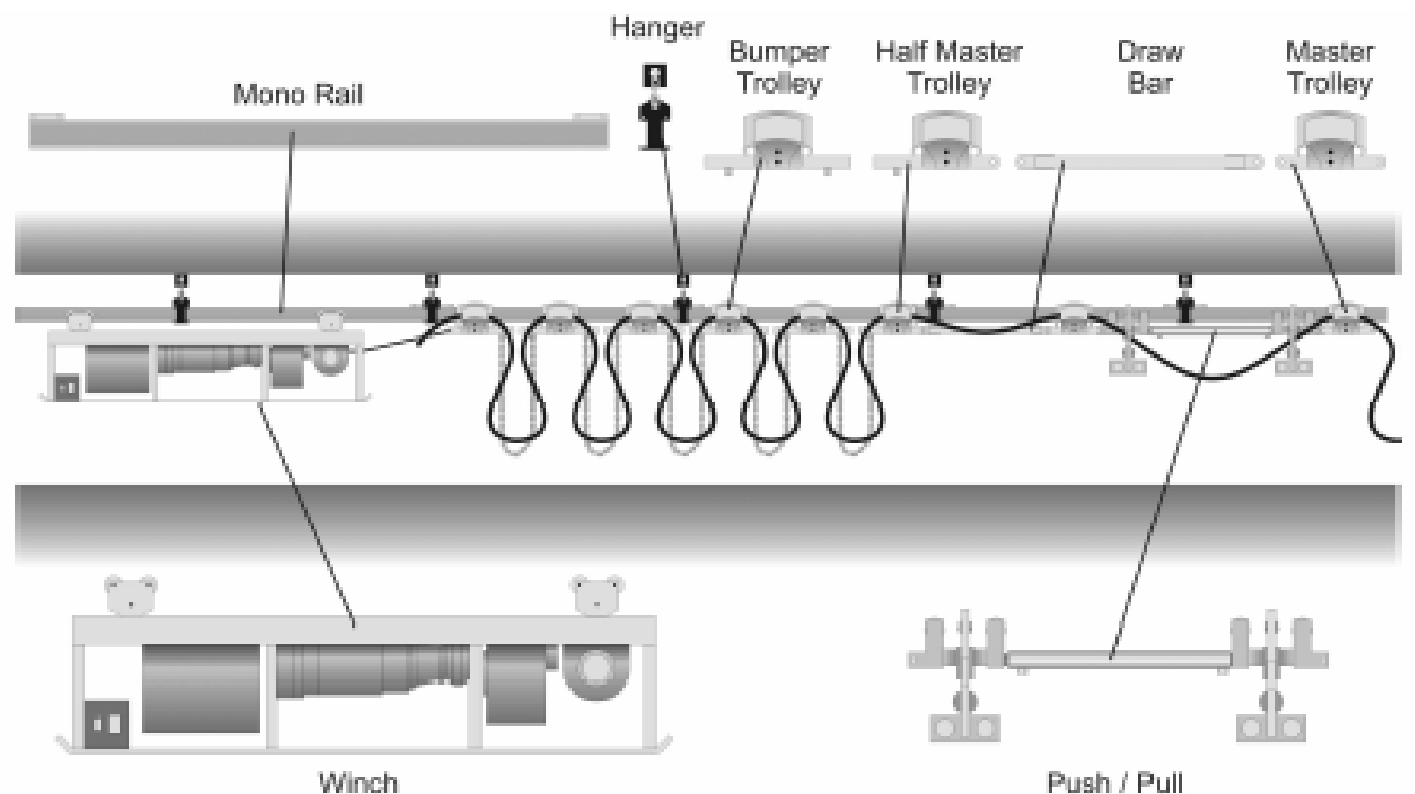

Figure 2-13, Longwall monorail (Source Peng, 2006)

As defined within the discipline of fluid dynamics, the hydraulic system used to support the longwall face shields is considered to constitute a complex network, because there are both parallel and series flow paths between the pump and shields. Also, there are both major and minor pressure losses, or head losses, in these networks. The major losses are caused by friction between the fluid and the conduit walls. The minor losses, often referred to as shock losses, are those associated with component connections, diametric changes, filters, and other flow deviations. The pressure losses are affected by the flow required by the longwall face supports as well as the inherent properties of the components. Likewise, the flow is affected by the pressure losses in the system. The pressure losses are not additive and are considered to be a function of various dynamic and fluid flow parameters, generally studied by a series of loss equations within this discipline. Therefore, the system of loss equations determinant for complex 
networks in the fluid dynamics domain must be solved to determine the pressure loss attendant on the various system-wide decrements to optimal pressure.

\subsection{FLUID MECHANICS OF HYDRAULIC SUPPLY SYSTEMS}

In order to develop a basic understanding of the calculations performed by the software to determine the ability of the system to delivery the desired flow and pressure to the face supports, a brief overview of fluid mechanics is necessary (Young et al.,2001).

\section{Static Fluid Mechanics}

The first area of concern is static fluid mechanics. This primarily consists of categorizing the fluids and systems. One of the main distinctions in static fluid mechanics is compressibility. A fluid is considered incompressible if its density does not significantly change with varying pressure and temperature over the operating range; whereas a fluid with a varying density is called compressible. The pressure head $(\mathrm{H})$, or the height of a column of fluid of specific weight $(\gamma)$ required to give a pressure difference $\left(P_{1}-P_{2}\right)$, is represented by the following equation:

$$
H=\frac{P_{1}-P_{2}}{\gamma}
$$

where:

$\mathrm{H}=$ Hydraulic head

$\mathrm{P}_{\mathrm{a}}=$ Pressure with "a" being the location descriptor

$\gamma=$ Specific weight

The previous concepts were those most relevant to this project based on static fluid mechanics. 


\section{Fluid Dynamics}

The second area of fluid mechanics is fluid dynamics. Fluid dynamics is the branch of the applied science that is concerned with the movement of gases and liquids. The first concept of interest is the Bernoulli Equation, which defines the total head or pressure at any location by its 3 components; the pressure head, the velocity head, and the elevation head. The Bernoulli equation is as follows:

$$
\begin{aligned}
& P+\frac{1}{2} \rho V^{2}+\gamma Z=\text { A constant } \\
& \text { where: } \\
& P \quad=\text { Pressure } \\
& V=\text { Velocity } \\
& P=\text { Density } \\
& \gamma=\text { Specific weight } \\
& Z=\text { Height }
\end{aligned}
$$

There are two methods to describe flow, Eulerian and Lagrangian. An Eulerian flow is one in which the fluid characteristics, pressure, density, velocity, etc., are a function of space and time. A Lagrangian flow description occurs when the individual particles are studied as they move. Steady flow is a flow which has a constant velocity at a given point with respect to time. An unsteady flow is one where the velocity varies with time and may be periodic or non-periodic, i.e. not a constant velocity. Turbulent flow is unsteady flow that is random. Turbulent flow can be characterized by a mixing action throughout the flow field. Laminar flow is "smooth" or constant flow. Laminar fluid does not exhibit the intense mixing phenomena and eddies that are common to turbulent flow. The difference between turbulent and laminar flow is measured by the Reynolds number. The Reynolds number is a dimensionless combination of variables that is important in the study of viscous flow through pipes in that it is an index relating to turbulence. 


$$
\operatorname{Re}=\frac{\rho V D}{\mu}
$$

where:

$\operatorname{Re}=$ Reynolds number

$\rho=$ Density

$\mathrm{V}=$ Velocity

$\mathrm{D}=$ Diameter

$\mu \quad=$ Absolute viscosity

A Reynolds number greater than 2100 signifies the beginning of the turbulent flow region with 3000 typically signifying fully turbulent flow.

\section{Conservation of Mass}

Another important principle in pipe flow studies is the conservation of mass. The Continuity Equation states that the time rate of change of the system mass equals zero.

$$
\mathrm{M}_{\text {sys }}=\int_{\text {sys }} \rho \mathrm{d} \forall=0
$$

$$
\begin{aligned}
\text { where: } & \\
\mathrm{M}_{\text {sys }} & =\text { Mass of the system } \\
\rho & =\text { Density } \\
\forall & =\text { Volume }
\end{aligned}
$$

The conservation of mass for steady flow as used in viscous flow in pipes means that the flow in must equal the flow out.

\section{First Law of Thermodynamics}

The First Law of Thermodynamics is another important principle in fluid mechanics. It is commonly referred to as the energy equation. It simply states that the time rate of increase of the total stored energy of the system equals the net time rate of energy addition by heat transfer into the system plus the net time rate of energy addition by 
work transfer into the system. The energy equation is used in the pump motor sizing in fluid networks.

\section{Viscous Flow in Pipes}

The next area of fluid mechanics to be discussed is that of viscous flow in pipes. This subject area is very broad and every element is not pertinent to this thesis. Due to the information presented in section 2.4, the discussion of viscous flow in pipes will be limited to the following categories; major pressure losses, minor pressure losses, the network flow equations, and some of the methods to solve these systems of equations.

The first area of concern is with major losses, or frictional losses. The most notable method of calculating frictional losses was developed by Henry Darcy and Julius Weisbach, and termed the Darcy-Weisbach method. The Darcy-Weisbach equation states that head loss is proportional to the square of velocity (flow rate $x$ area) and is expressed as follows:

$$
H_{f}=f \frac{L}{D} \frac{V^{2}}{2 g}
$$

$$
\begin{aligned}
\text { where: } & \\
\mathrm{H}_{\mathrm{f}} & =\text { Head loss due to friction } \\
\mathrm{f} & =\text { Friction factor, Darcy } \\
\mathrm{L} & =\text { Length } \\
\mathrm{D} & =\text { Diameter } \\
\mathrm{V} & =\text { Velocity } \\
\mathrm{g} & =\text { Gravity }
\end{aligned}
$$

The Darcy-Weisbach equation requires knowledge of a previously undefined parameter, the friction factor (f). The friction factor or resistance coefficient can be determined several different ways. It can be determined either mathematically or graphically. 
Historically, the most well know method has been the Moody diagram. With the introduction of computers, a mathematical formula was used to perform friction factor calculations. The most commonly used formula is the Colebrook White formula. The Colebrook White formula has many different formulations including:

$\frac{1}{\sqrt{f}}=-2.0 \log \left(\frac{\varepsilon / D}{3.7}+\frac{2.51}{\operatorname{Re} \sqrt{f}}\right)$

where:

$\mathrm{f}=$ Friction factor

$\varepsilon=$ Relative roughness

$\mathrm{D}=$ Diameter

$\operatorname{Re} \quad=$ Reynolds number

Another popular method for calculating major head losses is the Hazen-Williams method. The Hazen-Williams equation is as follows:

$\mathrm{H}_{\mathrm{f}}=\mathrm{L}\left[\frac{\mathrm{V}}{\mathrm{kC}}\left(\frac{4}{\mathrm{D}}\right)^{0.63}\right]^{1 / 0.54}$

where:

$\mathrm{H}_{\mathrm{f}}=$ Head loss, Hazen-Williams

$\mathrm{L}=$ Length

$\mathrm{V}=$ Velocity

$\mathrm{k}=0.85$ for $\mathrm{m}$ and $\mathrm{s}$ and 1.318 for $\mathrm{ft}$ and sec

$\mathrm{C}=$ Hazen-Williams coefficient

$\mathrm{D}=$ Diameter

Similar to the Darcy-Weisbach formula, the Hazen-Williams equation requires the determination of another unknown. In this instance it is C, the Hazen-Williams roughness coefficient. This unknown can only be determined through experimentation. There are several commercial materials which have experimentally determined HazenWilliams roughness coefficients, see Table 2-1. 
Table 2-1. Hazen-Williams coefficients for some common materials

\begin{tabular}{|c|c|c|c|}
\hline Material & $\begin{array}{c}\text { Hazen- } \\
\text { Williams } \\
\text { Coefficient } \\
\text {-c- }\end{array}$ & Material & $\begin{array}{c}\text { Hazen- } \\
\text { Williams } \\
\text { Coefficient } \\
\text {-c- }\end{array}$ \\
\hline Asbestos Cement & 140 & Glass & 130 \\
\hline Brass & $130-140$ & Lead & $130-140$ \\
\hline Brick sewer & $90-100$ & $\begin{array}{l}\text { Metal Pipes - Very to extremely } \\
\text { smooth }\end{array}$ & $130-140$ \\
\hline Cast-Iron - new unlined (CIP) & 130 & Plastic & $130-150$ \\
\hline Cast-Iron 10 years old & $107-113$ & Polyethylene, PE, PEH & 150 \\
\hline Cast-Iron 20 years old & $89-100$ & PVC, CPVC & 150 \\
\hline Cast-Iron 30 years old & $75-90$ & Smooth Pipes & 140 \\
\hline Cast-Iron 40 years old & $64-83$ & Steel new unlined & $140-150$ \\
\hline Cast-Iron, asphalt coated & 100 & Steel & $60-150$ \\
\hline Cast-Iron, cement lined & 140 & Steel, welded and seamless & 100 \\
\hline Cast-Iron, bituminous lined & 140 & $\begin{array}{l}\text { Steel, interior riveted, no } \\
\text { projecting rivets }\end{array}$ & 100 \\
\hline Cast-Iron, wrought plain & 100 & Steel, projecting girth rivets & 100 \\
\hline Concrete & $100-140$ & Steel, vitrified, spiral-riveted & $90-100$ \\
\hline Copper or Brass & $130-140$ & Steel, corrugated & 60 \\
\hline Corrugated Metal & 60 & Tin & 130 \\
\hline Ductile Iron Pipe (DIP) & 140 & Vitrified Clays & 110 \\
\hline Fiber & 140 & $\begin{array}{l}\text { Wooden or Masonry Pipe - } \\
\text { Smooth }\end{array}$ & 120 \\
\hline Fiber Glass Pipe - FRP & 150 & Wood Stave & $110-120$ \\
\hline Galvanized iron & 120 & & \\
\hline
\end{tabular}

This leads to the evaluation of minor losses. Minor losses must be determined through experimental testing. Young et al., (2001) stated that the most common method used to determine minor losses is to specify the loss coefficient, $\mathrm{K}_{\mathrm{L}}$. Furthermore, they presented the coefficient as:

$K_{L}=\frac{h_{L}}{V^{2} / 2 g}=\frac{\Delta P}{\frac{1}{2} \rho V^{2}}$

So that

$\Delta P=K_{L} \frac{1}{2} \rho V^{2}$ 
Or

$h_{L}=K_{L} \frac{V^{2}}{2 g} \quad$ (Young et al., 2001, pg 321)

This method is a simple adaptation of the Darcy-Wiesbach equation where

$K_{L}=f \frac{L}{D}$. Typical loss coefficients can be seen in Table 2-2. 
Table 2-2, Component loss coefficients, $\mathrm{K}_{\mathrm{L}}$

\begin{tabular}{|c|c|c|c|}
\hline $\begin{array}{c}\text { Type of Component or } \\
\text { Fitting }\end{array}$ & $\begin{array}{c}\text { Minor Loss } \\
\text { Coefficient } \\
-\xi-\end{array}$ & $\begin{array}{c}\text { Type of Component or } \\
\text { Fitting }\end{array}$ & $\begin{array}{c}\text { Minor Loss } \\
\text { Coefficient } \\
-\xi-\end{array}$ \\
\hline Flanged Tees, Line Flow & 0.2 & Threaded $180^{\circ}$ Return Bends & 1.5 \\
\hline Threaded Tees, Line Flow & 0.9 & Fully Open Globe Valve & 10 \\
\hline Flanged Tees, Branched Flow & 1 & Fully Open Angle Valve & 2 \\
\hline Threaded Tees, Branch Flow & 2 & Fully Open Gate Valve & 0.15 \\
\hline Threaded Union & 0.08 & 1/4 Closed Gate Valve & 0.26 \\
\hline Flanged Regular $90^{\circ}$ Elbows & 0.3 & 1/2 Closed Gate Valve & 2.1 \\
\hline Threaded Regular $90^{\circ}$ Elbows & 1.5 & 3/4 Closed Gate Valve & 17 \\
\hline Threaded Regular $45^{\circ}$ Elbows & 0.4 & $\begin{array}{c}\text { Forward Flow Swing Check } \\
\text { Valve }\end{array}$ & 2 \\
\hline $\begin{array}{c}\text { Flanged Long Radius } 90^{\circ} \\
\text { Elbows }\end{array}$ & 0.2 & Fully Open Ball Valve & 0.05 \\
\hline $\begin{array}{c}\text { Threaded Long Radius } 90^{\circ} \\
\text { Elbows }\end{array}$ & 0.7 & 1/3 Closed Ball Valve & 5.5 \\
\hline $\begin{array}{c}\text { Flanged Long Radius } 45^{\circ} \\
\text { Elbows }\end{array}$ & 0.2 & 2/3 Closed Ball Valve & 200 \\
\hline Flanged $180^{\circ}$ Return Bends & 0.2 & & \\
\hline
\end{tabular}

Additional information is published in prior works: Crane, 1981; Streeter, 1961; Hydraulic Institute, 1990. Another method used to determine minor losses is the equivalent length theory and is expressed as follows:

$L_{e q}=\frac{\mathrm{KD}}{\mathrm{f}}$

Each component's equivalent length is determined and then added to the corresponding straight section of pipe for total head loss calculations.

The next area of focus is the network equations. First, some general terminology about complex networks must be discussed. The first term is a junction, which is a point where two or more flow paths meet, see Figure 2-14. 


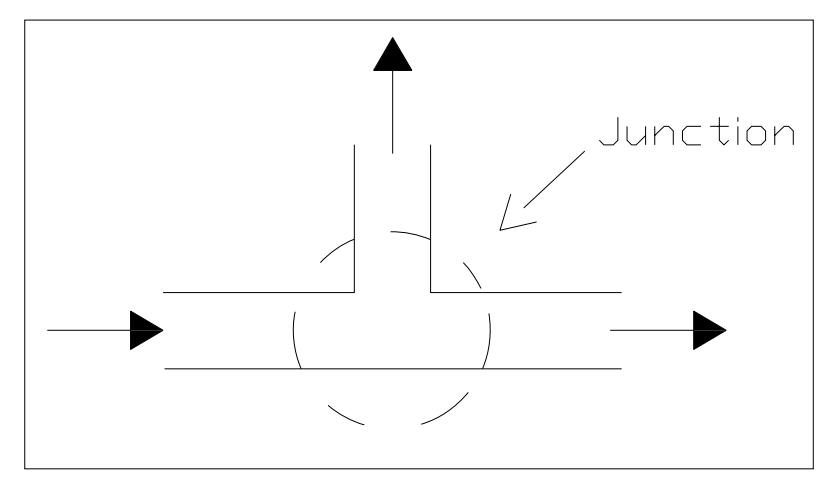

Figure 2-14, Complex network junction (Adapted from Benedict, 1980)

The second term is a closed loop, a path that leads from the input to the output (see Figure 2-15). There are three closed loops in Figure 2-15, from 1 to 2 by way of $A$, $B$ or $\mathrm{C}$.

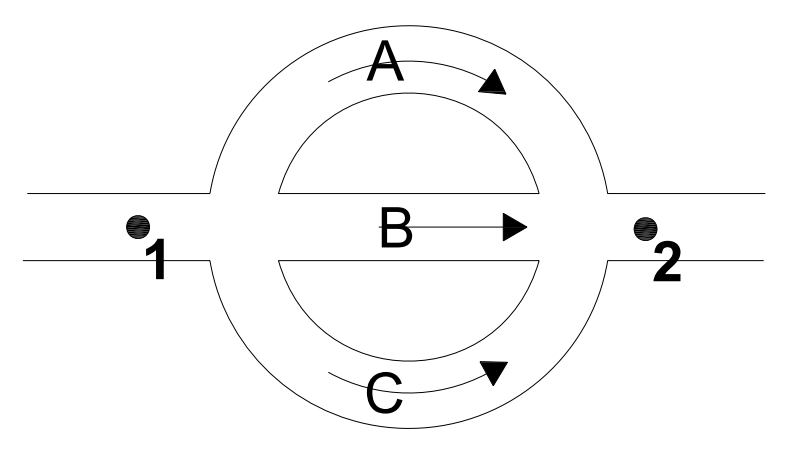

Figure 2-15, Complex network closed loop (Adapted from Benedict, 1980):

There are three sets of network equations needed to solve the complex fluid network. The first is the first network equation derived from Kirchhoff's first law or Kirchhoff's current law (KCL), which is related to the conservation of mass. The first network equations states that the flow into the system must equal flow out of the system. More specifically, that the flow into each junction must equal the flow out, $\sum Q_{i n}=\sum Q_{\text {out }}$, as 
seen in Figure 2-16 For the system in Figure 2-16, the first network equation requires that the flow into junction 1 equal the flow out of junction 1 , or $Q 1+Q 2+Q 3+Q 4=0$.

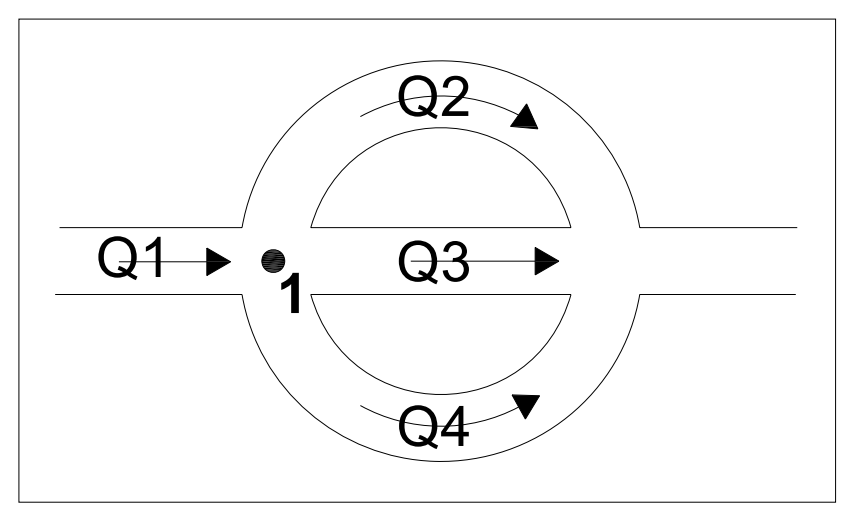

Figure 2-16, Depiction of the first network equation (Adapted from Benedict, 1980)

The second is referred to as the second network equation and is derived from Kirchhoff's second law or Kirchhoff's voltage law (KVL), which is related to the conservation of energy. The second network equation states that the summation of the pressure drops around each closed loop must equal zero, $\sum h_{\text {loop }}=0$, as seen in Figure 2-17. For the system in Figure 2-17, the second network equation requires that the pressure loss along path $A, B$, and $C$ must equal each other, or $\Delta P_{A}=\Delta P_{B}=\Delta P_{C}$. 


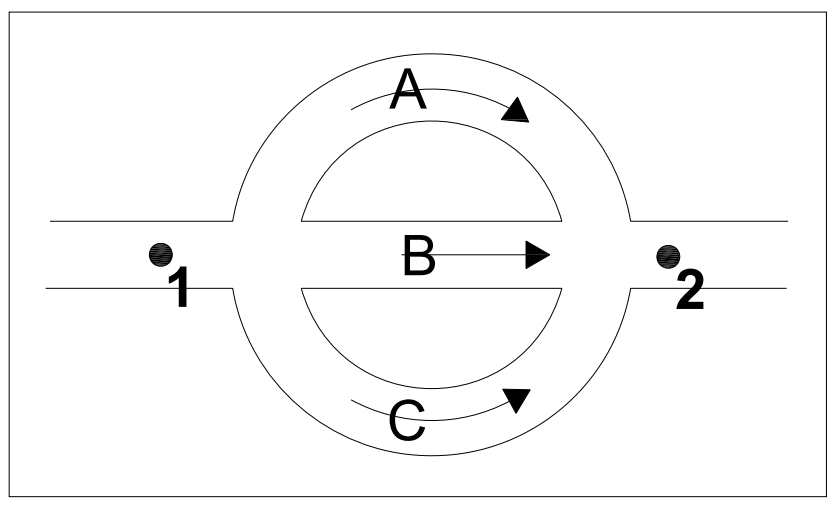

Figure 2-17, Depiction of the second network equation (Adapted from Benedict, 1980)

The third is the Darcy-Weisbach equation or a similar method of determining pressure losses in the system as a function of flow.

Once one has all the information required to evaluate a complex fluid network, a method of solving these systems of equations is needed. There have been several methods developed including the Hardy Cross method. This method is the most well known and commonly used. It is an iterative method, where an initial solution is given and is improved until the error is acceptably small. The Hardy Cross method is also known as the single path adjustment method and is a relaxation method. The flow rate in each pipe is adjusted iteratively until all equations are satisfied. The method is based on two primary physical laws. The first is that the flow into a junction equals the flow out of that junction. The second is that the hydraulic head (i.e. elevation head + pressure head, $\mathrm{Z}+\mathrm{P} / \mathrm{S})$ is single-valued. This means that the hydraulic head at a node is the same whether it is computed from upstream or downstream directions.

Pipe flows are adjusted iteratively using the following equation: 
$\Delta Q_{i}= \pm \sum_{i=1}^{\substack{\text { \#Pipes } \\ \text { inLoop }}} H_{i} / n \sum_{i=1}^{\substack{\text { \#Pipes } \\ \text { inLoop }}}\left(\frac{H_{i}}{Q_{i}}\right)$

until the change in flow in each pipe is less than the mathematical convergence criteria. More information on the Hardy Cross method can be found in (Cross, 1936). Some of the other methods to solve network equations include Gauss-Seidel, Newton Raphson, Euler, and linear methods.

\subsection{PREVIOUS WORKS IN HYDRAULIC SUPPLY SYSTEMS}

Although the use of hydraulic systems to power mechanized machinery is very old and well developed, a thorough evaluation of the system used in modern mining has yet to be completed. Over the years, there have been numerous developments and studies done on hydraulic systems, which is advantageous to the study of the longwall mining specific system. Since limited work has been done on the mining side, some of the other industrial uses should assist with the problem at hand.

From the literature reviewed for this thesis, most of the work done with the shields has been concerned with the yield valves, capacity, cycle time, force analysis, and load densities. These works are important but they do not shed much light on the design of the overall hydraulic supply system. Furthermore, the author found that there had been a few studies done that considered the setting pressure and the hydraulic system. Most of these were empirical studies of existing systems and focused solely on the pressures in the leg cylinders. There have been a few studies conducted in Germany that actually examined the hydraulic supply system. These studies looked at optimizing the pressure losses for differing systems. 
One study from Germany was performed by Dr. Bernd Fusser (2006) and titled "Requirements for an optimum hydraulic system resulting from the productivity increase in longwall faces." In this study, the pressure drops in the hydraulic system were examined. The effects of increased flow on the pressure loss across the system were evaluated. There were several solutions to improve systems which produced excessive pressure drops. Some of the proposed solutions were larger diameter hoses, substitute for pipes, more crossovers, and more hoses. Calculations were made of the effects of each of the proposed solutions on a typical longwall mine in the U.S. Another point of interest in Dr. Fusser's paper was that coiled hoses caused twice the pressure loss as the same hose fully extended. This is a typical occurrence in the monorail, thus this condition should be the simulated condition since it is the worst case scenario.

Another study from Germany was performed by Dr. Reinhard Bassier and Peter Migenda (2006) and titled "Planning of shield hydraulic systems for high performance longwalls." One of the key outcomes from this research was that pressure drops can be minimized by selecting sufficiently dimensioned components, and by monitoring and maintenance to avoid dynamic return pressure and short circuit flow of fluids. The study included numerous hydraulic measurements at underground sites. The hydraulic measurements, flow and pressure, were taken by electronic flow meters and pressure transducers connected to a data logger. Another interesting result was that of the fluid flow distribution of the evaluated hydraulic systems that was analyzed. The distributions showed that the lower flow peaks were caused by the retraction/advancing/setting cycle of a shield; whereas, the highest flow peaks were caused by conveyor advance. 
Although this is interesting, the main objective of ensuring adequate flow and pressure to the shields is affected equally by the high flow requirements of either the shield cycles or the conveyor push. The higher the flow, the greater the pressure drops across the system (Equation 5). 


\section{CHAPTER 3: FIELD STUDY}

This chapter presents the field study in its entirety. First, the physical information required from the mine site is presented, followed by the actual information of the field study site. The next section contains the location and the description of the instrumentation. The next section discusses the data collection plan, followed by a section discussing the data analysis plan. The last section discusses the results of the field study.

\subsection{INFORMATION REQUIRED FROM MINE SITE}

This section discusses mine design characteristics that affect the working relationship of the pump station as well as the rest of the hydraulic system. The following list contains the necessary information to model the hydraulic system:

1. Longwall design parameters

A. Shearer performance

i. Operating speed (average, $\max , \min$ )

B. Shield design

i. Width

ii. Cylinder sizes (piston and rod diameter)

iii. Leg retract/set distance

iv. Advancing ram stroke

v. Base lift stroke

vi. Cycle time

vii. Number of shields advancing per cycle

viii. Total number of shields

C. Mine design 
i. Longwall width

ii. Monorail length

iii. Pillar dimensions

iv. Entry width

D. Pump characteristics

i. Model number and manufacturer

ii. Performance curves

iii. Impeller sizes

iv. Horsepower

v. Number and method of connection

vi. Desired outlet pressure of each

vii. Desired outlet flow of each

E. Hose characteristics

i. Material (model number and manufacturer)

ii. Dimensions of hose network

a. Inner diameter of each hose

b. Length of each hose section

c. Length of longwall

d. Length of hose section between shields

e. Length of completely extended hose line in monorail

f. Length of coiled hose in monorail

g. Number of hoses in each section (pressure and return)

h. Hose connection descriptions/types

Information on all the elements in the preceding list is needed to construct a simulation model to evaluate the effectiveness of the hydraulic supply system. Some of the information can be best represented by physical values. For example, the shearer information and much of the shield information is needed to determine the flow requirements of the shield; this could be measured or estimated based on desired 
production rates. The flow could be approximated using the shield specifications, shearer specifications, and operational parameters, but this does not account for outside influence on the system and therefore does not meet the requirements of this study. If the flow were to be measured, then the measured flow will include leaks, damage, and other wear and tear. For example, leaks in hoses, leaks in shield legs, and activation of positive set would be included in the measured flow data.

In addition to the information mentioned above, there are some operational parameters that must be considered, such as the cycling of shields, the pushing of the pans, and any other draws on the hydraulic system. For the cycling of the shields, the batch characteristics, number of shields being advanced simultaneously and the location of these shields are required. The time delay between batches, variations in batches, and any other relevant information to the amount of flow needed and the location of that flow is required to accurately evaluate the hydraulic system. For pushing of the pan, the location relative to the shield batching and the number of pans being pushed at the same time is also needed. Also, there could be numerous other occurrences which would affect the amount of flow needed, the ability to transport that flow, or the ability to maintain the pressure required.

\subsection{FIELD SITE HYDRAULIC SYSTEM AND OPERATING PROCEDURES}

Based on the preceding information, the following is a description of the actual operational site characteristics of the longwall mining operation to be modeled. A hydraulic supply system typically consists of hydraulic pumps to generate high pressure and flow, hydraulic hoses to transport the fluid, filters to insure the cleanliness of the 
fluid, fluid mixing vessel, and a water supply system, either drawn from a reservoir or public water. The pumps are typically set up as a station, either centralized or decentralized. Generally within a pump station there are several pumps, each with a capacity of $80-125 \mathrm{gpm}$ at $4,200-5,000 \mathrm{psi}$. Typically one pump is constantly operating, when the flow demand exceeds its capacity or the pressure drops too much, the next pump begins operating. This cycle continues until all the pumps in the pump station are operating. Conversely, a pump will stop operating when it is no longer needed because of pressure increases or flow demand drops. The hydraulic hoses are typically flexible rubber hoses with an operating pressure in excess of 5,000 psi. There are typically two distinctly different sections of hoses, face and monorail. The monorail is normally configured with1 to 4 hoses running in parallel. The face hoses are generally found in one of the following three configurations: garland-shaped hoses from shield to shield, straight hose line along the AFC with a crossover connection to each shield, and two hose lines in a ring main system. The filters are not consistent among hydraulic supply systems, but there are two primary types: bypass and non-bypass filters. A bypass filter is one that has the ability to allow fluids to pass without being filtered and can be replaced or cleaned without disruption of fluid flow. Non-bypass does not have this characteristic. The fluid mixing vessel is typically close to the pump station and allows for a controlled concentration of emulsion fluid. The water supply system is typically an available water source such as an aquifer, a stream, a lake, or public water.

The longwall, which is being used to calibrate the model, is typical of today's high production longwall faces. The longwall has a three entry gate road section. The longwall face is approximately $1,250 \mathrm{ft}$ wide. The following description is that of the 
supply system shown in Figure 3-1, adapted from Syd Peng's book (2006) entitled "Longwall Mining." The longwall face is equipped with 187 shields, where the first three (\#1 to \#3) are headgate end shields and the last four (\#184 to \#187) are tailgate end shields. The water for the emulsion mixture is supplied primarily by river water from the surface. The water is then transported to the mine site where it is filtered by three consecutive bypass filters, a 60-micron, a 25-micron and a 12-micron. After being filtered, the water is mixed with the HFA concentrate (19:1 ratio) just prior to entering the 2,500 gallon emulsion tank. The HFA concentrate is stored in a 300 gal tank. The emulsion mixture is then pumped by a $500 \mathrm{gpm}, 50$-psi booster pump to the pump station. The pump station consists of two Kamat 100-gpm, 5,000-psi pumps and two Hauhinco 100-gpm, 5,000-psi pumps. At the pump station there are 32-liter accumulators to stabilize the pressure and flow rate required by the hydraulic system. There is also a direct return line, with 12-micron filters, to the emulsion tank for unused mixture. From the pump station, the fluid travels by two, 2-inch-diameter SuperStecko high press hoses along 125 -ft-long jumpers to the 1,650 -ft-long monorail. The monorail extends to $1,650 \mathrm{ft}$ and contracts to $\sim 700 \mathrm{ft}$ with the advancement of the face. This causes the hoses in the monorail to snake up. From the monorail, the lines enter the stage loader where the mixture is once again filtered by a 12-micron bypass filter and a 25-micron filter in each line. Then one of the lines goes to shield \#1 at the headgate and then moves along the face, shield to shield, in a 1.5-inch-diameter SuperStecko hose. The other line runs along the ring main with a ladder at shield \#39, shield \#84, shield $\# 130$ and at shield \#175. All of the shield-to-shield hoses are 108 inches long. Prior to entering each shield, there is a 40-micron filter. This completes the pressure side of the hydraulic system. 
For the return side, the fluid exits the shields and runs either shield-to-shield via a 2-inch-diameter Stecko hose or along the ring main via a 2.5-inch-diameter Stecko hose. The return has the same number of ladders but one shield closer to the tailgate. Just prior to re-entering the emulsion tank, the fluid is filtered by a 10-micron filter. 


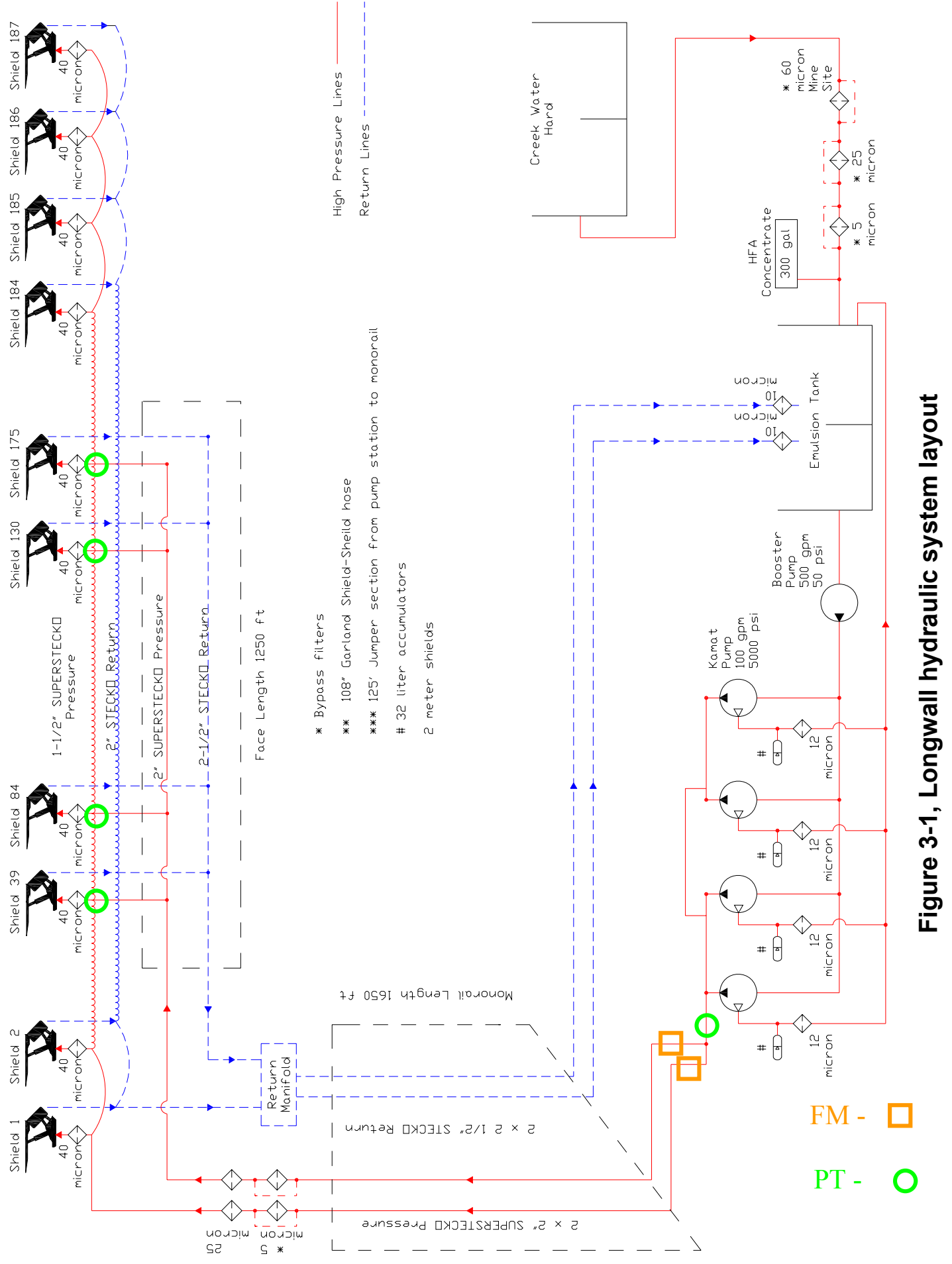

52 
The one operational parameter that stands out from the field study is the shield automation. The shields are set against the mine roof using the electrohydraulic control system. The method of setting the shields employed at the field study site is that referred to as "positive set". This method was developed to allow the shields along the entire face to have relatively similar setting pressures. Figure 3-2 is a flow chart of the positive set method employed at this particular mine. This method can be manipulated and turned off in the event a different setting criterion is deemed necessary.

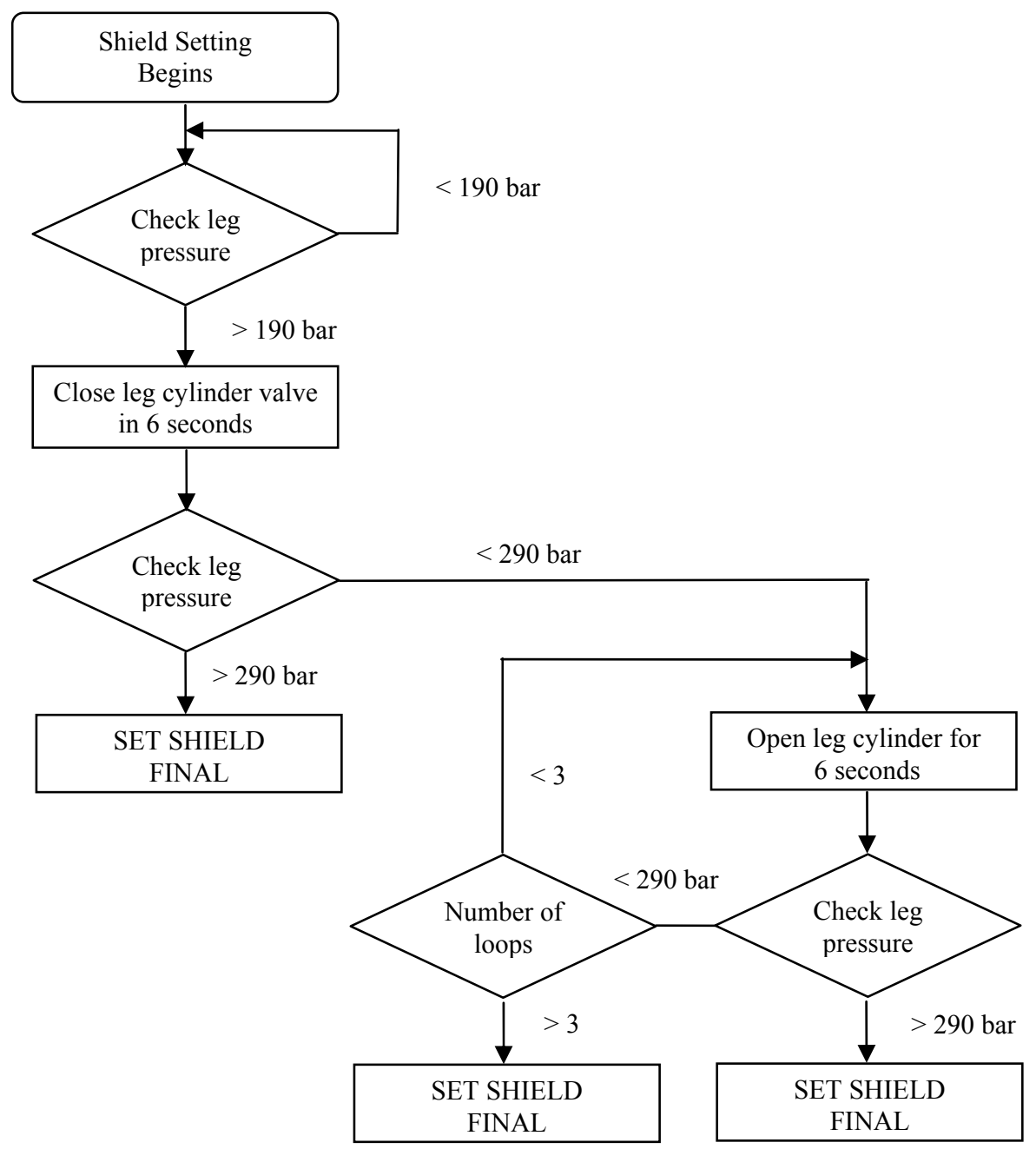

Figure 3-2, Positive set flow chart 
The above flow chart demonstrates the method that the shield goes thru to ensure proper setting pressure is attained. The positive set method allows the shield to go through a series of setting operations during a single cycle to reach a threshold pressure. The threshold pressure can be manipulated by the operators or the manufacturers.

\subsection{LOCATION AND DESCRIPTION OF INSTRUMENTATION}

The chosen site for the initial field study is the Cumberland Mine, located in southwestern Pennsylvania, specifically near the town of Waynesburg. This mine currently has one of the longest longwall faces, measuring 1,250 feet. The overburden at this location ranges from $300-700$ feet. This mine has been using the longwall method since its inception. The mine employs 187 shields, which are 894-ton, two-leg, lemniscate link shields. The complete equipment list to include the entire hydraulic supply system will be recorded for future use of model design and calibration.

There are two primary pieces of monitoring equipment used in this study, flow meters and pressure transducers. Each is equally important in the accurate determination of the calibration measurements. There are numerous types of both pressure transducers and flow meters. The hydraulic systems used at the face require substantially more pressure measurements than flow measurements, thus the pressure transducers will be discussed first.

Pressure transducers: The pressure transducers are those installed on the shields by the manufacturer to monitor the shield leg pressure. These pressure transducers are 
allowed by MSHA to be inby the last open cross-cut, which allows for their immediate use. They have approximately a plus or minus $5 \%$ error. The effect of this error is believed to be minimized by the number of transducers utilized in the system, which tend to nullify over the entire system (see Figure 3-3). Figure 3-3 depicts one of the four pressure transducers installed in the main pressure lines along the face. They were installed just prior to entering the shield. These pressure transducers are identical to those used in the shields.

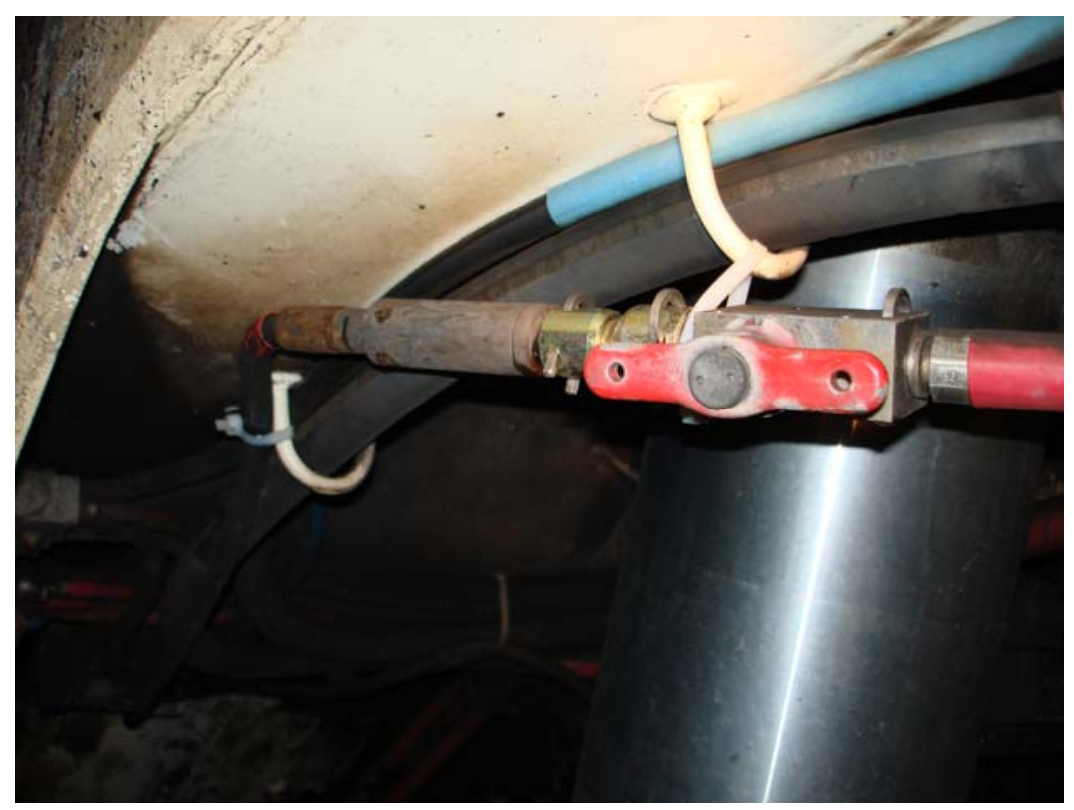

Figure 3-3, Photo of pressure transducer

Flow meters: The flow meters that are being used are manufactured by MIDEX. They were specially designed to measure the flow anticipated in this application in U.S. units. They are designed with the same connections as the Super Stucko hoses used in the hydraulic supply system. These are rated for $300 \mathrm{gpm}$ and over 5,000 psi. They have a 
resolution of $1.5 \%$ of full scale, but typically have $0.75 \%$ error. They use the electrical conductivity of the fluid to determine the flow rate. See Figure 3-4.

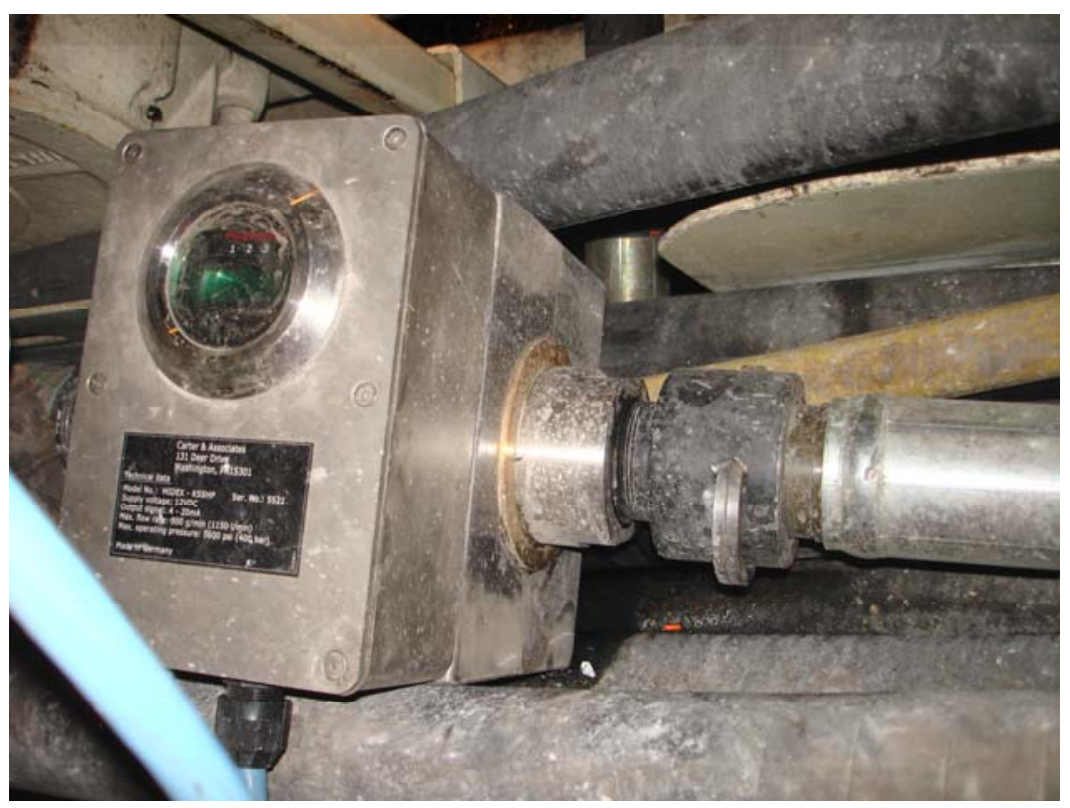

Figure 3-4, Photo of flow meter

Additional equipment: Additionally the $\mathrm{V}$-Shield program from the support manufacturer was utilized to determine the pressure in the shield legs, the time when the shields are advancing, and the time that the conveyor is being pushed. The shearer position and pump activity was monitored by pre-existing equipment at the stageloader.

\subsection{DATA COLLECTION PLAN}

To determine the fluid characteristics of the system, both pressure and fluid measurements are required. For the initial measurements, there was a considerably greater emphasis on the pressure readings. Pressure data was collected once per second at each shield across the longwall face for at least 10 shearer cycles, or until a 
power station move occurred. These pressure readings were taken from the shield's leg cylinder measurements through V-Shield, developed by DBT. This gave pressure readings for the entire cutting sequence for each shield. There were also four pressure measurements taken in the mainline hoses, located at shields \#39, 84, 130, and 175. These pressure readings were also recorded using the shields' data logging instrument, V-Shield.

Along with the pressure measurements, flow was measured. The flow was measured just after the pump station. At this point in the system, there are two supply lines in the system, one going to the headgate and the other to the panline for distribution along the face to the tailgate section. The flow rates in these lines gave the total flow in the system with respect to time. Some of the factors that affected the total flow were fluid leaks, leaky cylinders, bad valves, bad seals, and poor roof conditions. The flow was recorded using an Allen Bradley data logging system, already in place at the pump station. The location of the flow meters (FM) and pressure transducers (PT) can be seen in Figure 3-1.

After this initial data was analyzed, a much larger data set was created by collecting data over a substantially longer period of time. This insures that the initial calibration is accurate and that the high and low flow values can be established. 


\subsection{DATA ANALYSIS}

The flow and pressure readings must be analyzed to determine the expected output of the model. The model used an iterative solution method to determine the flow and pressures at each location throughout the hydraulic system. Since the roughness coefficients of the pipes and minor losses are associated with the components throughout the system, the measurements taken were used to determine these system values. Specific points in time were used in the calibration of the model; therefore a complete set of operating parameters for the system was developed along with corresponding specific points in time to calibrate the model. Once these values were determined, changes to the system were evaluated to determine the best design for the longwall layout.

The first step after data collection was to determine the appropriate values for the pressures and flow along the face. The flow measurements taken just after the pump station were used to set the input flow of the model. The flow measurements were evaluated based on the mining activities occurring at the time of the readings. In other words, the flow measurements were related to shield cycles and conveyor pushes and their location of occurrence. Microsoft Excel ${ }^{\mathrm{TM}}$ was used to determine the frequency, minimums, maximums, and average flow rates for each cycle, each cut, and the complete data set, as well as the coinciding pressure readings. From these derived values and the actual data points, the specific values used to calibrate the system were determined. 
Once the flow measurements were evaluated and categorized, the pressure reading across the face were analyzed. The pressure reading across the face was examined using an algorithm developed in Microsoft Excel ${ }^{\mathrm{TM}}$. The algorithm determined the setting pressures, location of shield setting, ram advance, and the location of the ram advance. The algorithm for the setting pressure determination is illustrated in

Figure 3-5. The algorithm functions as follows; it first looks for the pressure to drop below 1,450 psi (point A), then it looks for the pressure to rise above 2,900 psi (point $B$ ), and then it looks for a pressure change less than $2 \%$ between consecutive data points (point C). The $2 \%$ change in pressure is over a one second period and can be negative of positive. The pressure exhibited once the pressure increase was less than $2 \%$ was considered to define the setting pressure. This setting pressure determination algorithm is represented in the following figure: 


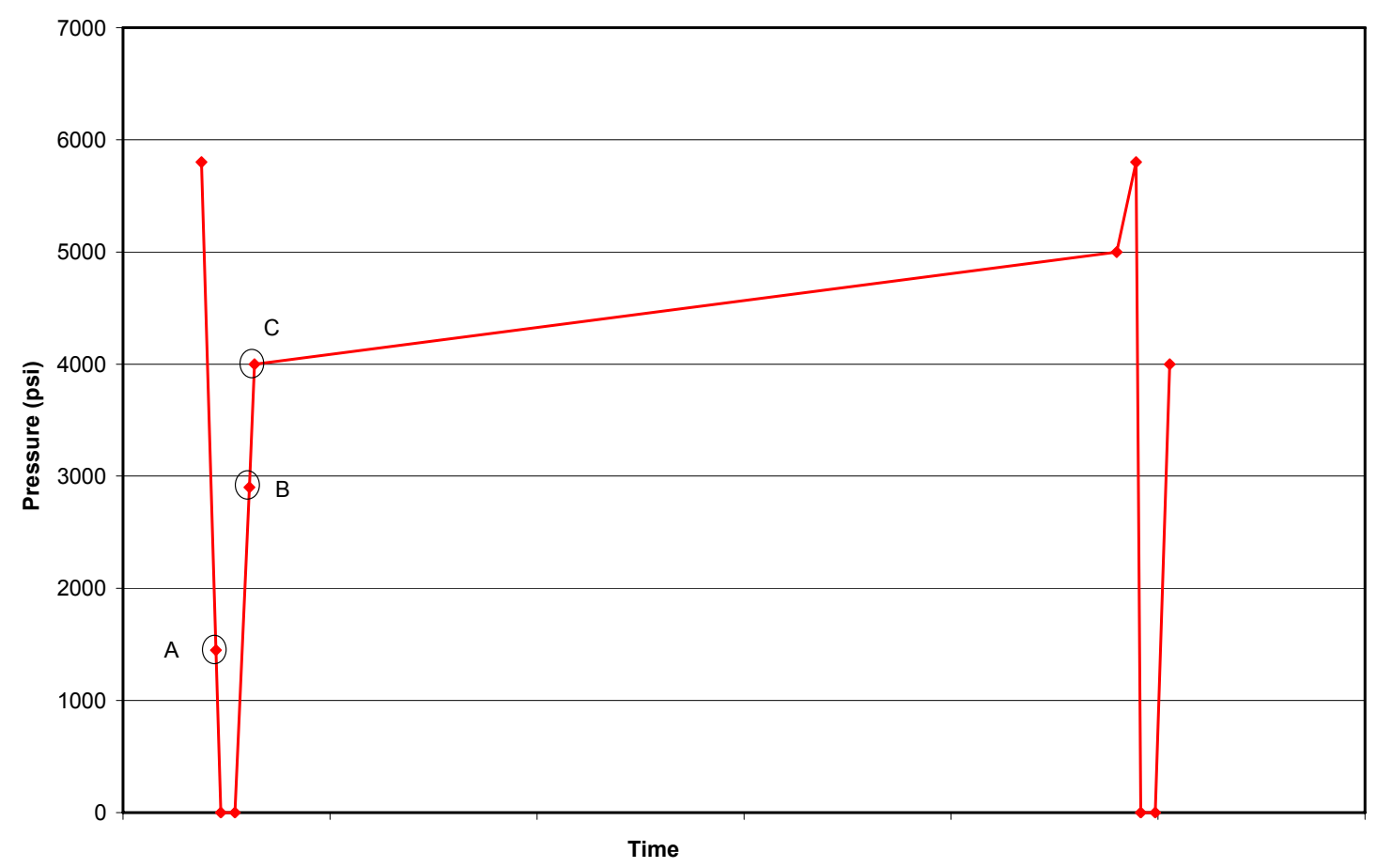

Figure 3-5, Depiction of the setting pressure determination algorithm

For the ram advance, the algorithm looked for ram position to be less than $100 \mathrm{~mm}$, then greater than $500 \mathrm{~mm}$, and then a change in ram position less than $2 \%$. The pressure readings were matched with the flow measurements with respect to time. This provided all the necessary values to determine the roughness coefficients of the hoses currently used at the field study site. Both peaks and minimums of flow were used to insure that the appropriate roughness factor has been determined to limit errors in future evaluations. 


\subsection{FIELD STUDY RESULTS}

The initial model used roughness coefficients determined from previous German research. A major part of the calibration effort was to determine roughness coefficients for the study mine site. Thus, flow and pressure measurements throughout the study site needed to be collected. From these measurements, calibrated input and output parameters were determined. Tables 3-1and 3-2 provides representative results from flow and pressure readings taken during the period from May 11-13, 2007. Table 3-1 is representative of the measurements taken prior to the power move. Conversely, Table 3-2 represents the measurements taken just after the power move. The table presents the minimum, maximum, mean, and median values for pump flow, pump pressure, and face pressure readings. The tables representing the remainder of this time period can be found in Appendix B, with the exception of the period 8 a.m.-4 p.m. on May 12, which had no recordable results because of a power station move.

Table 3-1, Central Tendency of Pump Flow \& Pressure, May 11, 2007, 12:00 a.m. to 8:00 a.m.

\begin{tabular}{|c|c|c|c|c|c|c|c|}
\hline & \multicolumn{7}{|c|}{ 12:00am-8:00am } \\
\cline { 2 - 8 } & $\begin{array}{c}\text { Flow1 } \\
\text { (gpm) }\end{array}$ & $\begin{array}{c}\text { Flow2 } \\
\text { (gpm) }\end{array}$ & $\begin{array}{c}\text { Pump } \\
\text { Pressure } \\
\text { (psi) }\end{array}$ & $\begin{array}{c}\text { Shield 39 } \\
\text { Pressure } \\
\text { (psi) }\end{array}$ & $\begin{array}{c}\text { Shield 84 } \\
\text { Pressure } \\
\text { (psi) }\end{array}$ & $\begin{array}{c}\text { Shield } \\
\mathbf{1 3 0} \\
\text { Pressure } \\
\text { (psi) }\end{array}$ & $\begin{array}{c}\text { Shield } \\
\mathbf{1 7 5} \\
\text { Pressure } \\
\text { (psi) }\end{array}$ \\
\hline Minimum & 0.00 & 0.00 & 0 & 0 & 0 & 0 & 0 \\
Maximum & 155.46 & 155.46 & 5214 & 5033 & 5091 & 5062 & 5076 \\
Mean & 47.70 & 37.78 & 4020 & 4317 & 4342 & 4276 & 4302 \\
Median & 28.71 & 23.02 & 4594 & 4641 & 4685 & 4612 & 4627 \\
\hline
\end{tabular}


Table 3-2, Central Tendency of Pump Flow \& Pressure, May 13, 2007, 12:00 a.m. to 8:00 a.m.

\begin{tabular}{|c|c|c|c|c|c|c|c|}
\hline & \multicolumn{7}{|c|}{ 12:00am-8:00am } \\
\cline { 2 - 8 } & $\begin{array}{c}\text { Flow1 } \\
\text { (gpm) }\end{array}$ & $\begin{array}{c}\text { Flow2 } \\
\text { (gpm) }\end{array}$ & $\begin{array}{c}\text { Pump } \\
\text { Pressure } \\
\text { (psi) }\end{array}$ & $\begin{array}{c}\text { Shield 39 } \\
\text { Pressure } \\
\text { (psi) }\end{array}$ & $\begin{array}{c}\text { Shield 84 } \\
\text { Pressure } \\
\text { (psi) }\end{array}$ & $\begin{array}{c}\text { Shield } \\
\mathbf{1 3 0} \\
\text { Pressure } \\
\text { (psi) }\end{array}$ & $\begin{array}{c}\text { Shield } \\
\mathbf{1 7 5} \\
\text { Pressure } \\
\text { (psi) }\end{array}$ \\
\hline Minimum & 0.13 & 0.00 & 31 & 1 & 1 & 1 & 1 \\
Maximum & 155.46 & 155.46 & 5016 & 5047 & 5265 & 5076 & 5091 \\
Mean & 45.71 & 35.56 & 4515 & 4555 & 4576 & 4515 & 4521 \\
Median & 29.79 & 23.03 & 4609 & 4656 & 4670 & 4598 & 4612 \\
\hline
\end{tabular}

The distribution of pump flow, pump pressure, and face pressure readings are provided in Figures 3-6 thru 3-19 as well as in tabular form in Appendix A. The first seven charts provide the distribution just prior to a power station move. This means that the monorail hoses are fully snaked and should display the greatest pressure losses. The last seven charts provide the distribution just after a power station move. This means that the monorail hoses are fully extended or straight and should display the smallest pressure losses. 


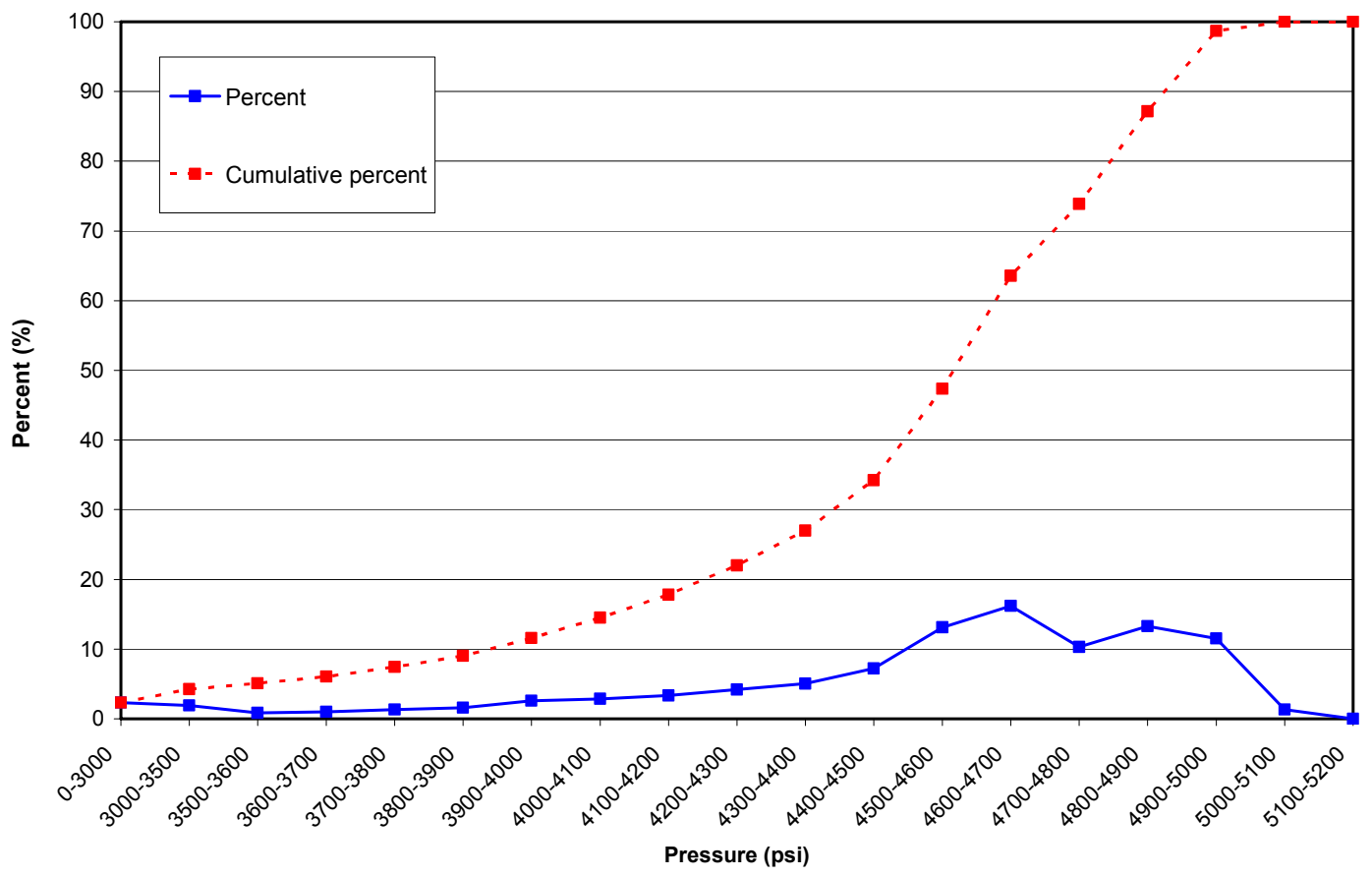

Figure 3-6, Pressure distribution of Shield 175, May 112007 12:00 a.m. to May 12 2007 8:00 a.m.

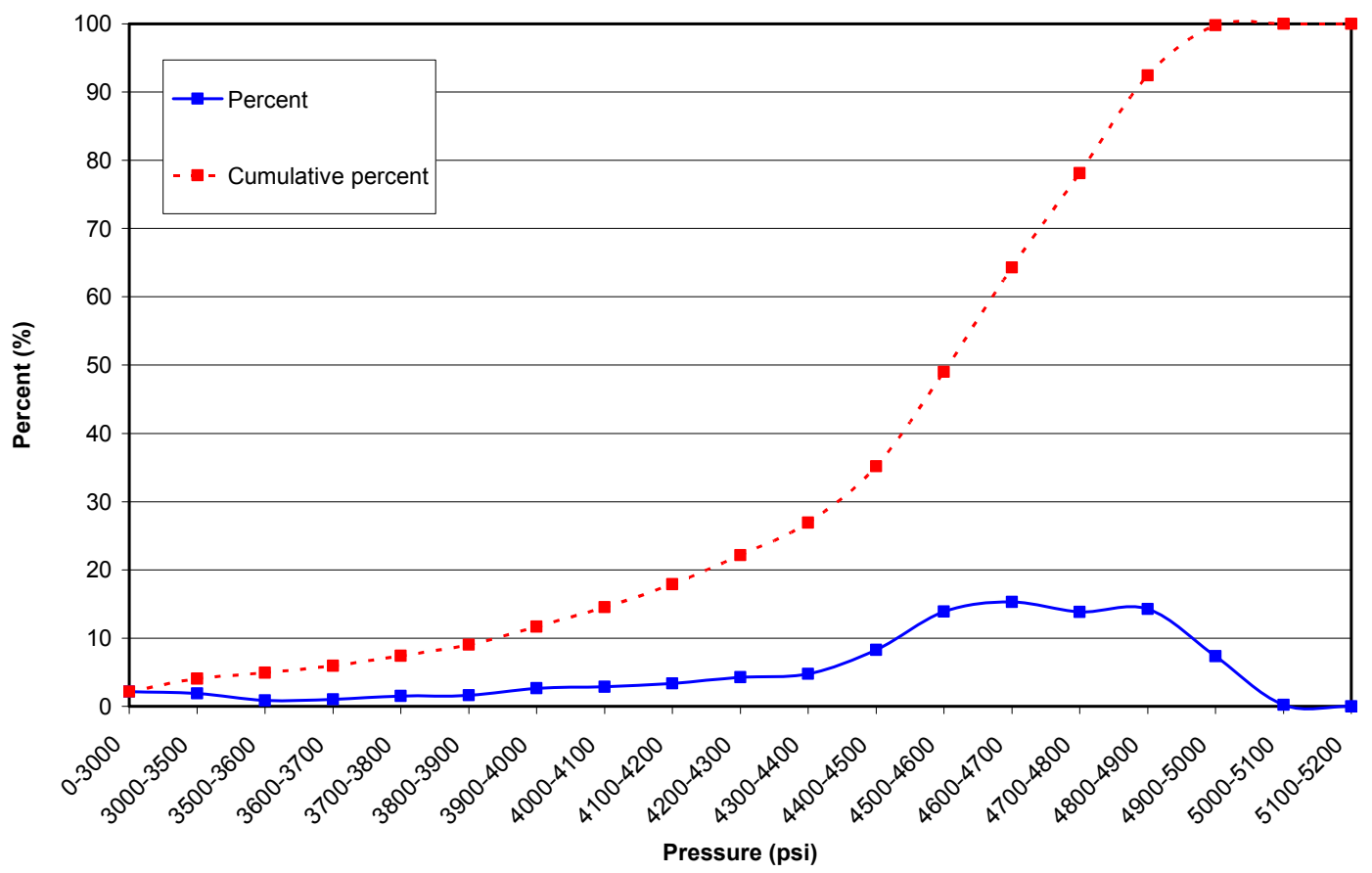

Figure 3-7, Pressure distribution of Shield 130, May 112007 12:00 a.m. to May 12 2007 8:00 a.m. 


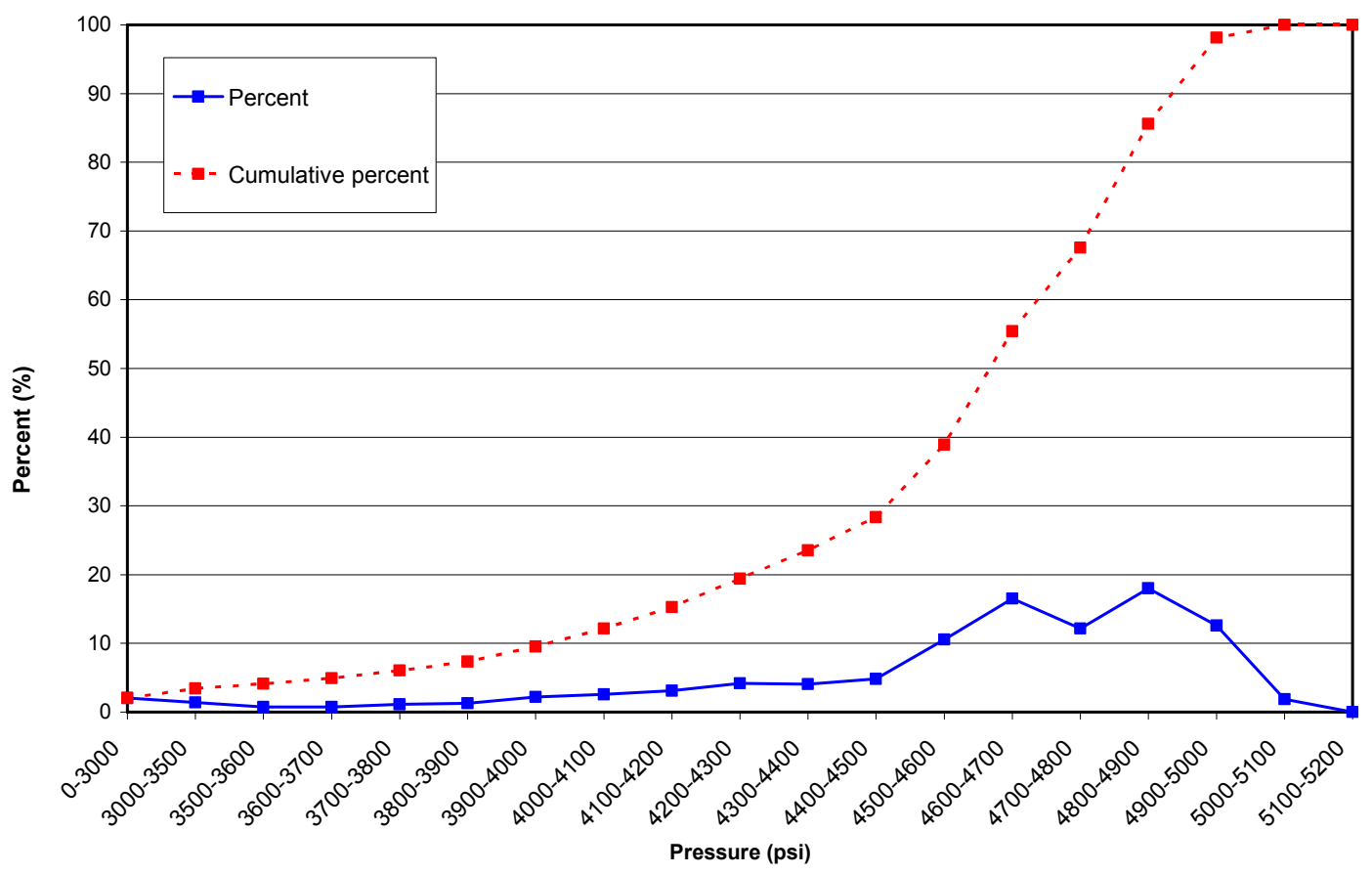

Figure 3-8, Pressure distribution of Shield 84, May 112007 12:00 a.m. to May 12 2007 8:00 a.m.

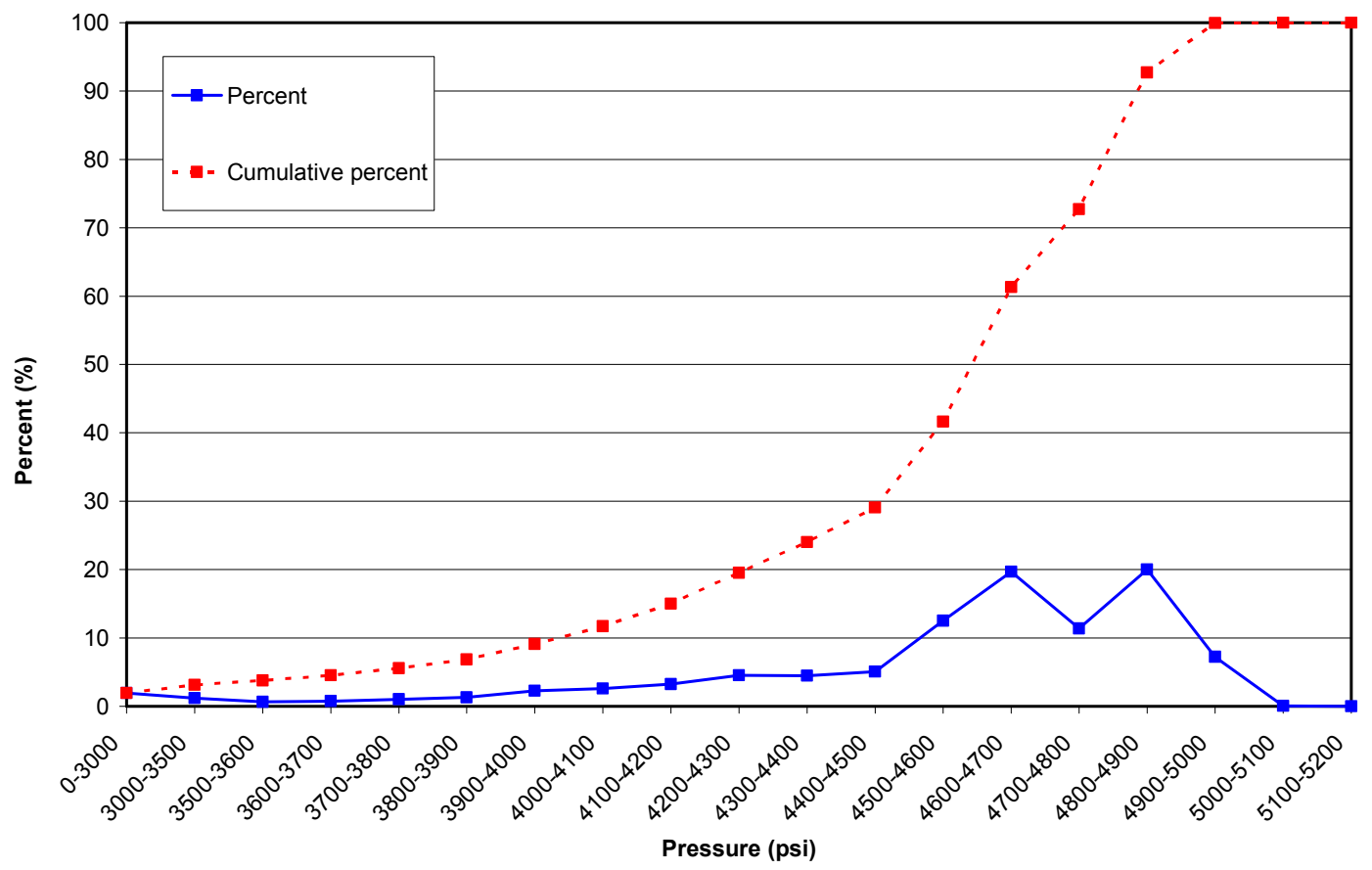

Figure 3-9, Pressure distribution of Shield 39, May 112007 12:00 a.m. to May 12 2007 8:00 a.m. 


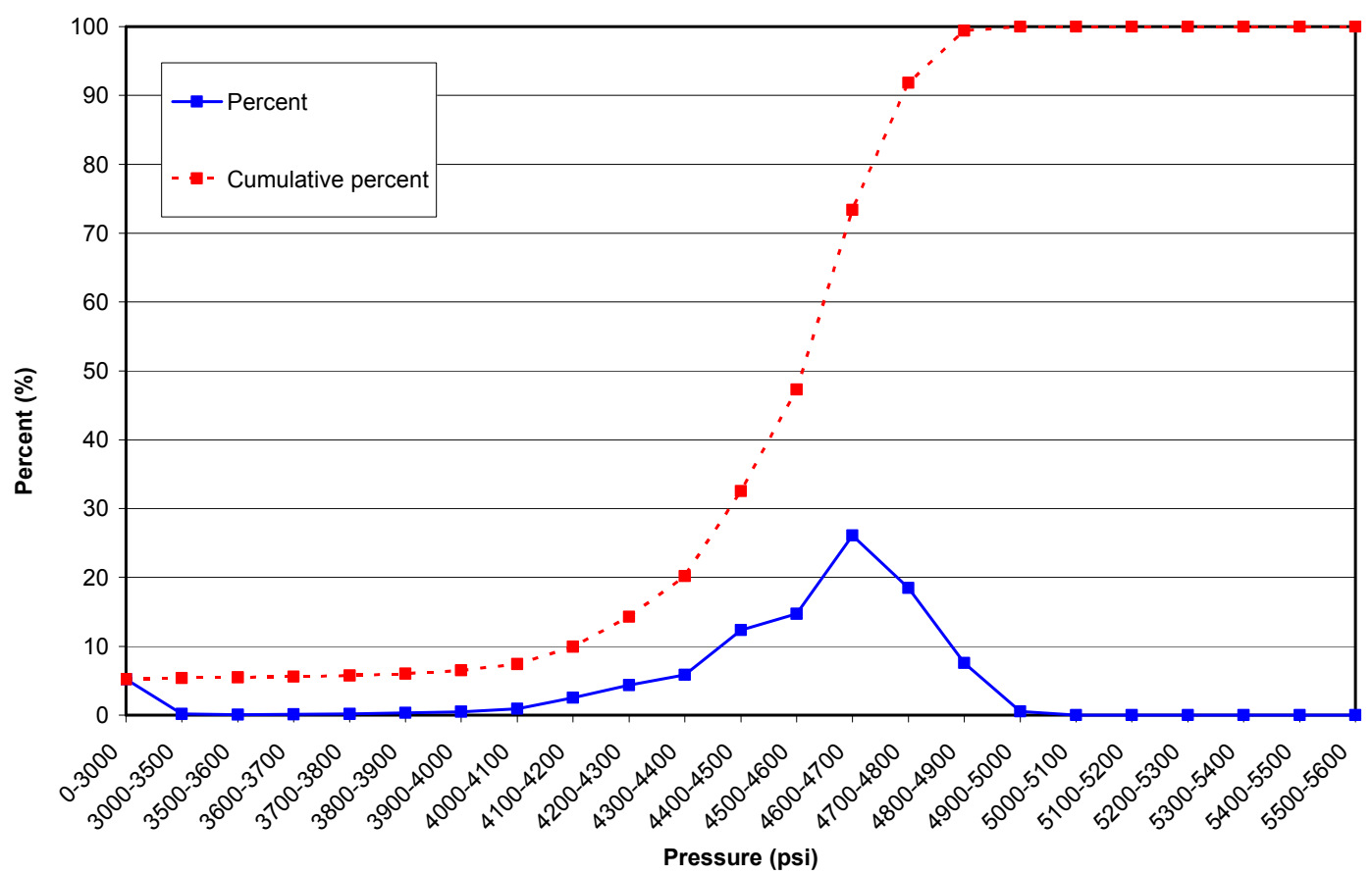

Figure 3-10, Pump Pressure distribution, May 112007 12:00 a.m. to May 122007 8:00 a.m.

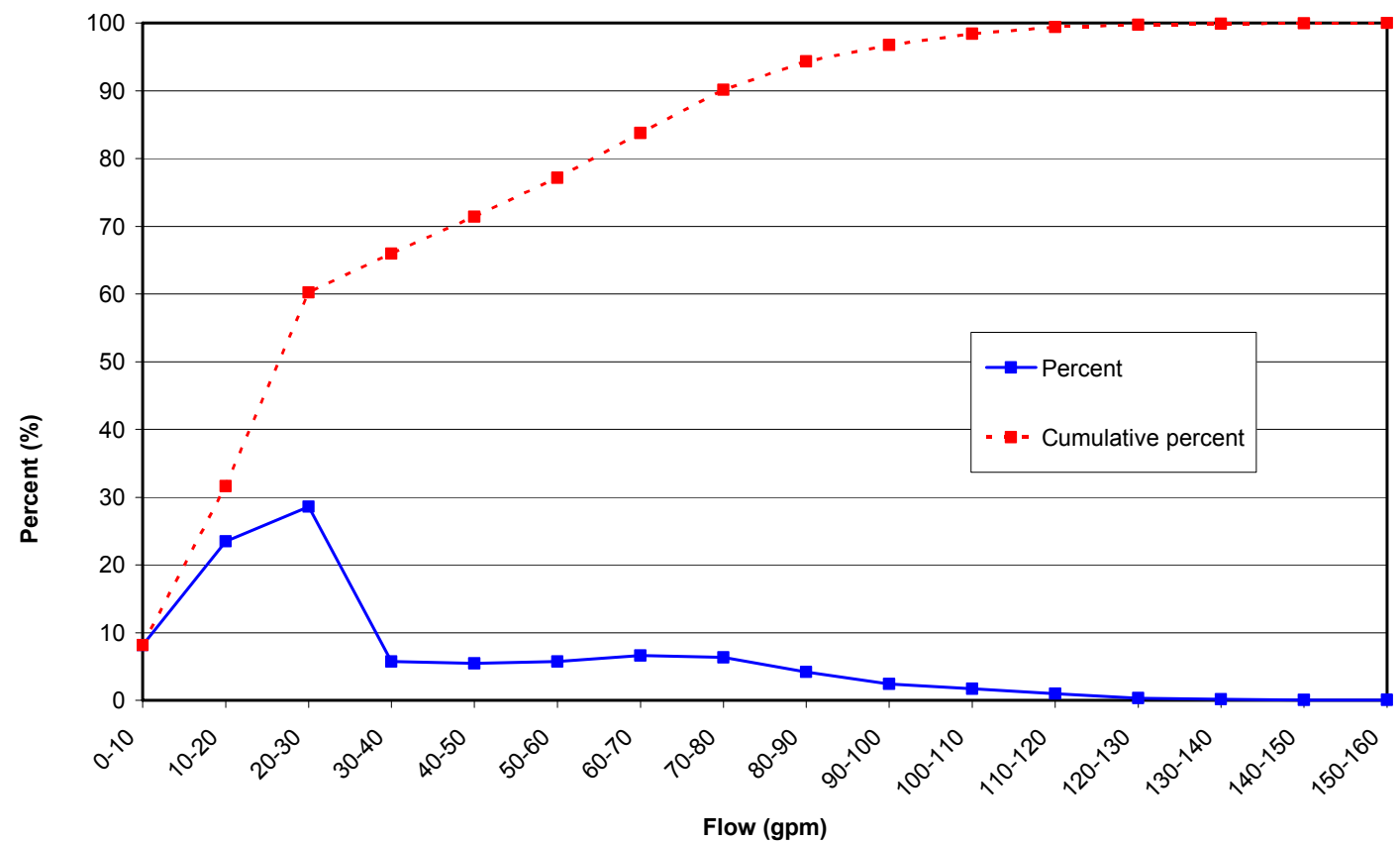

Figure 3-11, Flow distribution Flow 2, May 112007 12:00 a.m. to May 122007 8:00 a.m. 


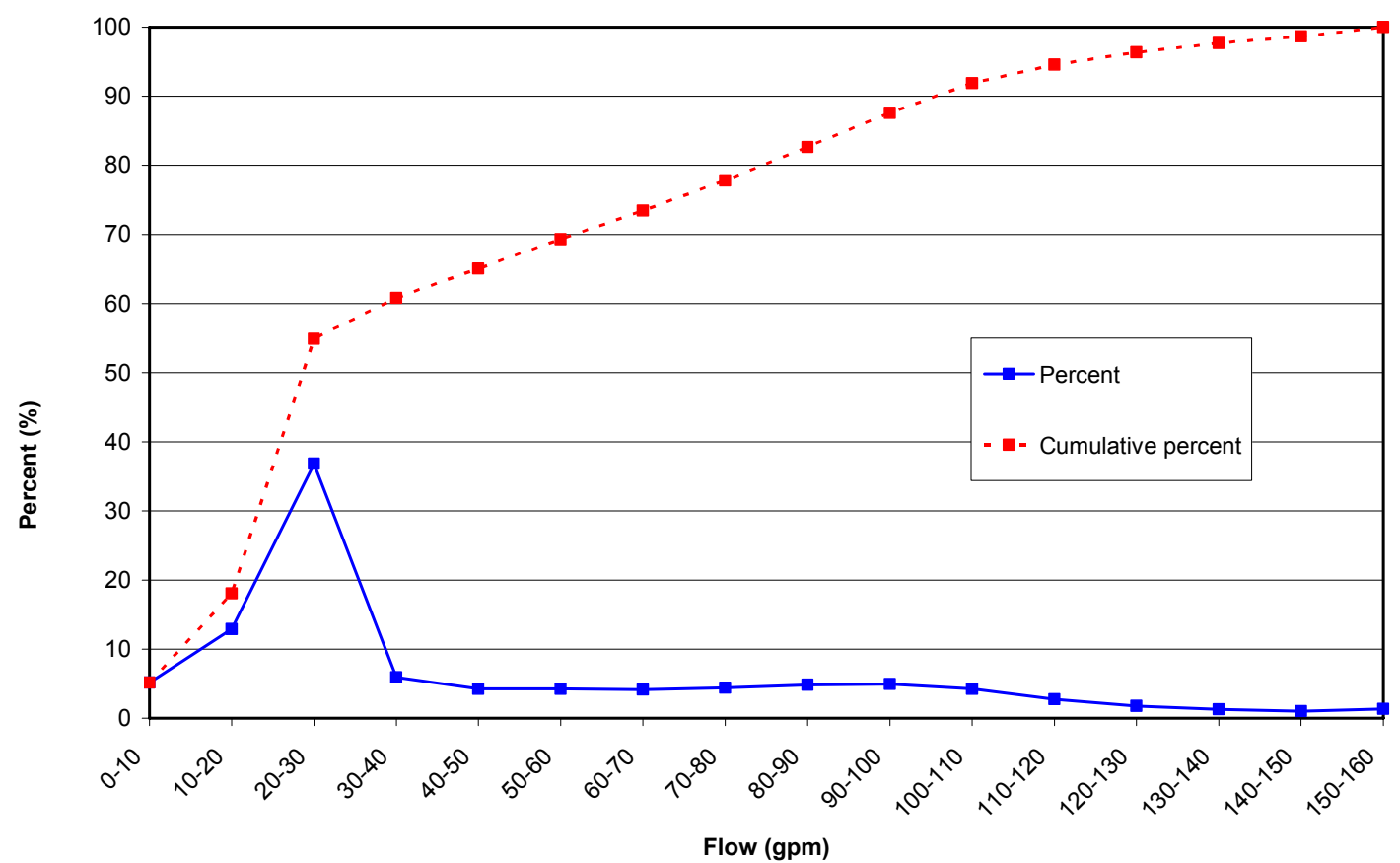

Figure 3-12, Flow distribution Flow 1, May 112007 12:00 a.m. to May 122007 8:00 a.m.

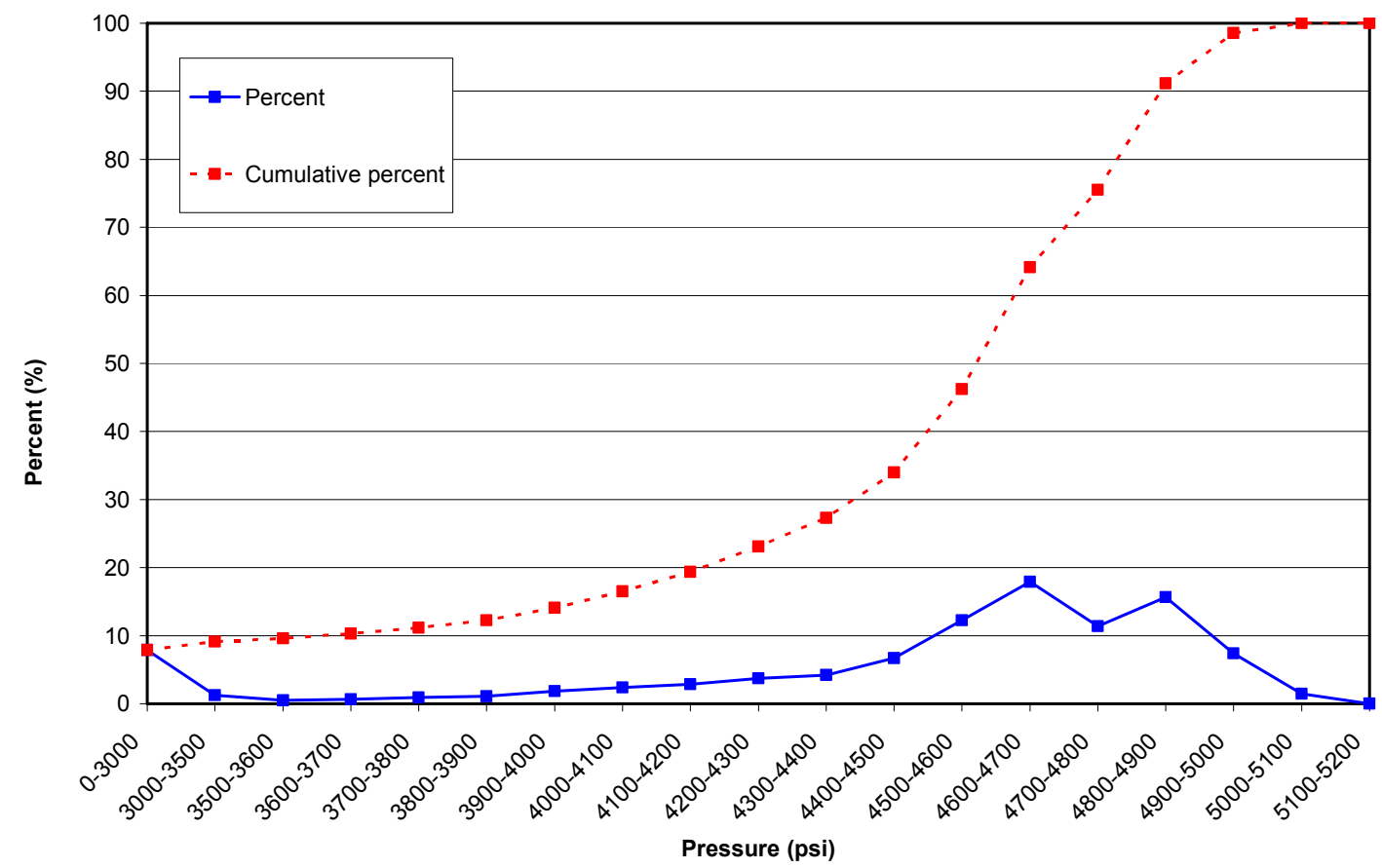

Figure 3-13, Pressure distribution of Shield 175, May 122007 4:00 p.m. to May 13 2007 11:59 p.m. 


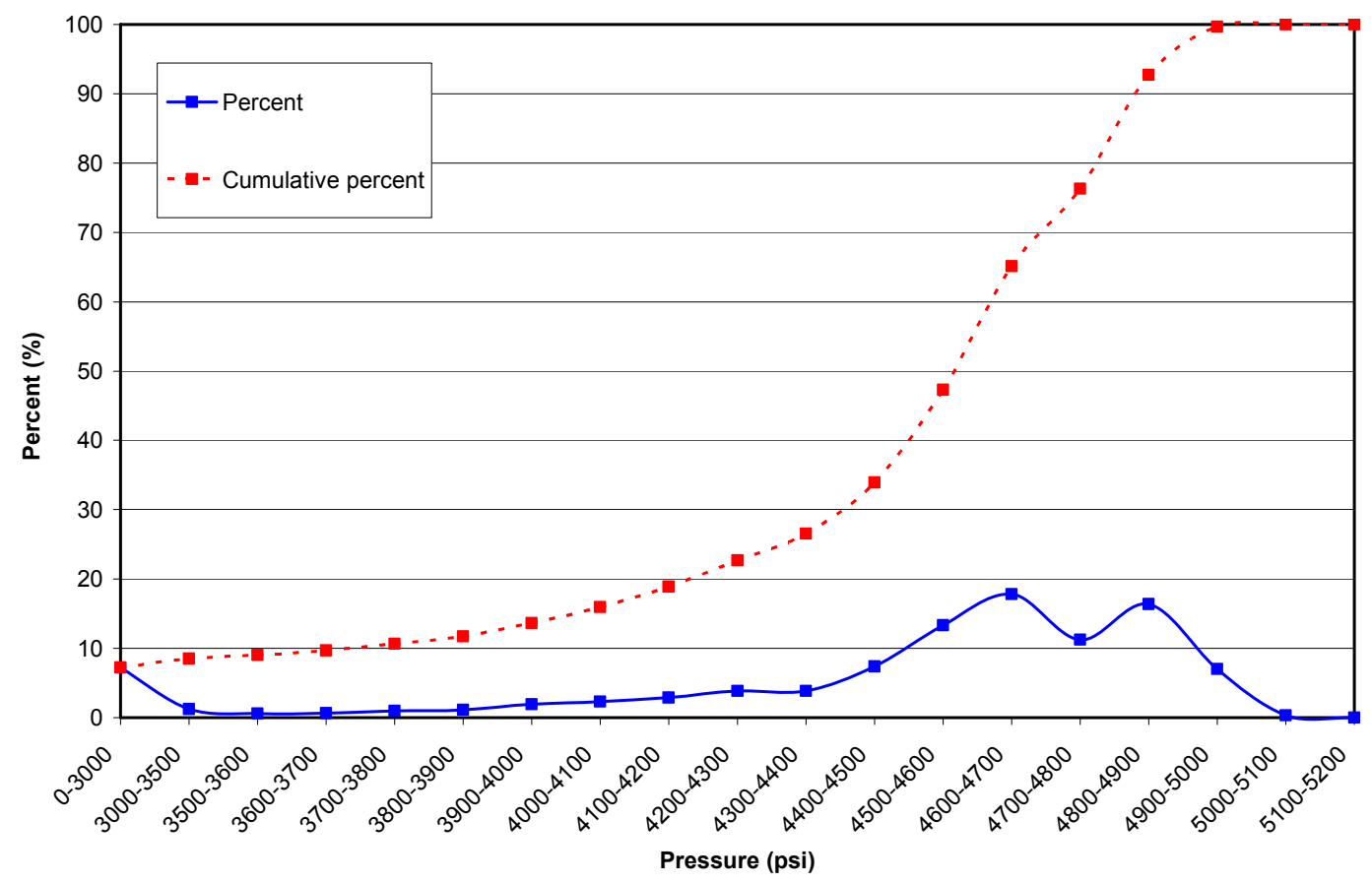

Figure 3-14, Pressure distribution of Shield 130, May 122007 4:00 p.m. to May 13 11:59 p.m.

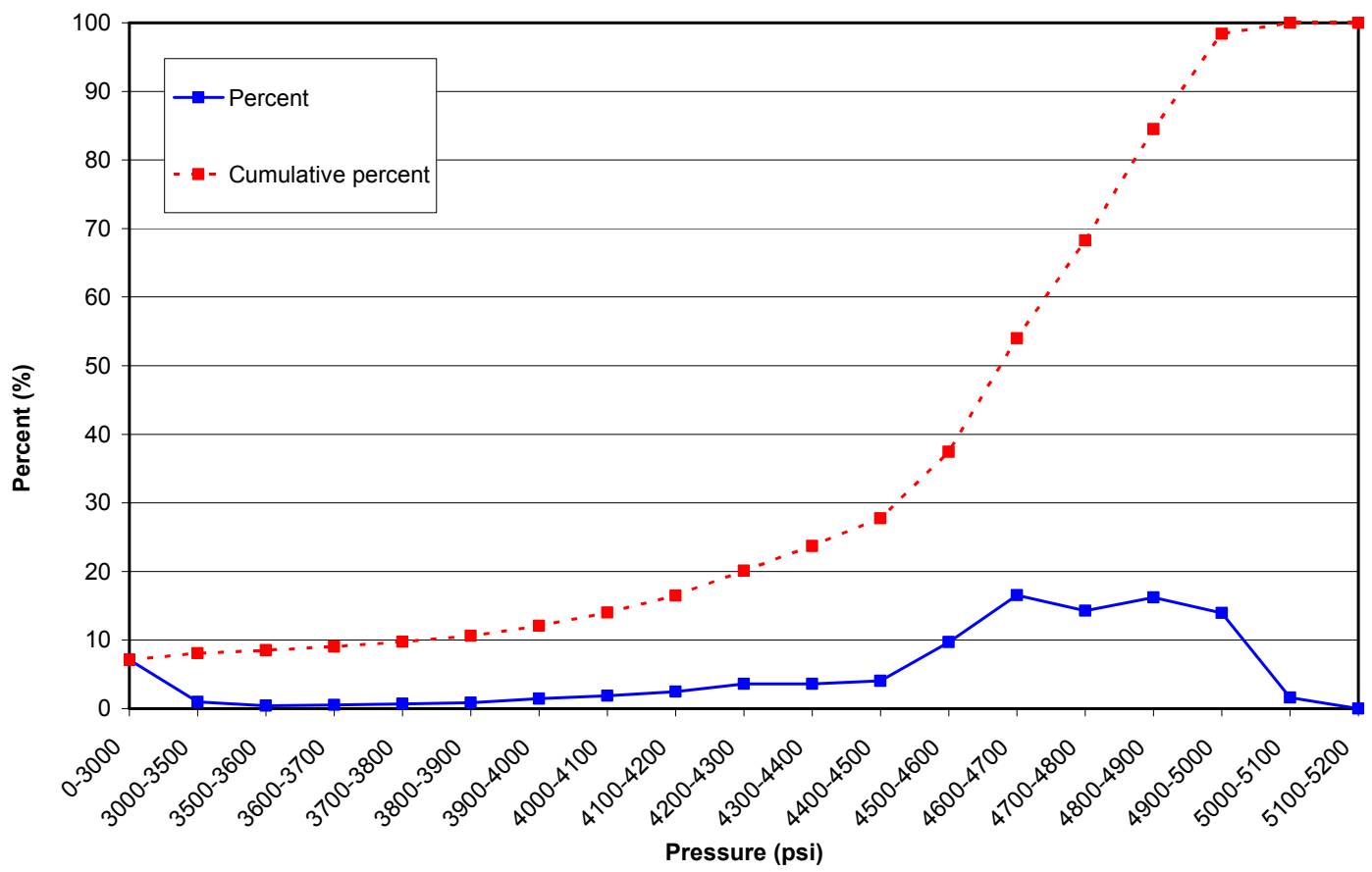

Figure 3-15, Pressure distribution of Shield 84, May 122007 4:00 p.m. to May 13 2007 11:59 p.m. 


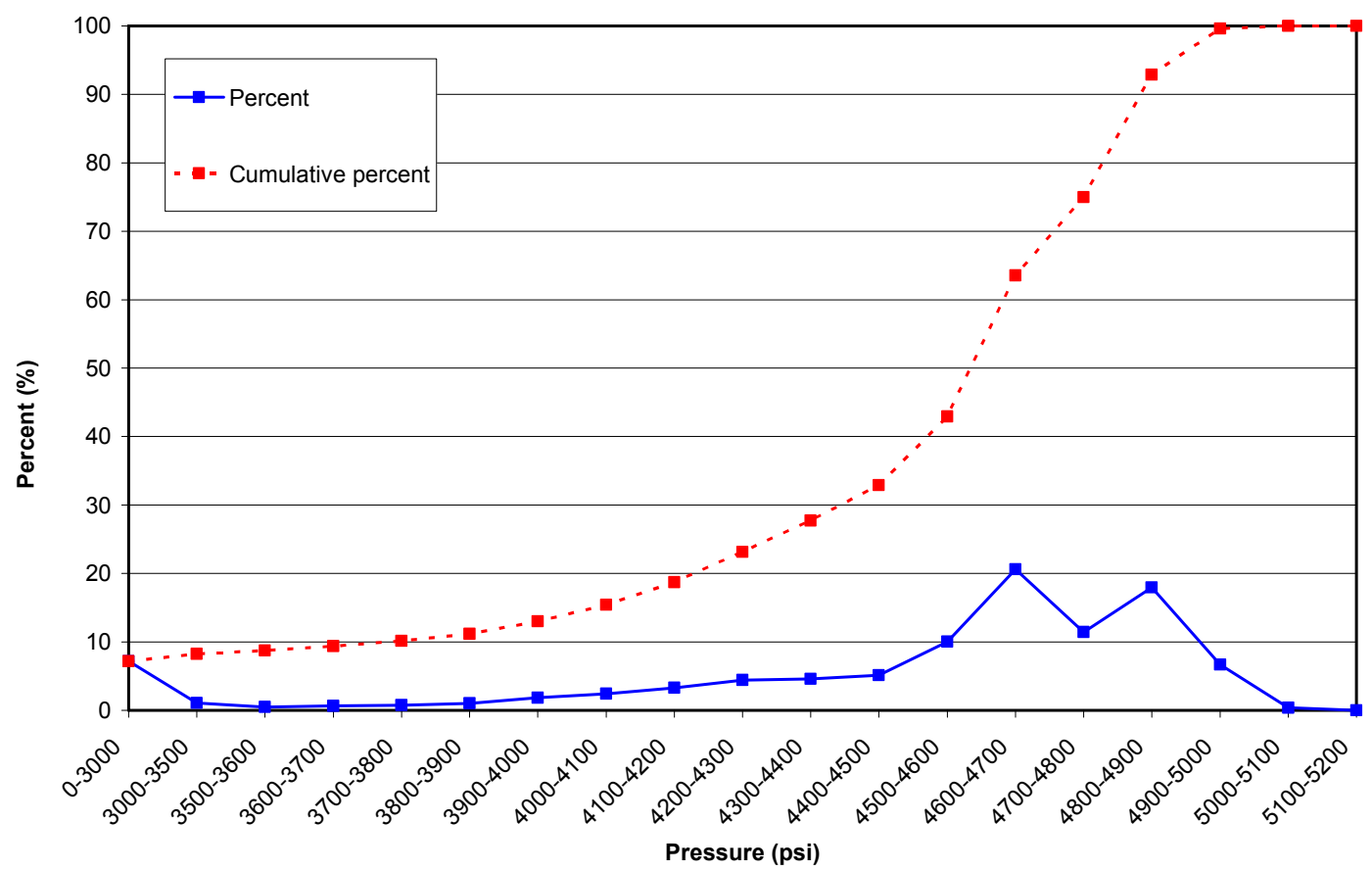

Figure 3-16, Pressure distribution of Shield 39, May 122007 4:00 p.m. to May 13 2007 11:59 p.m.

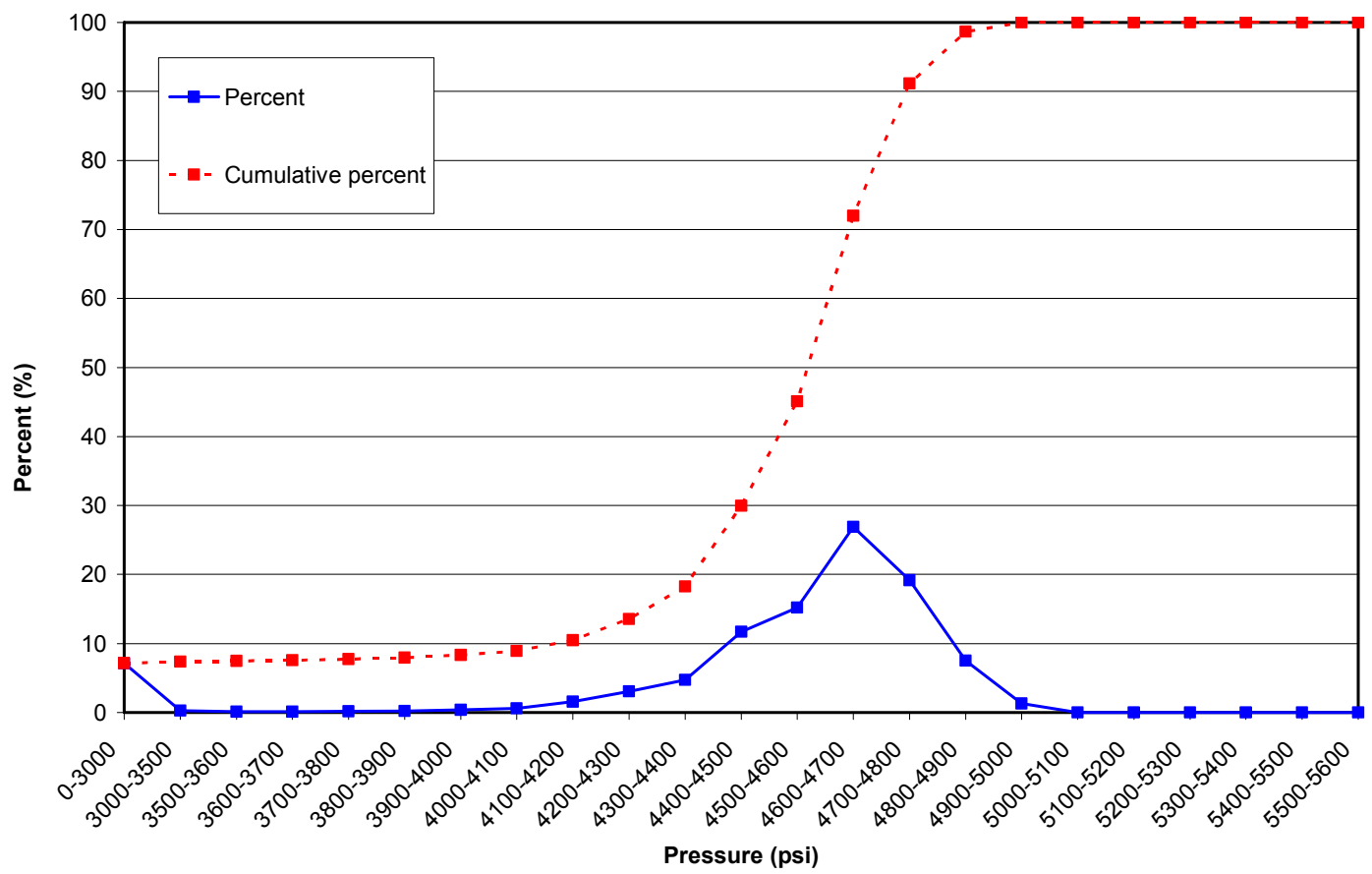

Figure 3-17, Pump Pressure distribution, May 12 2007 4:00 p.m. to May 132007 11:59 p.m. 


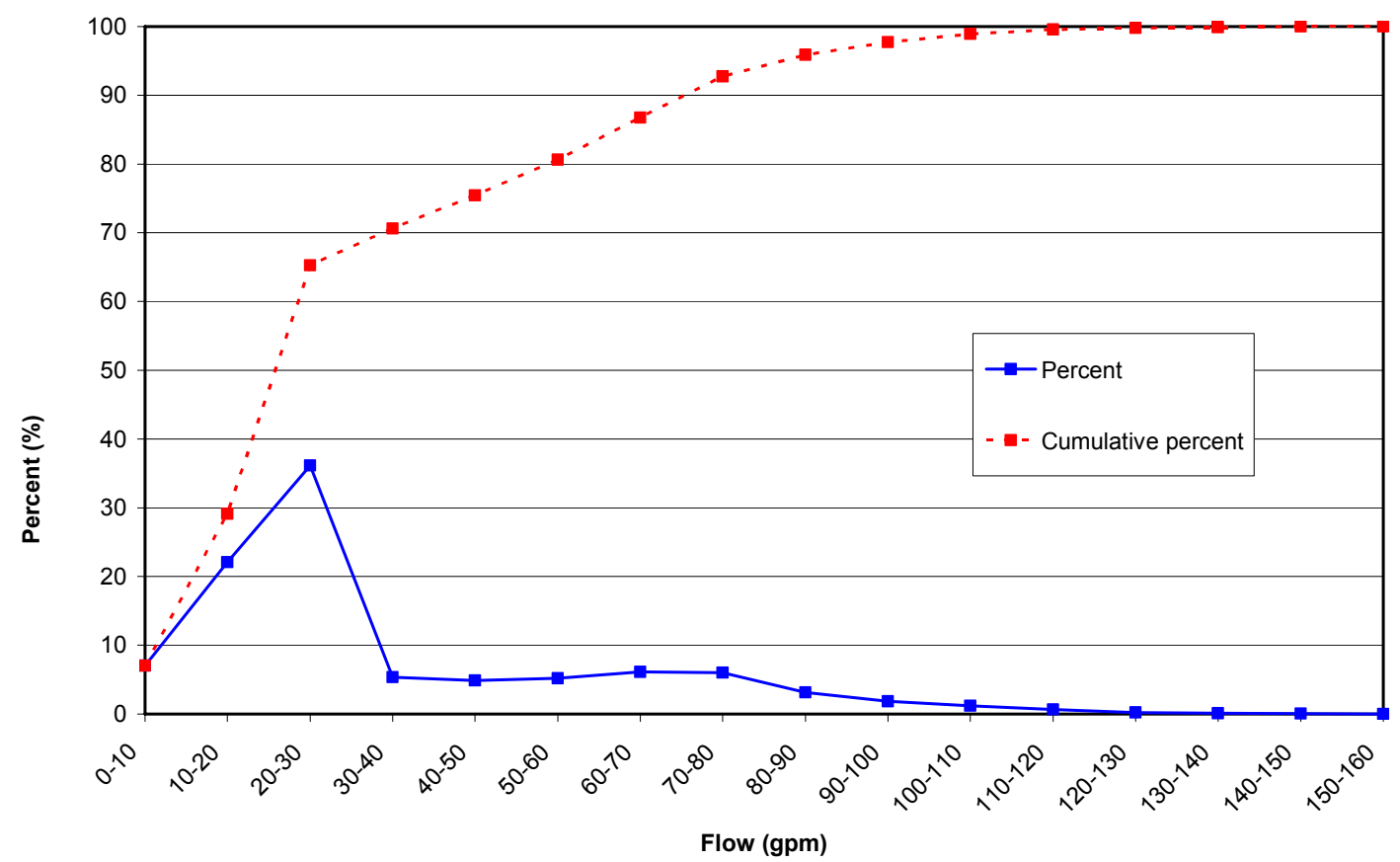

Figure 3-18, Flow distribution Flow 2, May 122007 4:00 p.m. to May 132007 11:59 p.m.

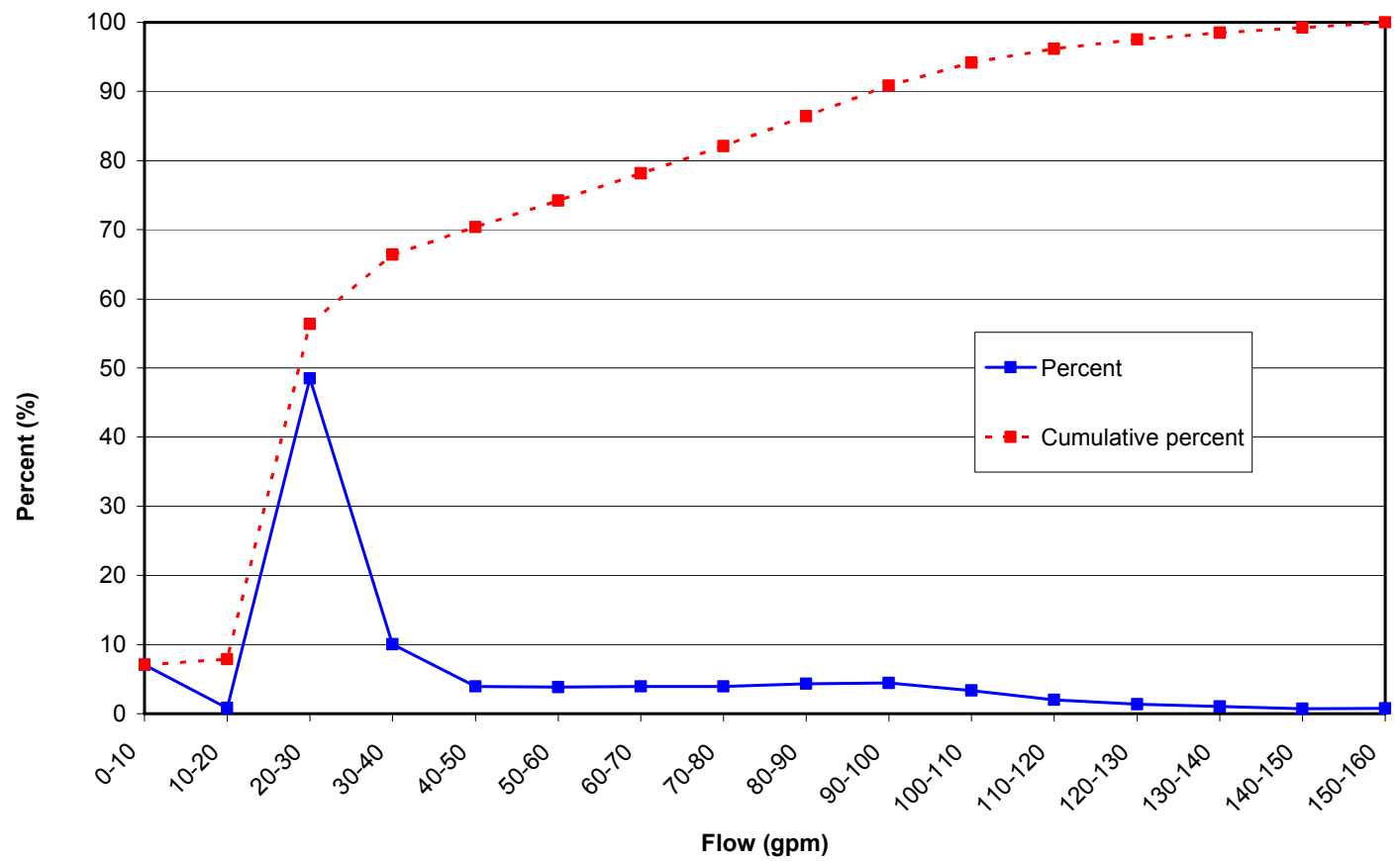

Figure 3-19, Flow distribution Flow 1, May 122007 4:00 p.m. to May 132007 11:59 p.m. 
In addition to the preceding graphs, the following charts were derived from the data in the field study. The first set of Figures, 3-20 and 3-21, shows the change in setting pressure before and after the power station move, respectively. Because the system hoses are fully snaked just prior to a power station move, Figure 3-20 shows a lower setting pressure, which implies higher pressure losses across the face. This is caused by a higher roughness coefficient of the coiled hoses. The Figures also show the general downward trend of setting pressure while approaching the tailgate. This is demonstrated by the line on the charts. Just before the power station move, the equation of the setting pressure with respect to the shield number is as follows:

Pressure $=-1.0850 \times($ shield \#) +4140.9 psi

Similarly, just after the power station move, the equation of the setting pressure with respect to the shield number is as follows:

Pressure $=-1.4524 \times($ shield \#) +4294.1 psi

The slopes of these two equations represent the decrease in setting pressure from headgate to tailgate. The intercept demonstrates the difference in setting pressure caused by the increase in roughness coefficient due to the coiled hose. 


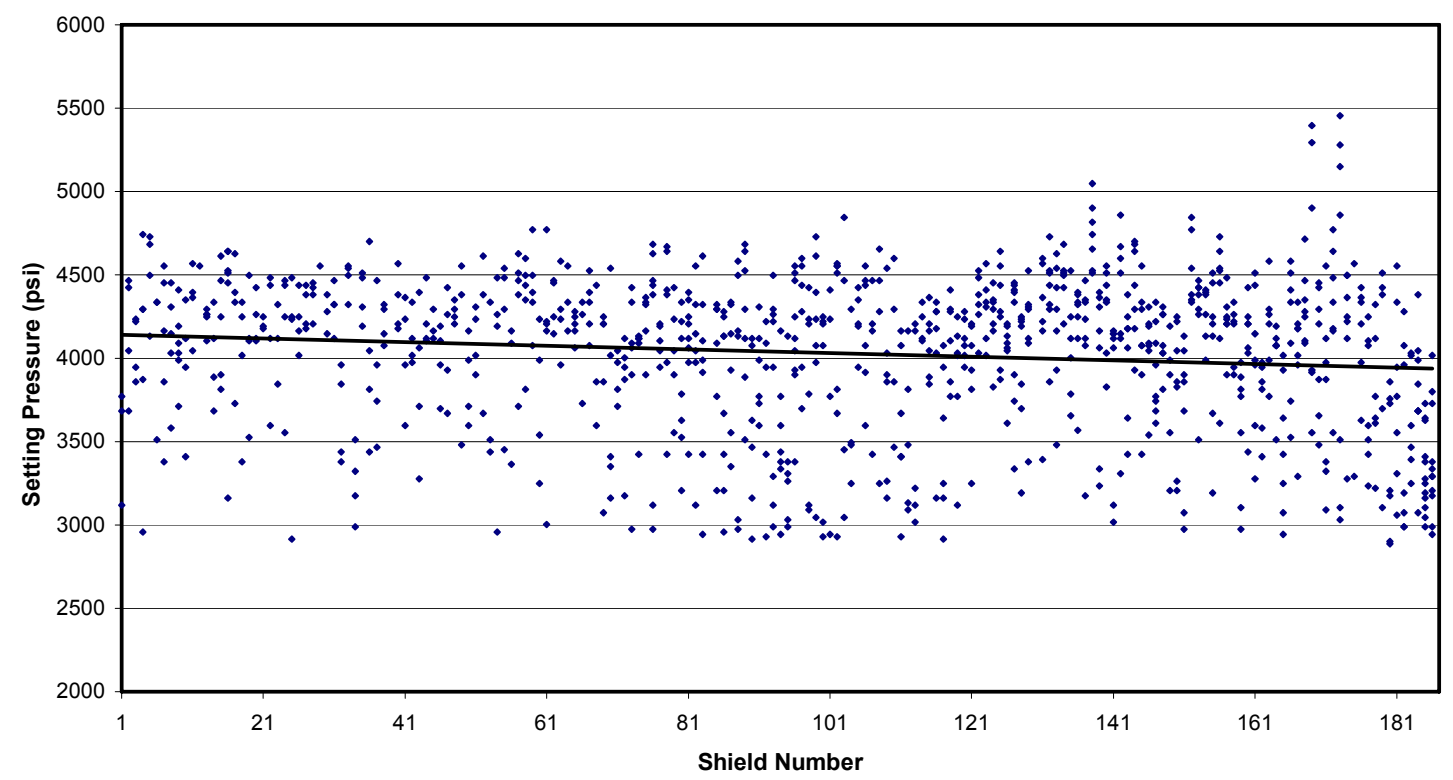

Figure 3-20, Setting pressure across face, May 1120078 a.m. to 4 p.m.

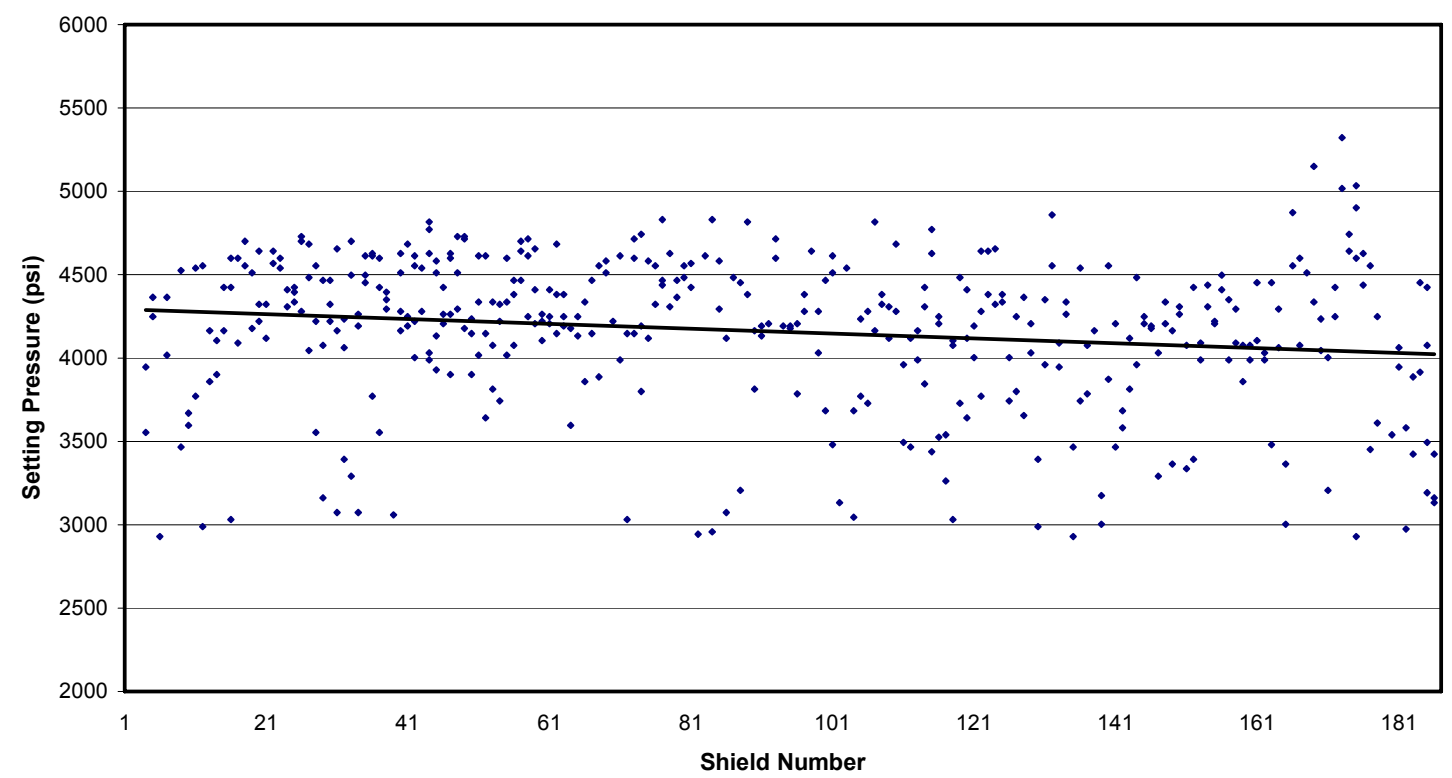

Figure 3-21, Setting pressure across face, May 1320078 a.m. to 4 p.m. 
Figures 3-22 and 3-23 show the pump flow and pressure for May 11, 2007, 12-8 a.m., before the power station move, and May 13, 2007, 12-8 a.m., after the power station move. It is apparent that the pump flow and pressures are relatively similar both before and after the power station move. There may be a slight increase in the pump pressure after the power station move, i.e. there are more instances where the pump pressure is above 5,000 psi. 


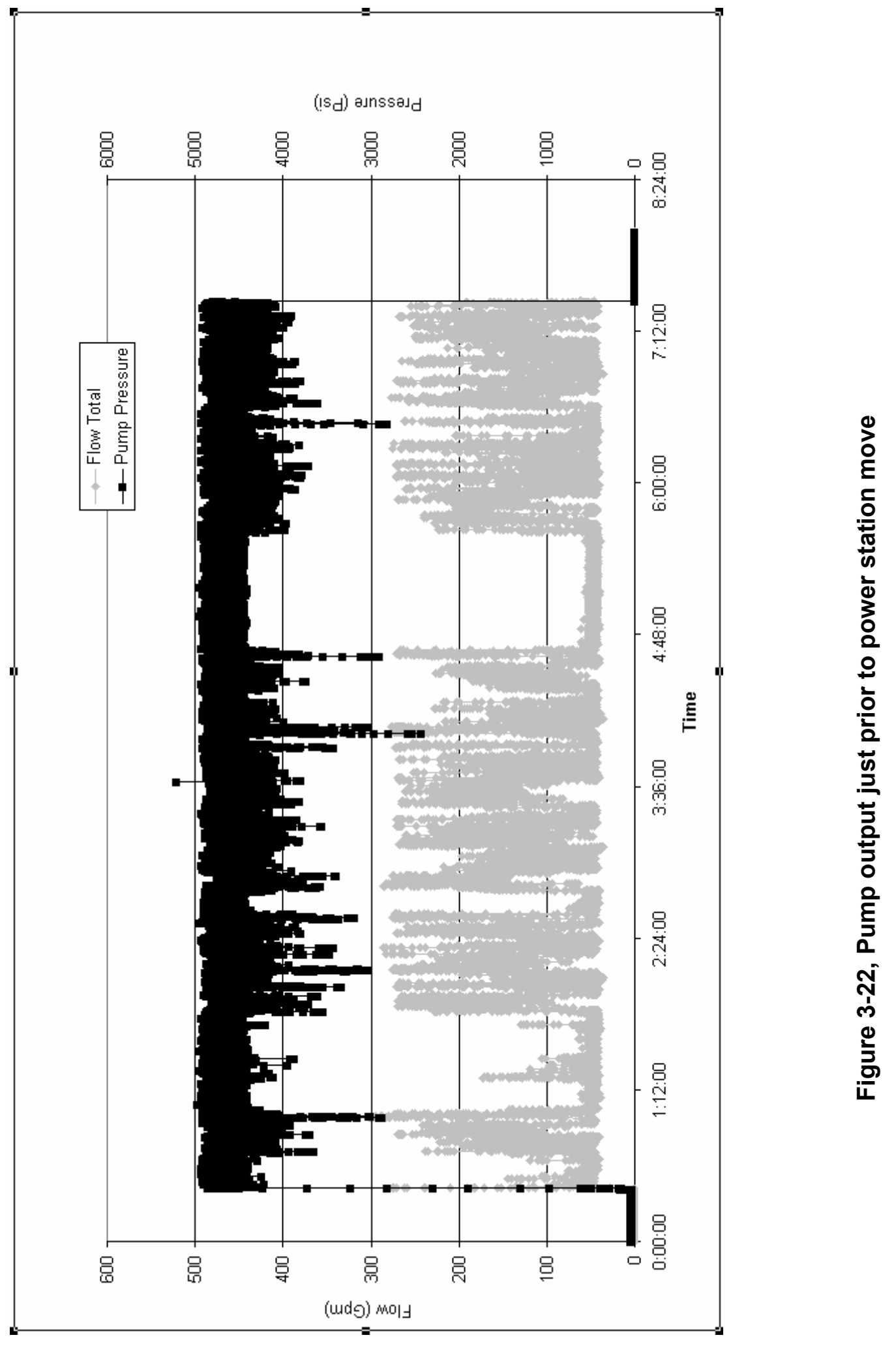




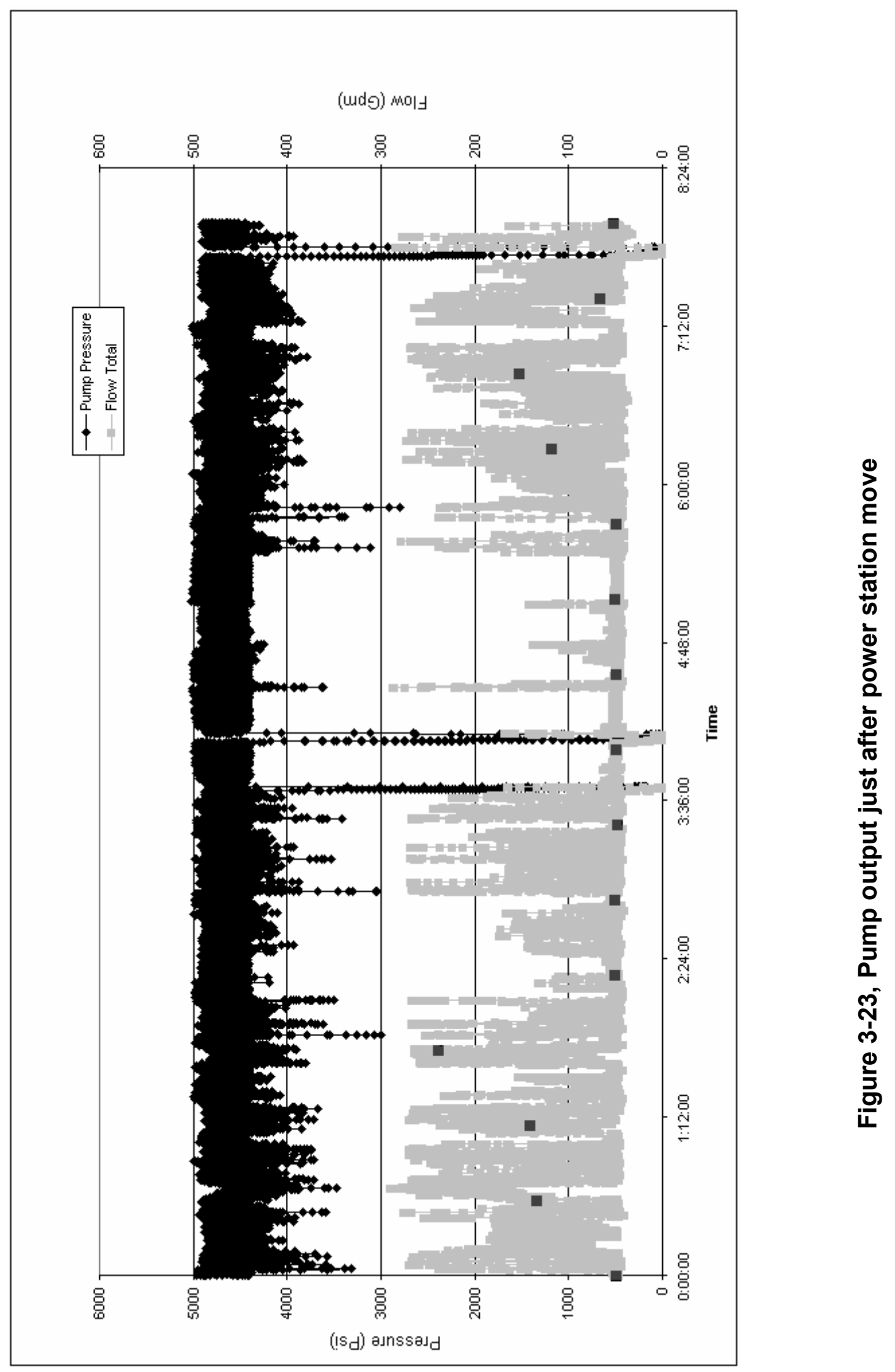


From Figures $3-22$ and $3-23$, it is seen that there is a slight increase in the pump pressure after the power station move. Upon closer examination of the pump data and the face data, there is a time delay between the two, depending on the operating conditions. To perform the model calibration, this time offset must be corrected for, that is, the data points must be synchronized. From Figures 3-24 and 3-25 the time offset of both the two data acquisition systems and the face can be seen. Figure 3-24 shows the time offset caused by the length of the face, about 2 seconds per 45 shields. This time offset is shown in the figure by the two vertical lines. Comparing Figures 3-24 and 3-25 for the point when the pressure first drops off, circled regions, it can be seen that there is about a 40 second time delay between the face data and the pump data. Part of this is caused by the data acquisition system for the pump station, in that it omits values about once every 30 minutes. 


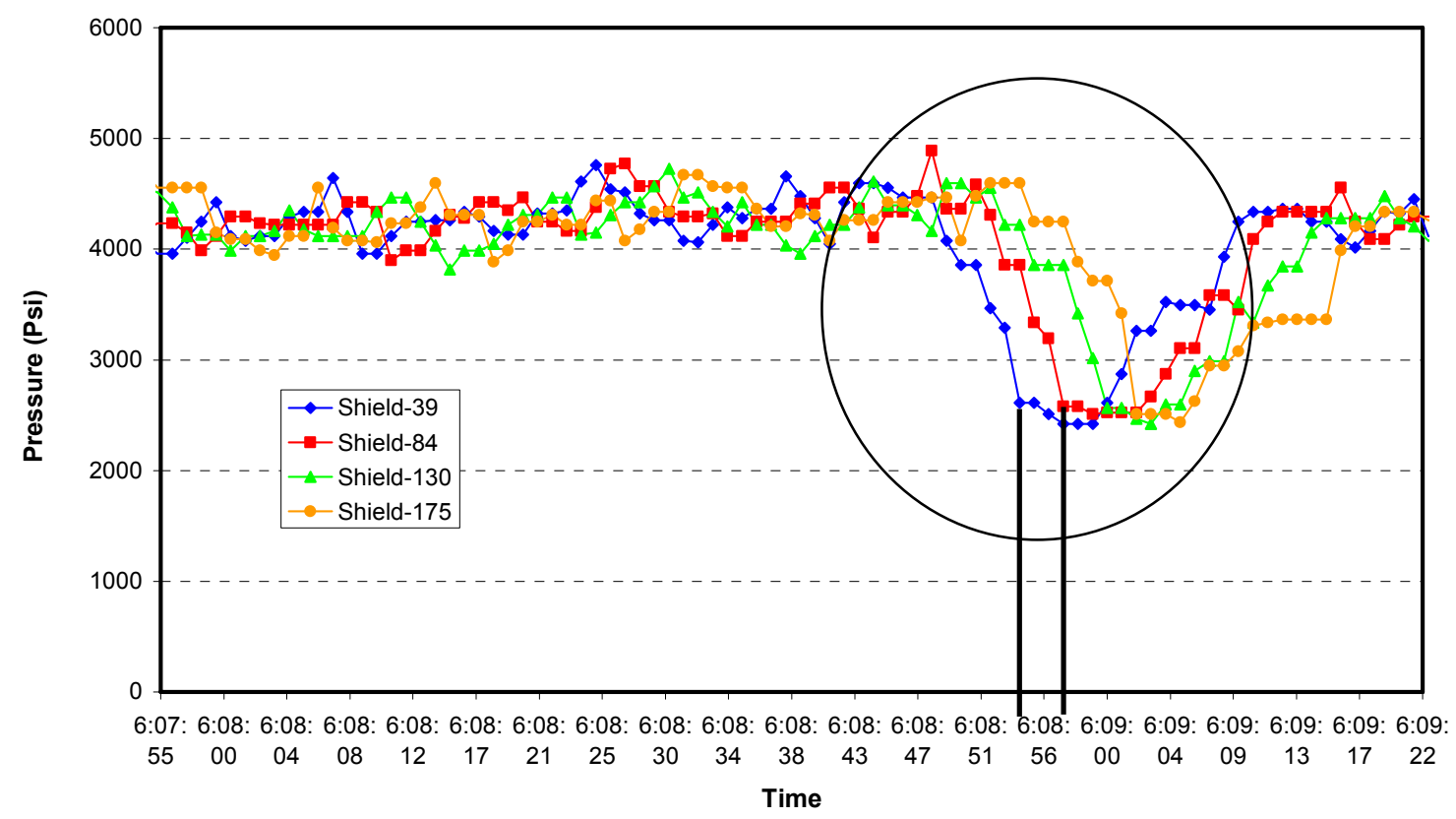

Figure 3-24. Depiction of time delay across the face

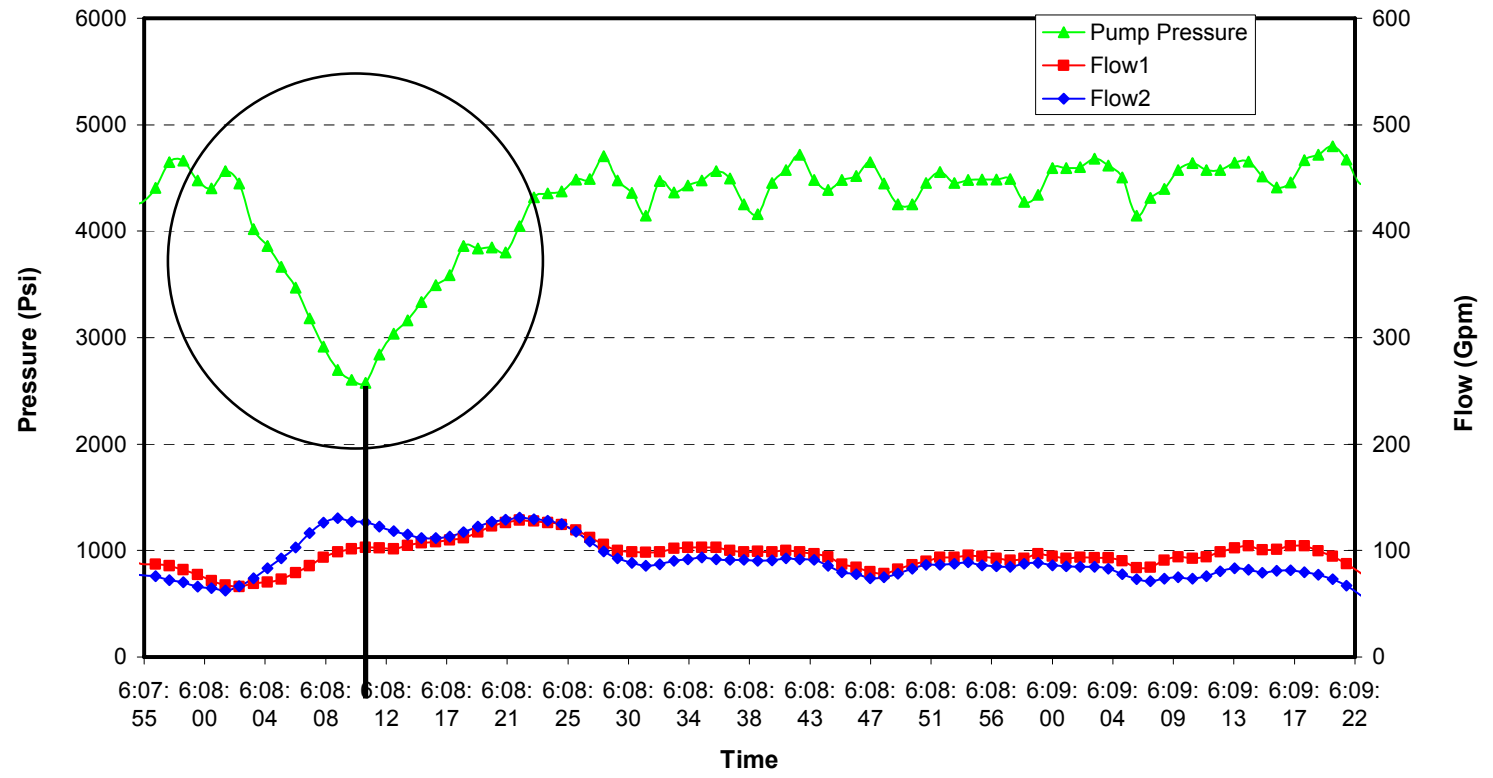

Figure 3-25. Close-up of pump data 
The face data contains the shield pressures as well as the pressures in the hoses. From the shield pressures, the shield cycles can be observed. Figure 3-26 is a representative display of typical shield cycles seen at the field study location during the time period observed.

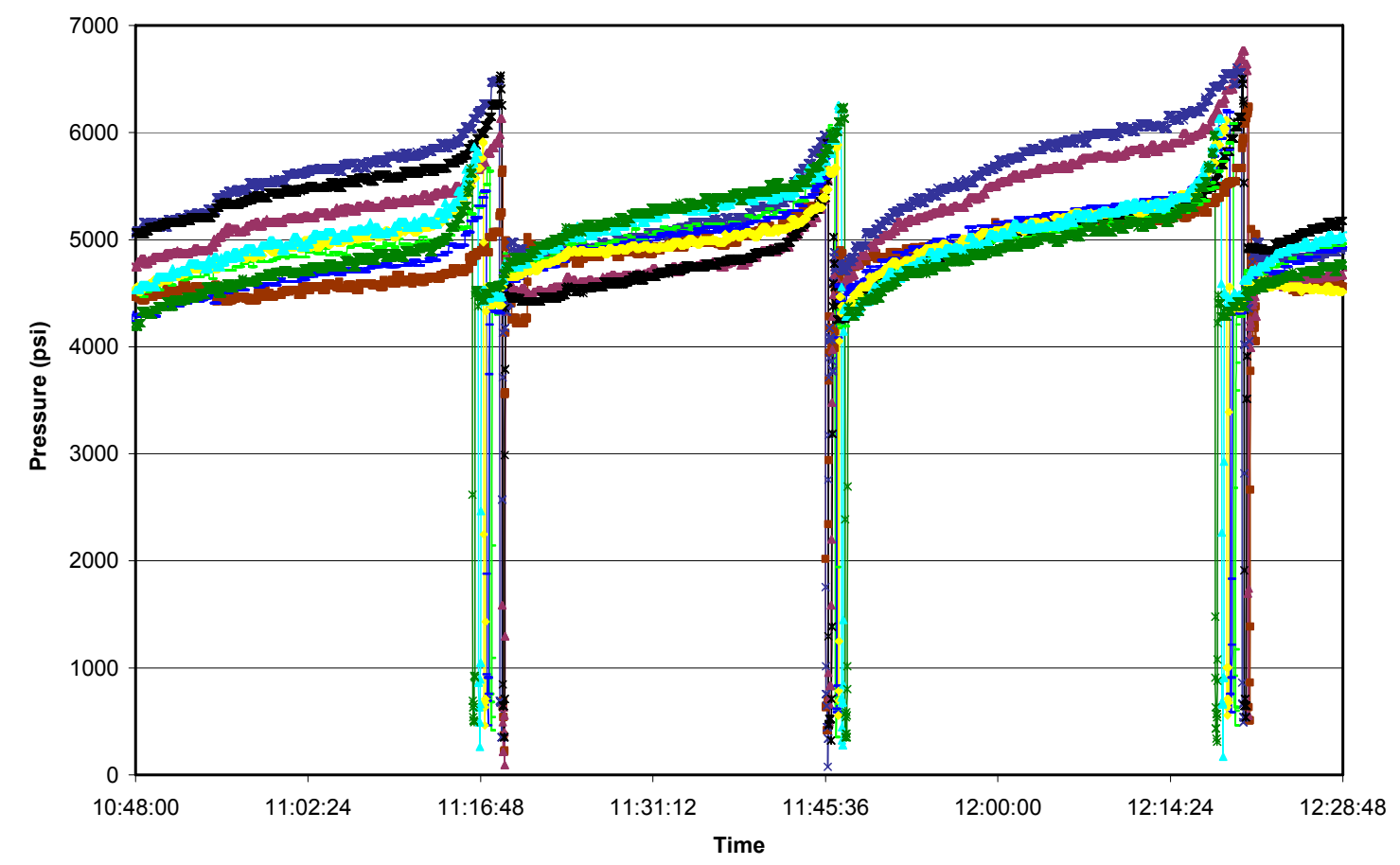

Figure 3-26. Characteristics of typical shield cycles 


\section{CHAPTER 4: SOFTWARE}

\subsection{CRITICAL EVALUATION OF SOFTWARE}

Because of the need for such an evaluative tool in other industries, several software packages suitable for analyzing the shield system have been previously developed and are commercially available. All of these packages are based on the principle of conservation of mass and energy, as discussed in Chapter 2. There are slight differences in the analytical solution techniques and the friction factor determinations. Since there are numerous choices, a critical evaluation of the software packages was performed.

This critical evaluation looked at the robustness of the individual programs. Other considerations include the speed of deriving solutions, general availability, availability of demo versions, limitations, operator friendliness, and cost. The program's graphical interfaces and other input formats were evaluated as well.

The majority of the information for this evaluation came from the individual software manufacturers' web sites. The programs were tested by inputting a simple system into those programs with downloadable demos (FluidFlow, AFT Fathom, and Pipe-Pro). Each area is rated on a scale of 1 to 5 , where 5 is the most desirable. The following table, Table 4-1, contains all the areas considered in the critical analysis of existing software. 
Table 4-1, Critical evaluation of existing software

\begin{tabular}{|c|c|c|c|c|c|c|c|c|}
\hline $\begin{array}{l}\text { Evaluative } \\
\text { Parameters }\end{array}$ & $\begin{array}{l}\frac{3}{0} \\
\frac{0}{4} \\
\frac{0}{3} \\
\frac{0}{4}\end{array}$ & 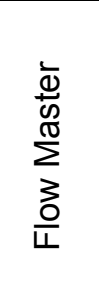 & 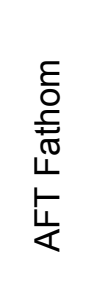 & $\begin{array}{l}\stackrel{0}{0} \\
\frac{1}{\phi} \\
\stackrel{0}{2}\end{array}$ & 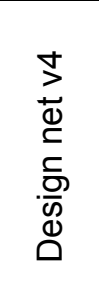 & $\begin{array}{l}\text { 음 } \\
\frac{\Phi}{0} \\
\frac{0}{0} \\
\cup\end{array}$ & $\begin{array}{l}0 \\
\frac{\pi}{0} \\
\frac{0}{0} \\
0 \\
\frac{0}{0} \\
\frac{\mathbb{x}}{1} \\
\frac{\underline{0}}{1}\end{array}$ & $\begin{array}{l}\overleftarrow{\Phi} \\
\stackrel{\Phi}{\Phi} \\
\stackrel{\varrho}{\alpha}\end{array}$ \\
\hline $\begin{array}{l}\text { Analytical Solution Technique \& } \\
\text { Robustness * }\end{array}$ & 5 & 4 & 5 & 5 & 5 & 4 & 5 & 5 \\
\hline Speed & 5 & 4 & 5 & 5 & 4 & 4 & 4 & 4 \\
\hline Availability & 4 & 4 & 4 & 5 & 5 & 5 & 4 & 4 \\
\hline Demo & 5 & 4 & 3 & 4 & 5 & 5 & 3 & 4 \\
\hline Limitations & 5 & 4 & 5 & 5 & 5 & 3 & 5 & 4 \\
\hline Operator Friendliness & 5 & 5 & 3 & 5 & 5 & 4 & 5 & 4 \\
\hline Cost & 3 & 3 & 4 & 3 & 4 & 5 & 4 & 4 \\
\hline I/O & 5 & 5 & 5 & 5 & 5 & 3 & 3 & 4 \\
\hline Other Applications & 5 & 3 & 5 & 5 & 4 & 3 & 5 & 4 \\
\hline Average Scores & 4.67 & 4.00 & 4.33 & 4.67 & 4.67 & 4.00 & 4.22 & 4.11 \\
\hline
\end{tabular}

Because three of the existing software had identical average scores of 4.67 , that criterion alone was insufficient to make a final selection. Upon analysis by the author, the $\mathrm{I} / \mathrm{O}$ design found in FluidFlow was deemed superior and therefore it was selected for use in this project.

\subsection{FLUIDFLOW SOFTWARE DESCRIPTION}

The following thorough description of this software was captured from the narrative found at http://www.accutech2000.com.au/. By the manufacturer's statement, Piping Systems FluidFlow is "state-of-the-art" software for the solution of fluid flow through complex piping networks. The performance of almost any type of line equipment pumps, valves, orifices, control valves, etc can be modeled. Equipment performance can be viewed graphically at the same time as the system flow sheet is displayed. The Darcy-Weisbach equation or Hazen-Williams can be used for evaluations of water flow. Extensive databases of user definable pipe schedules, fluids and equipment 79 
performance characteristics can be input into the software for future use. There are graphical displays of both input and output data. Simultaneous graphical display of the flow sheet, data input and calculated results are available.

Construction of the fluid network is in a familiar flow sheet format using click-and-drag to select piping components from the toolbar, for designing components for the model. Panning, zooming and cut-and-past operations are all available to allow users to design the network with minimum effort and maximum flexibility.

FluidFlow comes with 13 user-definable datasets for the storage of equipment performance characteristics and the physical properties of fluids. Data is entered in tabular and/or equation format and graphically displayed. Pump curves can be printed showing calculated duty points. The use of datasets greatly reduces the volume of data input and encourages the use of consistent design data throughout an organization or project. Equipment and fluid databases may be added to, copied and merged. Default data values can be locked to ensure company-wide consistency. Individual databases can be allocated to separate projects.

All $\varepsilon / D, K_{L}$, pipe diameter, pipe roughness values obtained from data tables can be instantly overridden from the input area. Overridden values are highlighted and can be reset at any time. (For instance, the effect of scaling of pipes can be modeled. All pipes 
can be listed and sorted according to size. Pipes of a particular size can then be selected and the ID and roughness changed to reflect scaling in one simple operation).

Having discussed the general description, a step-by-step method of inputting the hydraulic supply system into the software follows.

Step 1. Add components to existing system library

a. Click on "data sets" on tool bar

b. Select from pull down menu

1. select "pumps"

a. click on "new"

b. type in pump model name

C. change head units to psi

d. change flow units to usgpm

e. type in data points on pump curve

f. save permanently in library by clicking on "commit"

c. Repeat $a$ and b from above

1. select "pipe types"

a. click on "new"

b. type in pipe class name

c. type in pipe absolute roughness

d. type in nominal diameter

e. type in internal diameter

f. save permanently in library by clicking on "commit" 


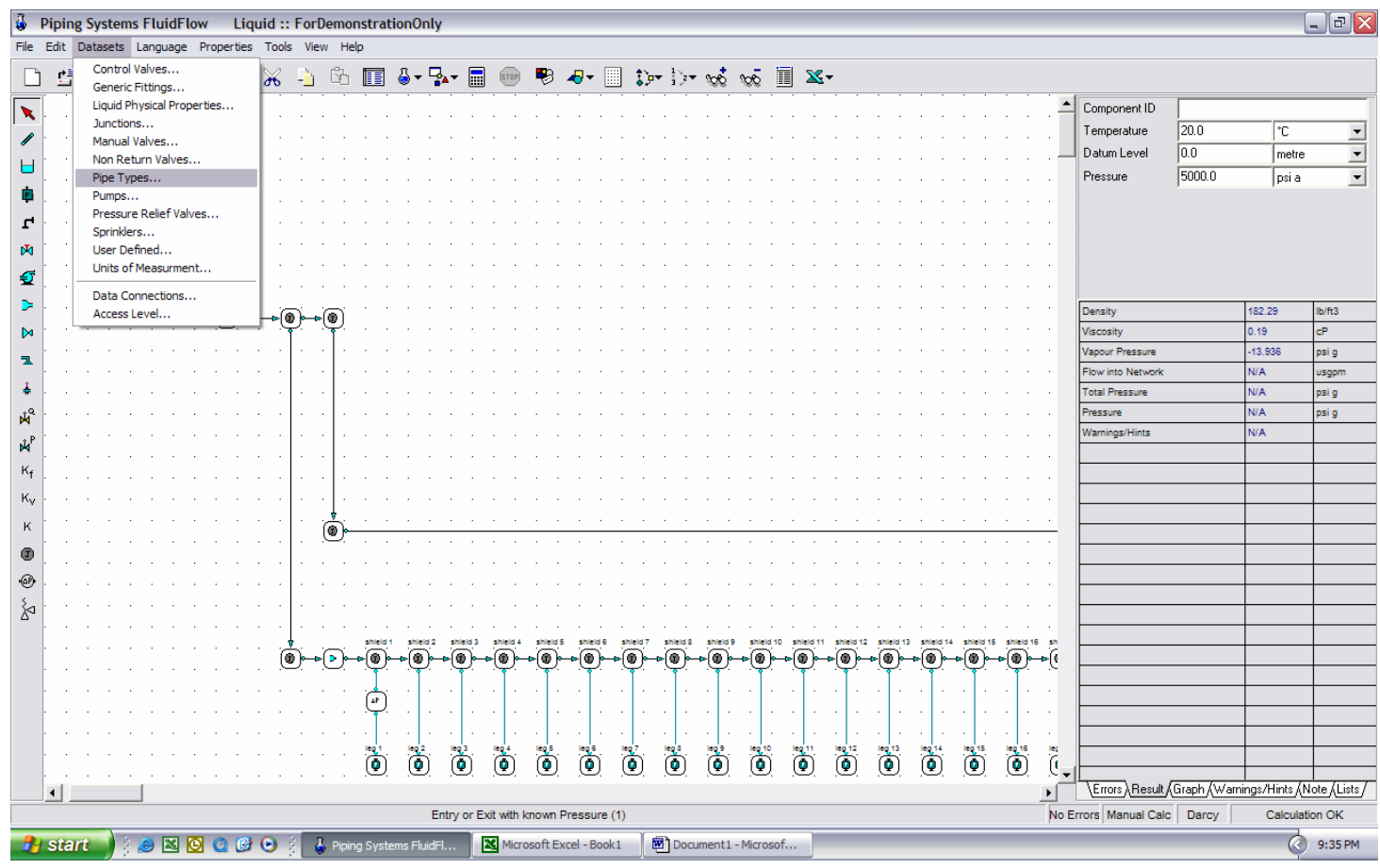

Figure 4-1, Sample display from FluidFlow, add components to library

Step 2. Set default components

a. click on "properties" from toolbar

b. select "default components" from pull down menu

c. select "pumps"

d. select pump model name from list

e. click "ok"

f. repeat steps $a$ and $b$

g. select "pipes"

h. select pipe type from list

I click "ok"

j. repeat steps $a$ and $b$

k select "entry/exit with known flow"

I. enter leg as component ID

$m$ set units to USGPM under flow

n. click "ok" 


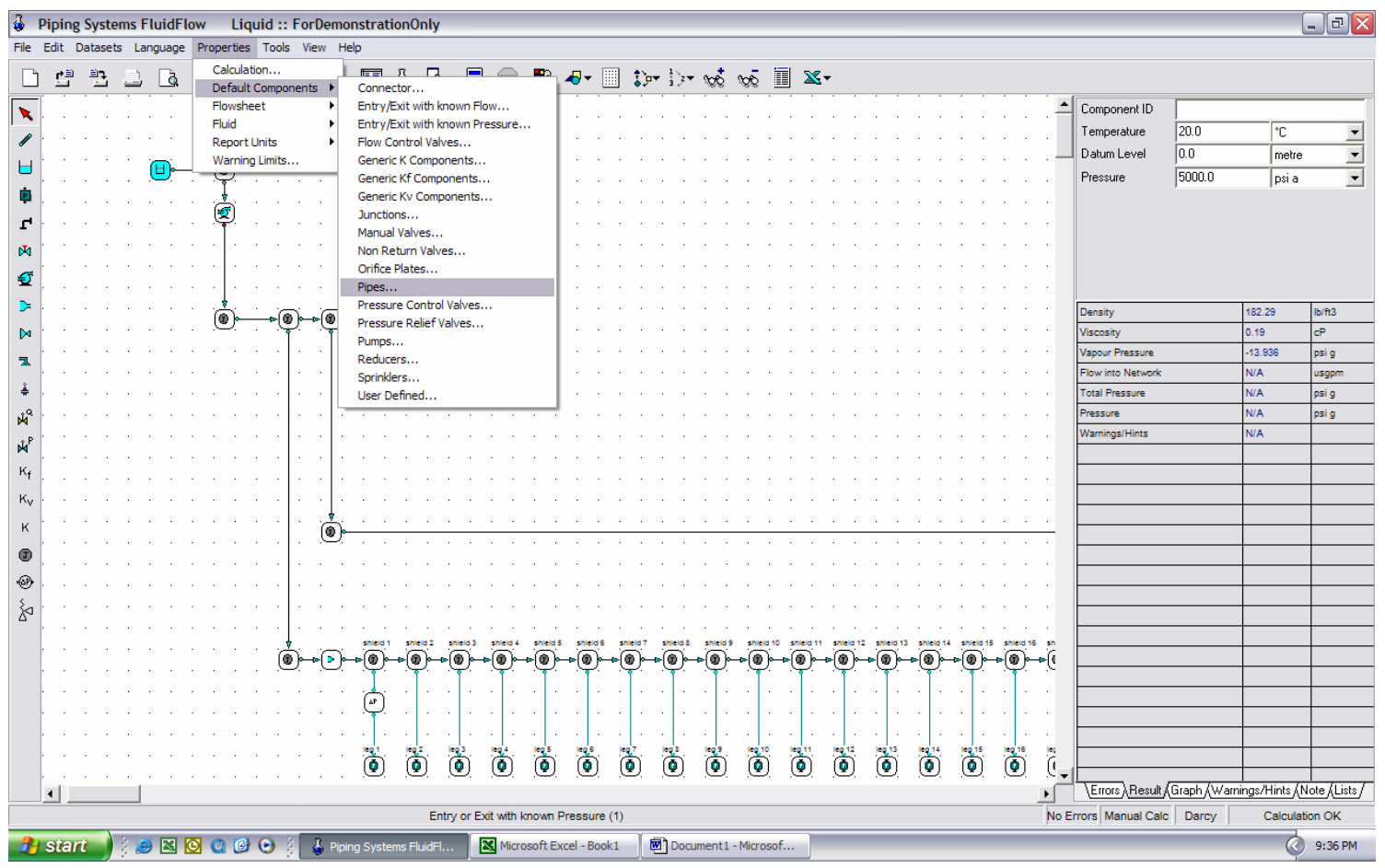

Figure 4-2, Sample display from FluidFlow, default component function

Step 3. Design system using the icons from the pallet on the left

a. click on element desired to include in the system

b. click on screen in the correct position

c. repeat $a$ and $b$ for each element included in the system until the graphical representation of the system is complete

d. input the appropriate characteristics in the box on the right for each element selected

e. select "file' then "save" from the top menu; enter appropriate name and location to save the system 


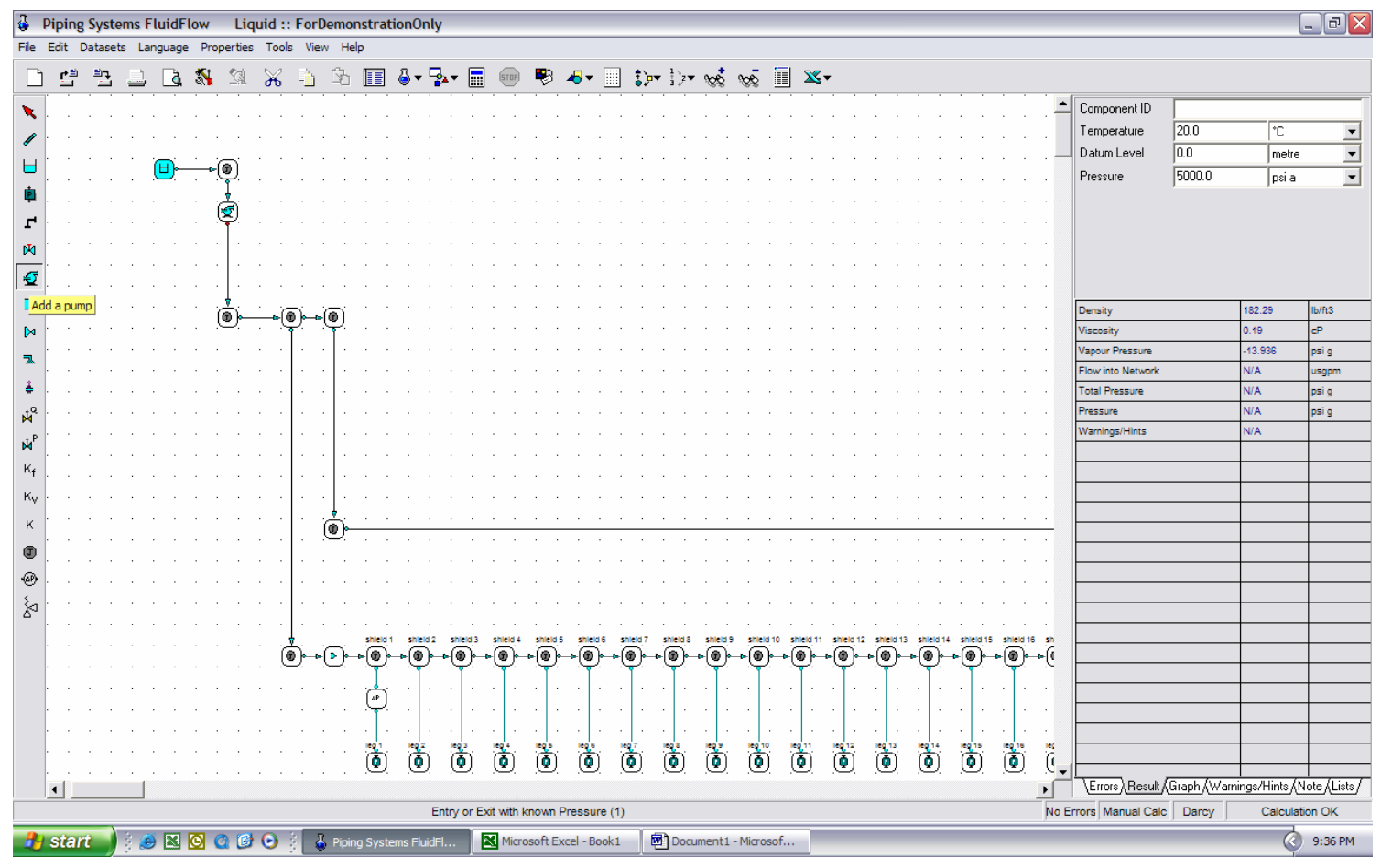

Figure 4-3, Sample display from FluidFlow, add component function

Step 4. Click on the calculator icon on the top toolbar to solve the network

a. click on the "results" tab in the lower right hand corner to see the results. 


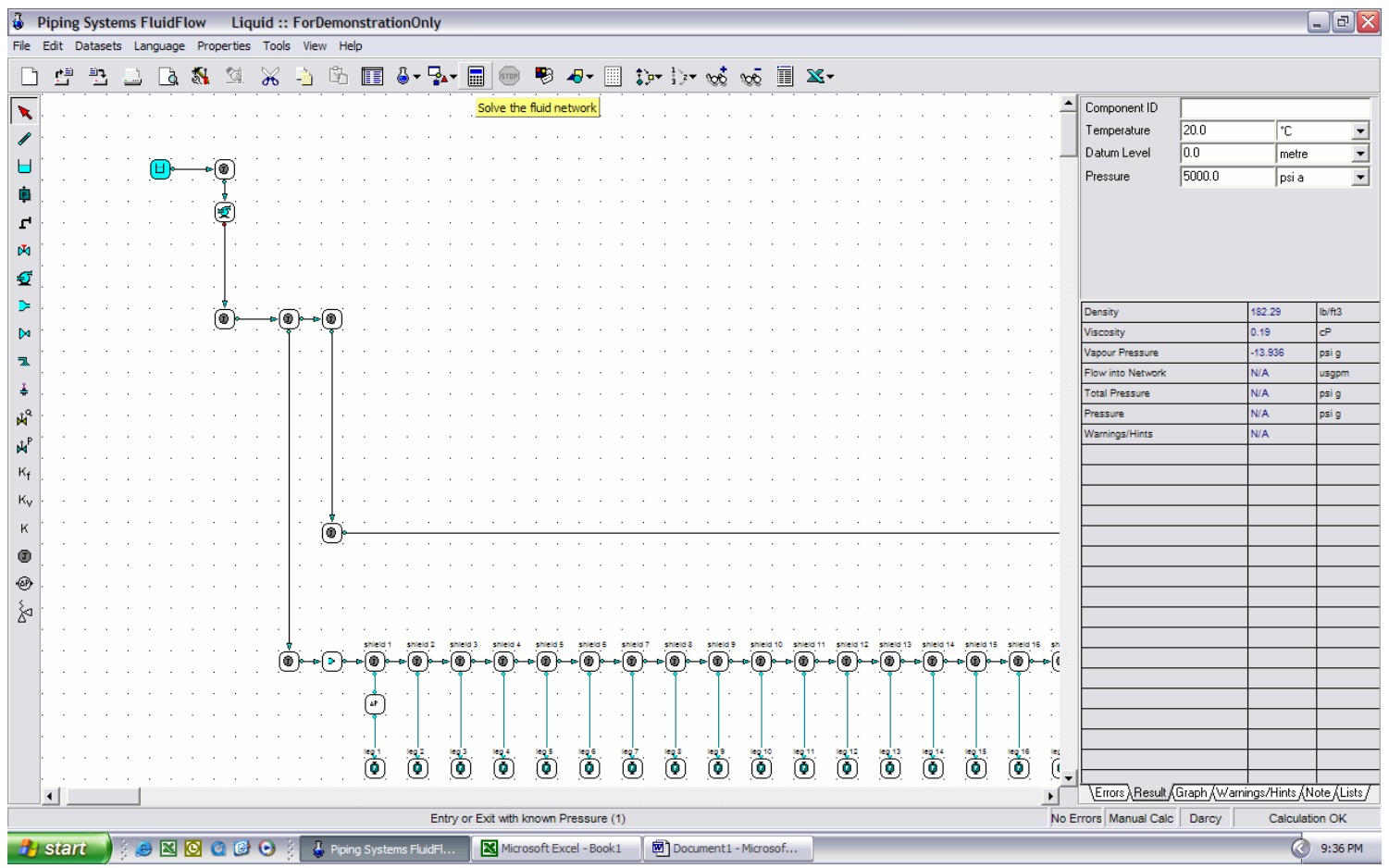

Figure 4-4, Sample display from FluidFlow, solve function

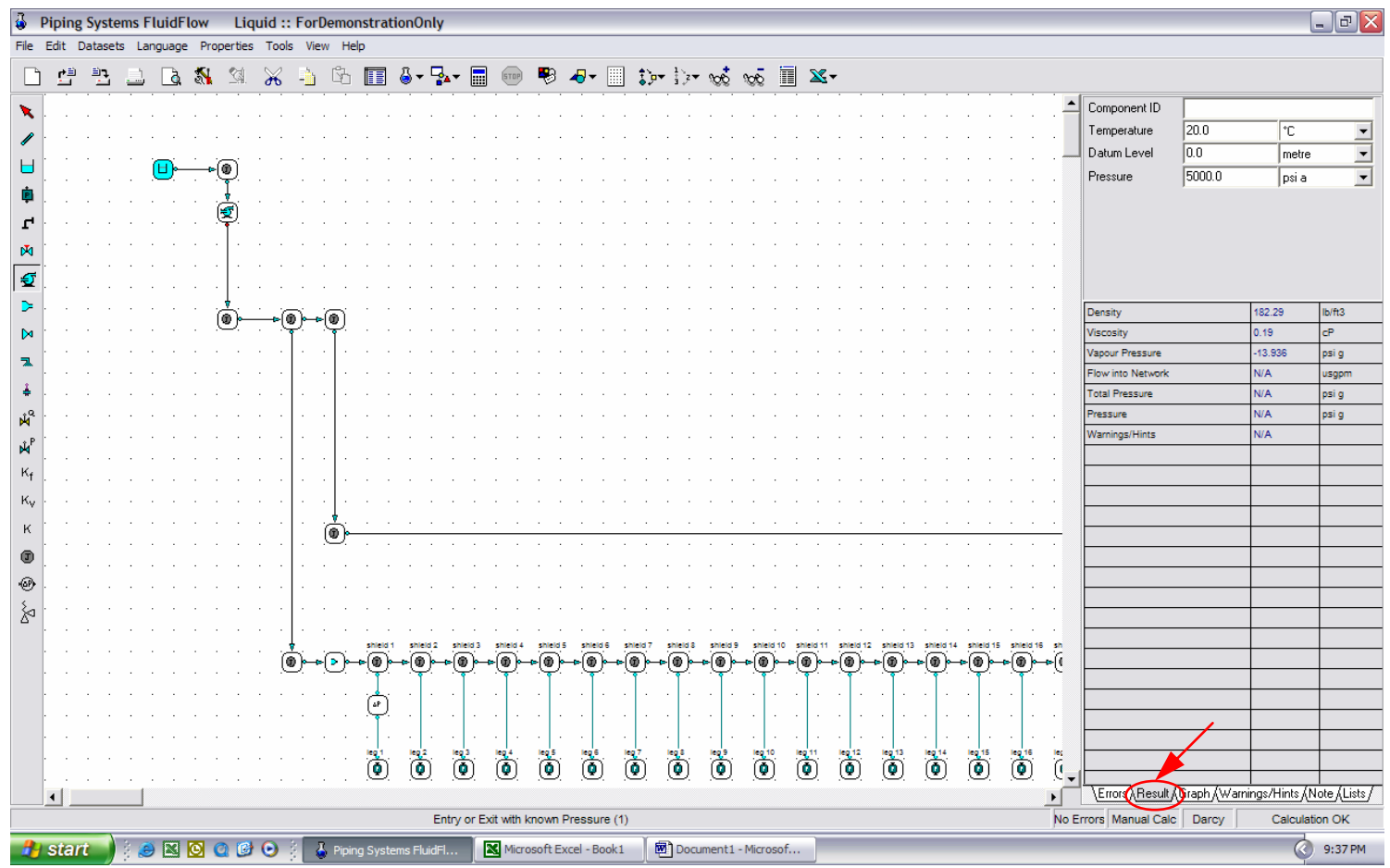

Figure 4-5, Sample display from FluidFlow, results template 
In addition to the prior discussions, there remain challenges in the modeling techniques required to address the longwall hydraulic supply system. These techniques are discussed in Section 5.1.1 and include simplification of the pumping station, representative shield models, and combination of the major and minor losses in the system. 


\section{CHAPTER 5: MODEL DEVELOPMENT}

\subsection{INITIAL MODEL DEVELOPMENT}

\subsubsection{Initial Inputs from Previous Research}

Due to limited previous analysis using the specific equipment found at the mine site, some of the initial assumptions made stem from other industries' work on hydraulic systems and other fluid mechanics. In order to develop the initial model which will then be calibrated from the field analysis, some characteristics needed to be estimated. The characteristics most important to the calculation process are the friction factors, roughness coefficients, the shock losses, and the flow rates. The roughness coefficients required are those for the hoses used in the system as well as those for other potential hoses, pipes, or tubes used. The shock pressure losses would be due to elbows, tees, crosses, filters, and other contractions or expansion elements.

For the roughness coefficients, there has been substantial work in other fields that provide starting points for potential replacement pipes, as seen in Table 5-1. 
Table 5-1. Darcy-Weisbach roughness coefficients

\begin{tabular}{|c|c|c|}
\hline \multirow{2}{*}{ Surface } & \multicolumn{2}{|c|}{ Roughness - $\varepsilon$} \\
\hline & $\times 10^{-3} \mathrm{~m}$ & feet \\
\hline $\begin{array}{l}\text { Copper, Lead, Brass, } \\
\text { Aluminum (new) }\end{array}$ & $0.001-0.002$ & $3.33-6.7 \times 10^{-6}$ \\
\hline PVC and Plastic Pipes & $0.0015-0.007$ & $0.5-2.33 \times 10^{-5}$ \\
\hline $\begin{array}{l}\text { Epoxy, Vinyl Ester and } \\
\text { Isophthalic pipe }\end{array}$ & 0.005 & $1.7 \times 10^{-5}$ \\
\hline Stainless steel & 0.015 & $5 \times 10^{-5}$ \\
\hline Steel commercial pipe & $0.045-0.09$ & $1.5-3 \times 10^{-4}$ \\
\hline Stretched steel & 0.015 & $5 \times 10^{-5}$ \\
\hline Weld steel & 0.045 & $1.5 \times 10^{-4}$ \\
\hline Galvanized steel & 0.15 & $5 \times 10^{-4}$ \\
\hline Rusted steel (corrosion) & $0.15-4$ & $5-133 \times 10^{-4}$ \\
\hline New cast iron & $0.25-0.8$ & $8-27 \times 10^{-4}$ \\
\hline Worn cast iron & $0.8-1.5$ & $2.7-5 \times 10^{-3}$ \\
\hline Rusty cast iron & $1.5-2.5$ & $5-8.3 \times 10^{-3}$ \\
\hline $\begin{array}{l}\text { Sheet or asphalted cast } \\
\text { iron }\end{array}$ & $0.01-0.015$ & $3.33-5 \times 10^{-5}$ \\
\hline Smoothed cement & 0.3 & $1 \times 10^{-3}$ \\
\hline Ordinary concrete & $0.3-1$ & $1-3.33 \times 10^{-3}$ \\
\hline Coarse concrete & $0.3-5$ & $1-16.7 \times 10^{-3}$ \\
\hline Well planed wood & $0.18-0.9$ & $6-30 \times 10^{-4}$ \\
\hline Ordinary wood & 5 & $16.7 \times 10^{-3}$ \\
\hline
\end{tabular}

However, for the longwall mining hoses, these evaluations, if done, are not readily available. Thus a back-calculation of the roughness coefficients was performed based on the results from the two studies conducted in Germany (previously discussed in Section 2.6). In order to perform the back calculations of the roughness coefficients, the following information was collected from the two German studies (Fusser, 2006) and (Bassier and Migenda, 2006): the head loss or pressure drop, length of hose, diameter of hose, and the velocity or flow rate. The back calculation was performed both by hand calculations and using FluidFlow. The hand calculation method involved three steps: (1) determine the friction factor (see Equation 5), (2) determine the Reynolds' number (see 
Equation 3), and (3) determine the roughness coefficients (see Equation 6). This gave the needed input factors to determine the major losses due to the friction between the liquid and the inner walls of the hoses.

For the minor pressure losses, there are several different avenues available to acquire these values. Obtaining them from the manufacturers of each component was the first approach. Since the required data was not available from them, other manufacturers of similar components, made of the same material, were contacted to provide insight. For the filters, there are additional complications, in that the pressure losses are dependent on the length of time they have been in operation. As the filters are used, they load with particles which are larger than the openings in the filter and thus the pressure losses increase across the site. Luckily, there was data available for the replacement pressure losses and the initial pressure losses of similar filters.

The flow rates are cyclical in nature because the operations of the shield supports are also cyclical. Due to the cyclical nature of the process, a range of available operating flow rates were used to impact the setting pressure seen at the face. For the initial values of the model, the operational procedures of the field site were used to determine the flow necessary to operate the equipment at the face as the site does.

\subsubsection{Initial Model Design}

An initial model needed to be designed based on the information obtained from the initial site evaluation, i.e. the results of section 3.2. Once the general software modeling procedures were understood (Section 4-2), the detail of the system to be modeled was 
considered. This was accomplished by developing methods of dealing with the unique components of the longwall hydraulic supply system. Since each component within the system must be represented in the software, different methods were investigated as appropriate. The shields needed to be represented such that they were capable of recording pressure and flow prior to entering the main valve bank of the shield as well as the pressure in the shields' hydraulic cylinders, or legs. A method of simulating the pump station was developed. This included one version with a single pump which was capable of simulating the entire range of the pump station and another with the actual configuration of the pump station.

Due to the number of variables within the hydraulic supply system, it was decided to aggregate the minor losses (component losses) with the major losses (hoses). This is an approach consistent with the equivalent length theory discussed in Section 2.5, but it will has the drawback that it will not independently determine the minor and major system losses.

An extremely complex component of the hydraulic system is the pump station. Once again a modeling technique that limited the complexity of the pump station was needed. The pump station was modeled with a single pump with a designed output to match that of the full pump station. It was capable of producing flow rates in the range of 1 to 500 gpm and pressures from 1,500 to 6,000 psi. The pump was also directly influenced by the water source in the model. This source was a pressurized reservoir. The pressure at the exit of the reservoir was manipulated to control the pump pressure as desired. In other words, if the pump was flowing at $25 \mathrm{gpm}$ and the pump pressure was $5,000 \mathrm{psi}$, 
the reservoir pressure would need to be $4,900 \mathrm{psi}$, but if the flow rate needed to be increased to $300 \mathrm{gpm}$ the reservoir pressure needed to be changed to 4,700 psi to maintain the 5,000 psi pump pressure. The components used to represent the pump station in the model can be seen in the following figure.

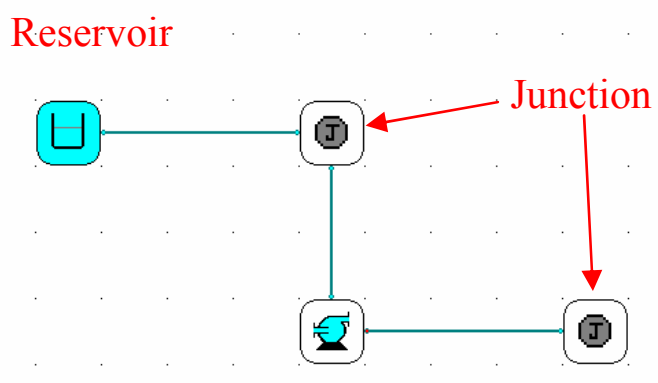

Pump

Figure 5-1, Modeling scheme for the pump station

The next consideration was the minor, shock losses throughout the hydraulic supply system. This was dealt with by combing the minor and major losses into the frictional losses associated with the hoses of the system. The hoses in the hydraulic system were also in 50-ft sections with line connections between each hose section. The losses associated with these connections were also incorporated into the frictional losses of the hoses. This was done to limit the unknowns in the system, since there were limited data collection points. This incorporation has been performed for years in the form of the equivalent length theory, as discussed in Chapter 2. In the model the hoses are modeled as the longest possible component to limit the number of variables in the system. Thus the monorail consists of two hoses, each $1650 \mathrm{ft}$ in length as can be seen 
in Figure 5-2. It can be observed that the physical lengths of the two monorail hoses in the model were not equal but the numerically modeled lengths were both $1650 \mathrm{ft}$.

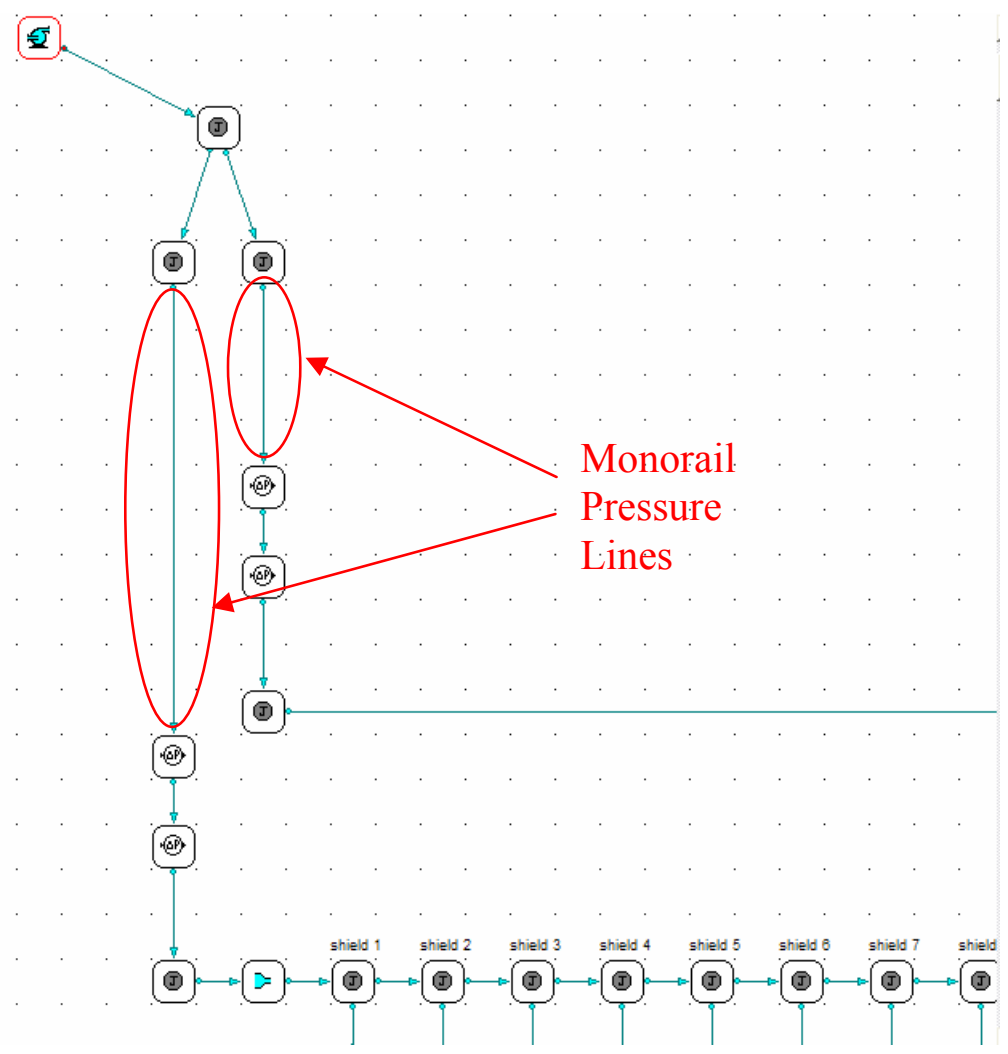

Figure 5-2, Modeling scheme for the monorail

The shield is another very complex component of the hydraulic system. The shield must be simplified due to the lack of data on the pressure losses through the shield and inside the shield. This simplification was done by simply turning the intake valve bank into a single no-pressure-loss joint $(A)$, the internal working of the shield into a single hose with a known pressure loss component (B), and the hydraulic legs into a single known flow exit element (C). This can be seen in Figure 5-3. 


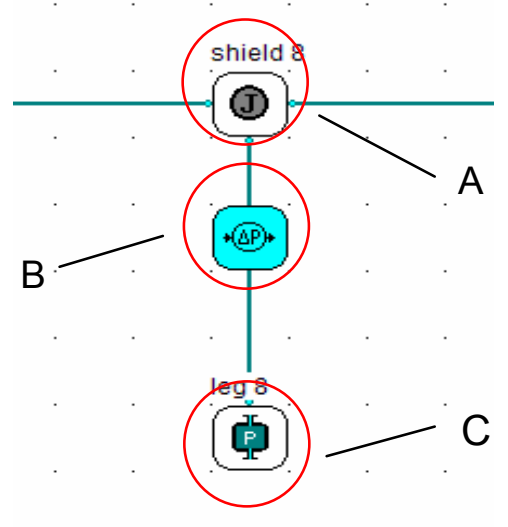

Figure 5-3, Modeling scheme for a shield

The next consideration was shock losses associated with the filters in the system. Since the majority of the filters were located in areas which were simplified--the shield and pump station--there were only a few filters modeled. The filters modeled were those along the monorail. They were modeled with a constant pressure loss. This was done because the filters' actual resistances were not known. The only values for the filters that were available were the replacement pressure losses. 


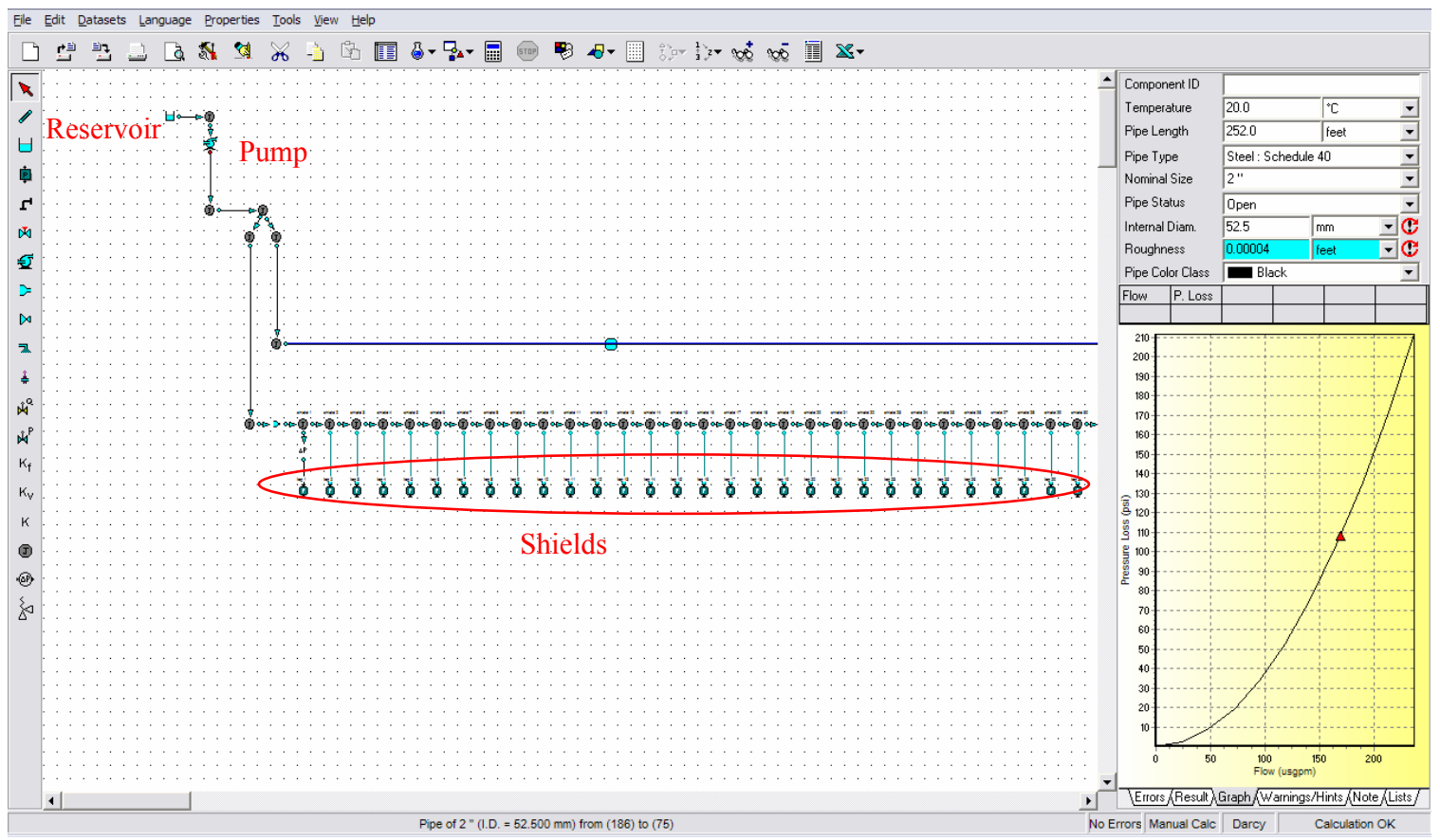

Figure 5-4, Initial model with panline potential pressure loss

Figure 5-4 illustrates the first 20 shields of the initial model. The far right of the figure shows the possible pressure losses associated with the first 252 feet of the monorail. This figure also clearly illustrates the ring main system. The one major component of the hydraulic supply system not shown in this figure is a ladder.

The ladder was a small challenge. It required a reducer since the panline hose is a size larger than the garland hoses. This reducer also needed to have essentially no pressure loss since these are being incorporated into hose frictional losses. An illustration of a ladder in the program is in Figure 5-5. 


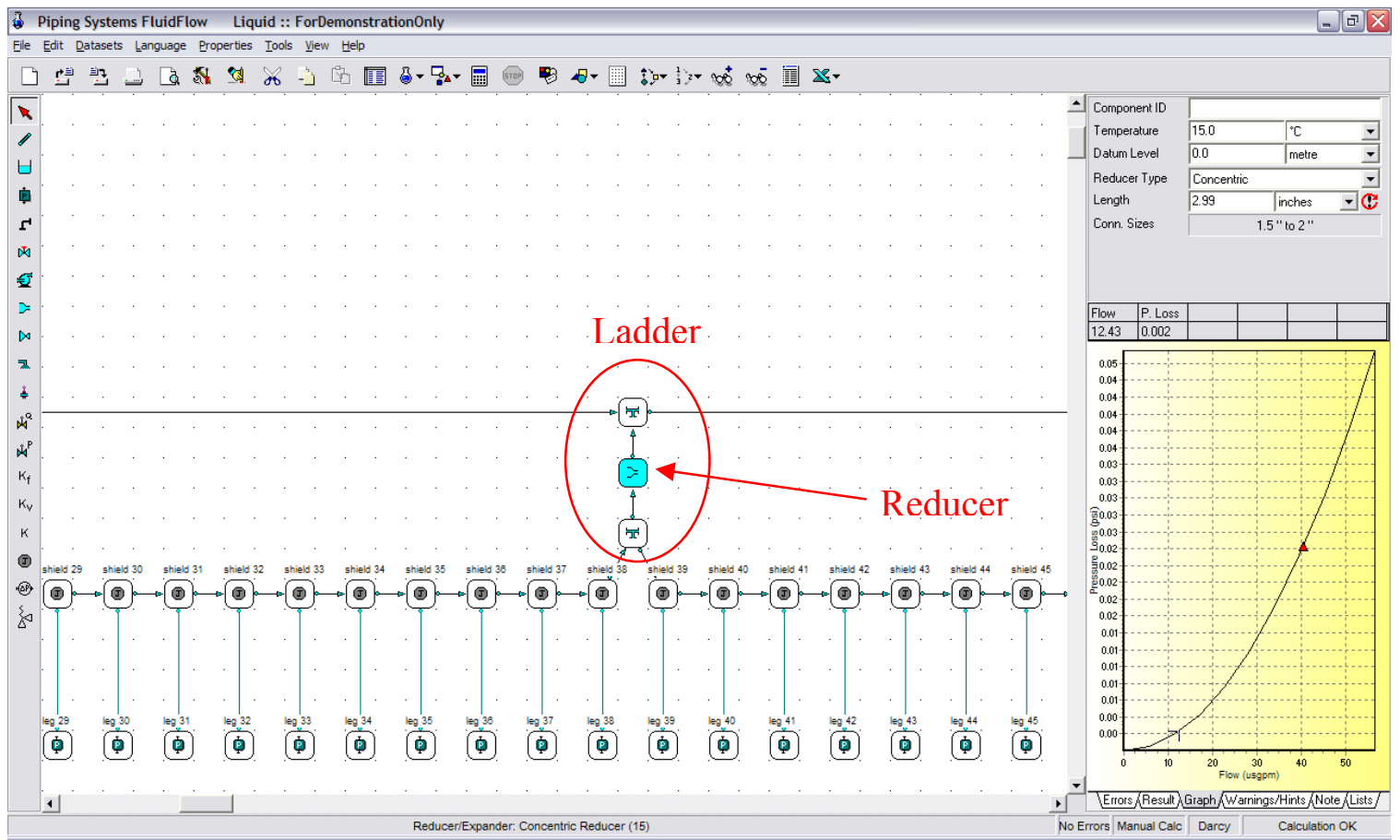

Figure 5-5, Modeling scheme of a ladder

The last interesting part of the model is the tailgate end of the hydraulic supply system. This was not a difficult area to model, but it did present interesting results, which will be discussed in Chapter 6. This portion of the model can be seen in the following figure. 


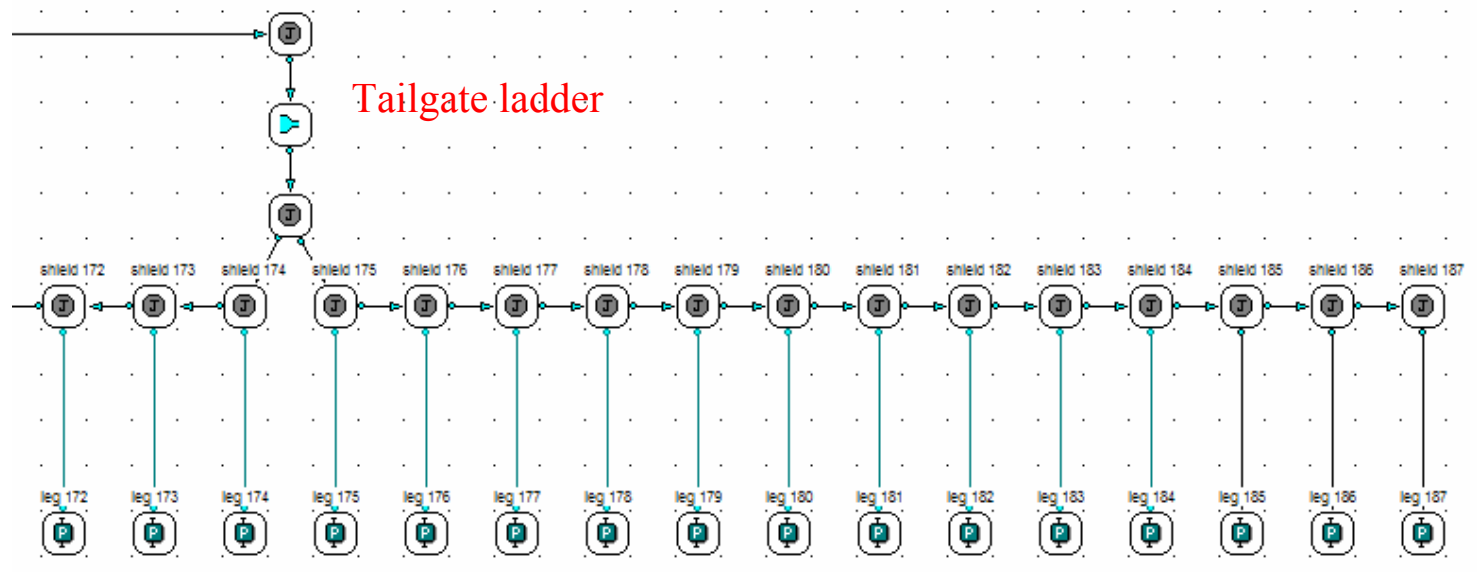

Figure 5-6, Model of the tailgate end of the face

\subsubsection{Initial Model Analysis}

In order to evaluate the entire longwall face, each shield would have to be individually evaluated as the fluid draw source, or part of the fluid draw source. In other words approximately 187 runs would have to be performed to evaluate the entire face. Since this was computationally infeasible, a scheme had to be determined to evaluate the entire face. This scheme was developed using the base case. The base case showed the following locations were most important:

- The shields $39,84,130$, and 175 where chosen because these shields were at the location of the ladders (where the pressure should be the highest) in the current system and that is where the field study measurements were taken. 
- The decision to inspect at shield locations $20,62,107$, and 153 , was based on the results of the initial case. These locations had the highest pressure losses between the points measured in the field study.

- Also shields 1, 94 and 187 were selected because of their location relative to the face, with shield 1 being closest to the headgate, shield 94 being the center shield, and shield 187 being closest to the tailgate.

There were also two methods used to demonstrate the results due to manipulations of the hydraulic supply system. The first was pressure losses, which is defined as the difference between the pressure at the pump and the pressure at a particular shield. The pressure losses are represented with a graph where the x-axis is the shield which is being lowered, advanced, and reset. The y-axis is pressure loss in psi of the corresponding shield shown on the x-axis. The second is the actual pressure in the main pressure line at a particular shield. This is a direct output of the software program.

\section{Sensitivity Analysis}

In order to demonstrate the accuracy of the program and the variability possible within the system, a sensitivity analysis was performed. The base case developed for the sensitivity analysis had the following characteristics:

Pump flow - $150 \mathrm{gpm}$

Pump pressure - 5000 psi

Draw location - shield 94 (selected because it is the middle shield)

Filter $\Delta \mathrm{P}-20 \mathrm{psi}$

Monorail roughness coefficient $-0.00035 \mathrm{ft}$

Panline roughness coefficient $-0.00002 \mathrm{ft}$

Shield to shield (garland) roughness coefficient $-0.004 \mathrm{ft}$ 
General Layout - same as field site

This analysis focused primarily on the variability within a simple longwall hydraulic system. The variables of interest were the pressure losses from the filters in the system, the roughness factors of the hoses, and the flow and pressure at the pump station. These variables were evaluated individually as well as together to determine the effects of each.

The pressure losses due to the filters used in the hydraulic system will vary with time. This operational-time-dependent variability is due to the buildup of particles on the filtration media. The purpose of the filters is to stop any particulates greater than the rated size of the filter. As additional particulates mount on the filters the resistance to flow increases, which causes pressure losses. Some filters have a linear increase to resistance over time, while others have various non-linear responses. Since there is such variation in the filters' degradation over operational time, a simple variation over the recommended use cycle was conducted.

The roughness factors of hoses are fairly consistent over their expected lifetime. Although there could be some variability in the production standards causing different sections to have different roughness factors, this variation should be insignificant in comparison to the variation caused by the snaking of the lines. The roughness factors were evaluated in two methods. The first method maintained a constant relationship between the roughness factors of the three distinct areas-the ring main, the monorail, and the shield to shield lines. These roughness factors also account for any 
connections in the system and for the initial valve bank in the shield. The second method varied the three areas independently.

The third variation dealt with the flow rates and pressure at the pump station. Since both of these values have direct effects on the pressure at the shield and the time required for setting a batch of shields, these variations are extremely important. The pressure at the pump station was varied from 3,000 to 5,500 psi. The flow rate at the pump station was varied from 60 to $360 \mathrm{gpm}$. This variation accounted for batching of one to four shields simultaneously, shields with different leg cylinder sizes, production speed, and leakage.

\section{Scenario Analysis}

In order to demonstrate the programs' ability to determine the best system layout, a scenario analysis was completed. The scenarios included previously studied changes to the hydraulic system, and compared the results from this program to the previous work described in Chapter 2. It also demonstrated as many options as possible to fully show the potential of the software. The primary areas of focus was the flow distribution among the two loops and the pressures at the following shields; $1^{\text {st }}, 20^{\text {th }}, 39^{\text {th }}, 62^{\text {nd }}, 84^{\text {th }}, 94^{\text {th }}$, $107^{\text {th }}, 130^{\text {th }}, 163^{\text {rd }}, 175^{\text {th }}$ and $187^{\text {th }}$.

The first scenario evaluated was the field study location. The parameters of the system are discussed in Section 3.2. The system was evaluated at different locations as the shearer moved along the face. This allowed for a greater understanding of the dynamic system. For the actual mine being studied, each batch contained a single shield. The approximate shield setting time was 6 seconds. 
Three other scenarios were evaluated to demonstrate the program's ability to adapt to changes which are likely to occur. These scenarios involved adding 4 additional ladders between the already existing ladders, changing the monorail hoses to pipes by reducing the roughness coefficient in the model, and increasing the face length to $1,650 \mathrm{ft}$ by adding length to each hose in the face area of the model. The batch size, pump pressures and changes to shields were accounted for in the sensitivity analysis and were not included in the scenario analysis. The change from hoses to pipes was also accounted for in the sensitivity analysis, but a more direct approach was taken in the scenario analysis. The roughness coefficients of pipes and hoses were adjusted to simulate likely changes. The increase in the face length was accomplished by simply increasing the lengths of the monorail hoses and the garland hoses.

\subsection{MODEL CALIBRATION}

Once the model is constructed and operating properly, it must be calibrated against field measurements to insure that it accurately portrays the hydraulic supply systems' flow behavior. A complete comparison of the resultant pressures of the hydraulic supply system from the model will be compared to data recorded from the field measurements. Comparisons will include conditions while shields are advancing at various positions along the face between the headgate and tailgate. Specific instances when the demand flow is either extremely low or high will also be evaluated to maximize the correlation between the model and field measurements. 
On a global scale, the model will be calibrated for varying degrees of monorail extension. This will cause significantly different pressure losses along the face. When the monorail is fully extended the pressure loss in the monorail can be less than half that of a fully collapsed monorail. The monorail loss can be as much as $50 \%$ of the complete system. 


\section{CHAPTER 6: RESULTS OF MODEL DEVELOPMENT}

This chapter begins by presenting the field site hydraulic system and operating procedures and rating of the criteria for selection of software. The results from the initial model development, which includes the initial input determination, the model design, followed by sensitivity and scenario analysis, is included in this chapter. Finally, the results associated with the field study, model calibration, and the hydraulic system optimization is presented.

\subsection{RESULTS OF INITIAL MODEL DEVELOPMENT}

\subsubsection{Results of Initial Input Determination}

There are several initial input parameters that can be derived from previous research. These include the roughness coefficients, component resistance coefficients, and typical pump flow and pressures. The first to be determined is the roughness coefficient.

\section{Roughness coefficient}

There are 21 cases from prior German research (Fusser, 2006; Bassier and Migenda, 2006) that can be used to determine the roughness coefficient. The following table is a representation of those cases. 
Table 6-1, Roughness coefficient existing cases

\begin{tabular}{||c|c|c|c|c|c|c||}
\hline Case & $\begin{array}{c}\text { Referenc } \\
\mathbf{e}\end{array}$ & Type & $\begin{array}{c}\text { Diameter, } \\
\mathbf{D} \text { (inch) }\end{array}$ & $\begin{array}{c}\text { Flowrate, } \\
\mathbf{Q} \text { (gpm) }\end{array}$ & $\begin{array}{c}\text { Pressure } \\
\text { loss, } \mathbf{A P} \\
\mathbf{( p s i )}\end{array}$ & $\begin{array}{c}\text { Length, } \\
\mathbf{L} \text { (ft) }\end{array}$ \\
\hline \hline $\mathbf{1}$ & Migenda & panline hose & 2.0 & 158.5 & 435.1 & 984.3 \\
\hline $\mathbf{2}$ & Migenda & panline hose & 2.0 & 211.3 & 725.2 & 984.3 \\
\hline $\mathbf{3}$ & Migenda & panline hose & 2.0 & 264.2 & 1160.3 & 984.3 \\
\hline $\mathbf{4}$ & Migenda & panline hose & 2.0 & 317.0 & 1667.9 & 984.3 \\
\hline $\mathbf{5}$ & Migenda & panline pipe & 2.0 & 158.5 & 304.6 & 984.3 \\
\hline $\mathbf{6}$ & Migenda & panline pipe & 2.0 & 211.3 & 536.6 & 984.3 \\
\hline $\mathbf{7}$ & Migenda & panline pipe & 2.0 & 264.2 & 841.2 & 984.3 \\
\hline $\mathbf{8}$ & Migenda & panline pipe & 2.0 & 317.0 & 1189.3 & 984.3 \\
\hline $\mathbf{9}$ & Migenda & garland hose & 1.5 & 158.5 & 391.6 & 65.6 \\
\hline $\mathbf{1 0}$ & Migenda & garland hose & 1.5 & 211.3 & 609.2 & 65.6 \\
\hline $\mathbf{1 1}$ & Migenda & garland hose & 1.5 & 264.2 & 1087.8 & 65.6 \\
\hline $\mathbf{1 2}$ & Migenda & garland hose & 1.5 & 317.0 & 1522.9 & 65.6 \\
\hline $\mathbf{1 3}$ & Migenda & garland hose & 1.5 & 158.5 & 754.2 & 131.2 \\
\hline $\mathbf{1 4}$ & Migenda & garland hose & 1.5 & 211.3 & 1305.3 & 131.2 \\
\hline $\mathbf{1 5}$ & Migenda & garland hose & 1.5 & 264.2 & 2030.5 & 131.2 \\
\hline $\mathbf{1 6}$ & Migenda & garland hose & 1.5 & 317.0 & 3045.8 & 131.2 \\
\hline $\mathbf{1 7}$ & Migenda & garland hose & 1.5 & 158.5 & 1160.3 & 196.9 \\
\hline $\mathbf{1 8}$ & Migenda & garland hose & 1.5 & 211.3 & 2030.5 & 196.9 \\
\hline $\mathbf{1 9}$ & Migenda & garland hose & 1.5 & 264.2 & 3190.8 & 196.9 \\
\hline $\mathbf{2 0}$ & Fusser & monorail & 2.0 & 246.0 & 444.0 & 1000.0 \\
\hline $\mathbf{2 1}$ & Fusser & monorail & 2.0 & 220.0 & 350.0 & 1000.0 \\
\hline
\end{tabular}

From the cases in Table 6-1 and following the procedure described in Section 5.1.1, the roughness coefficients were determined. The results of the roughness calculations can be seen in Table 6-2 and 6-3. Table 6-2 contains the roughness coefficients calculated by hand. Theses hand calculations were performed to insure that the roughness coefficients were reasonable with a real fluid since FluidFlow demo version uses a imaginary fluid. Table 6-3 contains the roughness coefficients calculated using a demo version of FluidFlow. The demo version of FluidFlow is fully functional, but it uses a 
special fluid which has a much different viscosity causing substantially different roughness coefficients. The roughness coefficients calculated using FluidFlow were used for the remainder of the study because FluidFlow will be the program used to determine the effects of changes to the system.

Table 6-2, Roughness coefficient hand calculations using existing cases

\begin{tabular}{||c|c|c|c|c|c|c|c||}
\hline \multirow{2}{*}{$\begin{array}{c}\text { Cas } \\
\mathbf{e}\end{array}$} & \multirow{2}{*}{ Reference } & Type & $\mathbf{D}$ & $\mathbf{Q}$ & $\mathbf{\Delta P}$ & $\mathbf{L}$ & $\boldsymbol{\varepsilon} / \mathbf{D}$ \\
\cline { 4 - 8 } & & & $\mathbf{i n c h}$ & $\mathbf{g p m}$ & $\mathbf{p s i}$ & $\mathbf{f t}$ & $\mathbf{f t}$ \\
\hline \hline $\mathbf{1}$ & Migenda & panline hose & 2.0 & 158.5 & 435.1 & 984.3 & 0.01032905 \\
\hline $\mathbf{2}$ & Migenda & panline hose & 2.0 & 211.3 & 725.2 & 984.3 & 0.00853331 \\
\hline $\mathbf{3}$ & Migenda & panline hose & 2.0 & 264.2 & 1160.3 & 984.3 & 0.00921030 \\
\hline $\mathbf{4}$ & Migenda & panline hose & 2.0 & 317.0 & 1667.9 & 984.3 & 0.00918309 \\
\hline $\mathbf{5}$ & Migenda & panline pipe & 2.0 & 158.5 & 304.6 & 984.3 & 0.00310640 \\
\hline $\mathbf{6}$ & Migenda & panline pipe & 2.0 & 211.3 & 536.6 & 984.3 & 0.00306391 \\
\hline $\mathbf{7}$ & Migenda & panline pipe & 2.0 & 264.2 & 841.2 & 984.3 & 0.00313897 \\
\hline $\mathbf{8}$ & Migenda & panline pipe & 2.0 & 317.0 & 1189.3 & 984.3 & 0.00295500 \\
\hline $\mathbf{9}$ & Migenda & garland hose & 1.5 & 158.5 & 391.6 & 65.6 & 0.22793239 \\
\hline $\mathbf{1 0}$ & Migenda & garland hose & 1.5 & 211.3 & 696.2 & 65.6 & 0.18803889 \\
\hline $\mathbf{1 1}$ & Migenda & garland hose & 1.5 & 264.2 & 1087.8 & 65.6 & 0.22796415 \\
\hline $\mathbf{1 2}$ & Migenda & garland hose & 1.5 & 317.0 & 1522.9 & 65.6 & 0.21913393 \\
\hline $\mathbf{1 3}$ & Migenda & garland hose & 1.5 & 158.5 & 754.2 & 131.2 & 0.21614236 \\
\hline $\mathbf{1 4}$ & Migenda & garland hose & 1.5 & 211.3 & 1305.3 & 131.2 & 0.20803565 \\
\hline $\mathbf{1 5}$ & Migenda & garland hose & 1.5 & 264.2 & 2030.5 & 131.2 & 0.20671671 \\
\hline $\mathbf{1 6}$ & Migenda & garland hose & 1.5 & 317.0 & 3045.8 & 131.2 & 0.21913393 \\
\hline $\mathbf{1 7}$ & Migenda & garland hose & 1.5 & 158.5 & 1160.3 & 196.9 & 0.22400704 \\
\hline $\mathbf{1 8}$ & Migenda & garland hose & 1.5 & 211.3 & 2030.5 & 196.9 & 0.21911380 \\
\hline $\mathbf{1 9}$ & Migenda & garland hose & 1.5 & 264.2 & 3190.8 & 196.9 & 0.22089541 \\
\hline $\mathbf{2 0}$ & Fusser & monorail & 2.0 & 246.0 & 444.0 & 1000.0 & 0.04698969 \\
\hline $\mathbf{2 1}$ & Fusser & monorail & 2.0 & 220.0 & 350.0 & 1000.0 & 0.04549135 \\
\hline & & & & & & \\
\hline
\end{tabular}


Table 6-3, Roughness coefficient FluidFlow calculations using existing cases

\begin{tabular}{||c|c|l|c|c|c|c|c||}
\hline \multirow{2}{*}{ Case } & Referenc & \multirow{2}{*}{ Type } & $\mathbf{D}$ & $\mathbf{Q}$ & $\mathbf{\Delta P}$ & $\mathbf{L}$ & $\mathbf{\varepsilon} / \mathbf{D}$ \\
\cline { 4 - 8 } & & & $\mathbf{i n c h}$ & $\mathbf{g p m}$ & $\mathbf{p s i}$ & $\mathbf{f t}$ & $\mathbf{f t}$ \\
\hline \hline $\mathbf{1}$ & Migenda & panline hose & 2.0 & 158.5 & 435.1 & 984.3 & 0.00002400 \\
\hline $\mathbf{2}$ & Migenda & panline hose & 2.0 & 211.3 & 725.2 & 984.3 & 0.00001700 \\
\hline $\mathbf{3}$ & Migenda & panline hose & 2.0 & 264.2 & 1160.3 & 984.3 & 0.00002000 \\
\hline $\mathbf{4}$ & Migenda & panline hose & 2.0 & 317.0 & 1667.9 & 984.3 & 0.00002000 \\
\hline $\mathbf{5}$ & Migenda & panline pipe & 2.0 & 158.5 & 304.6 & 984.3 & 0.00000060 \\
\hline $\mathbf{6}$ & Migenda & panline pipe & 2.0 & 211.3 & 536.6 & 984.3 & 0.00000070 \\
\hline $\mathbf{7}$ & Migenda & panline pipe & 2.0 & 264.2 & 841.2 & 984.3 & 0.00000137 \\
\hline $\mathbf{8}$ & Migenda & panline pipe & 2.0 & 317.0 & 1189.3 & 984.3 & 0.00000135 \\
\hline $\mathbf{9}$ & Migenda & garland hose & 1.5 & 158.5 & 391.6 & 65.6 & 0.00415000 \\
\hline $\mathbf{1 0}$ & Migenda & garland hose & 1.5 & 211.3 & 696.2 & 65.6 & 0.00297000 \\
\hline $\mathbf{1 1}$ & Migenda & garland hose & 1.5 & 264.2 & 1087.8 & 65.6 & 0.00412000 \\
\hline $\mathbf{1 2}$ & Migenda & garland hose & 1.5 & 317.0 & 1522.9 & 65.6 & 0.00385000 \\
\hline $\mathbf{1 3}$ & Migenda & garland hose & 1.5 & 158.5 & 754.2 & 131.2 & 0.00376500 \\
\hline $\mathbf{1 4}$ & Migenda & garland hose & 1.5 & 211.3 & 1305.3 & 131.2 & 0.00352700 \\
\hline $\mathbf{1 5}$ & Migenda & garland hose & 1.5 & 264.2 & 2030.5 & 131.2 & 0.00348800 \\
\hline $\mathbf{1 6}$ & Migenda & garland hose & 1.5 & 317.0 & 3045.8 & 131.2 & 0.00385500 \\
\hline $\mathbf{1 7}$ & Migenda & garland hose & 1.5 & 158.5 & 1160.3 & 196.9 & 0.00400000 \\
\hline $\mathbf{1 8}$ & Migenda & garland hose & 1.5 & 211.3 & 2030.5 & 196.9 & 0.00385000 \\
\hline $\mathbf{1 9}$ & Migenda & garland hose & 1.5 & 264.2 & 3190.8 & 196.9 & 0.00391000 \\
\hline $\mathbf{2 0}$ & Fusser & monorail & 2.0 & 246.0 & 444.0 & 1000.0 & 0.00035000 \\
\hline $\mathbf{2 1}$ & Fusser & monorail & 2.0 & 220.0 & 350.0 & 1000.0 & 0.00033300 \\
\hline
\end{tabular}

Other Filter Losses

With the roughness coefficients determined, the next focus is the component resistance factors. Most of the components were incorporated into the hose resistances due to the complexity of determining all the coefficients given the limited measurement locations.

The one noted exception is that of the pressure losses across the filters, because there are fewer locations and their effects on the system are well documented. The next parameter to be determined is the pressure drop across the filters. Since these values were not available from the manufacturers, replacement criteria from the mine will be used. All the filters in the system are designed to be replaced when the pressure loss across the filter is between 42 and 45 psi. Thus a range of filter pressure losses from zero psi to 45 psi will be used in the evaluations. 


\section{Flow Characteristics}

The last parameter is the flow and pressure of the pump station. Typical pump characteristics of longwall hydraulic supply systems can be found in the following table.

\section{Table 6-4. Typical longwall pump station output}

\begin{tabular}{|c|c|}
\hline Flow $(\mathbf{g p m})$ & Pressure (psi) \\
\hline $0-26.4$ & 4351 \\
$26.4-92.5$ & 4641 \\
$52.8-317$ & 4786 \\
$0-396.3$ & 5004 \\
$82-500$ & $\sim 5000$ \\
\hline
\end{tabular}

Modifications to the initial model's flow and pressure will be made using field study data once available.

\subsubsection{Results of Initial Model Design}

Using Figure 3-1, a model of the components was developed using the FluidFlow program. The pump station was represented as described in Section 5.1.3. The shields were represented as described in Section 5.1.3. This resulted in the shield-shield pressure losses being combined with the hoses' roughness coefficients. The filters were represented by a user input pressure loss. All of the connections within the hoses were modeled using a zero pressure loss component and the pressure losses associated with the connections were added to the hoses' pressure losses. This was accomplished by artificially increasing the roughness coefficient of the hoses to account for the minor pressure loses in the hoses similar to the equivalent length theory. Other than these three exceptions, the system is pictorially represented in the software as it is set up in the mine (see Figure 3-1). 
The average roughness coefficients for each hose section determined in Section 6.1.2 were used in this model. The roughness coefficients for the initial model are as follows:

$$
\begin{aligned}
& \text { Monorail }-000035 \mathrm{ft} \\
& \text { Panline }-0.00002 \mathrm{ft} \\
& \text { Garland }-0.004 \mathrm{ft}
\end{aligned}
$$

The flow rates determined from previous research and the field study lead to a potential flow rates between $20 \mathrm{gpm}$ and $500 \mathrm{gpm}$. The one chosen for the initial model was 150 gpm. This value was chosen because it was not an extremely high or low flow rate based on the field study data.

The results of the initial model are the same as the base case in the scenario and sensitivity studies. Figure 6-1 and 6-2 represent the initial model results and can be found in section 6.1.3.

\subsubsection{Results of Initial Model Analysis}

There were two primary objectives for performing the model analysis. The first was to demonstrate the ability of the chosen software to accurately model the existing system as well as model potential alternative systems. The second was to demonstrate the likely variations of alternative systems or modifications which could be implemented in a mine to insure proper setting pressure is achieved. Both of these objectives are addressed in the data described in this section. 


\section{Sensitivity Analysis}

To perform the sensitivity analysis, a base case was developed. This base case had the following characteristics:

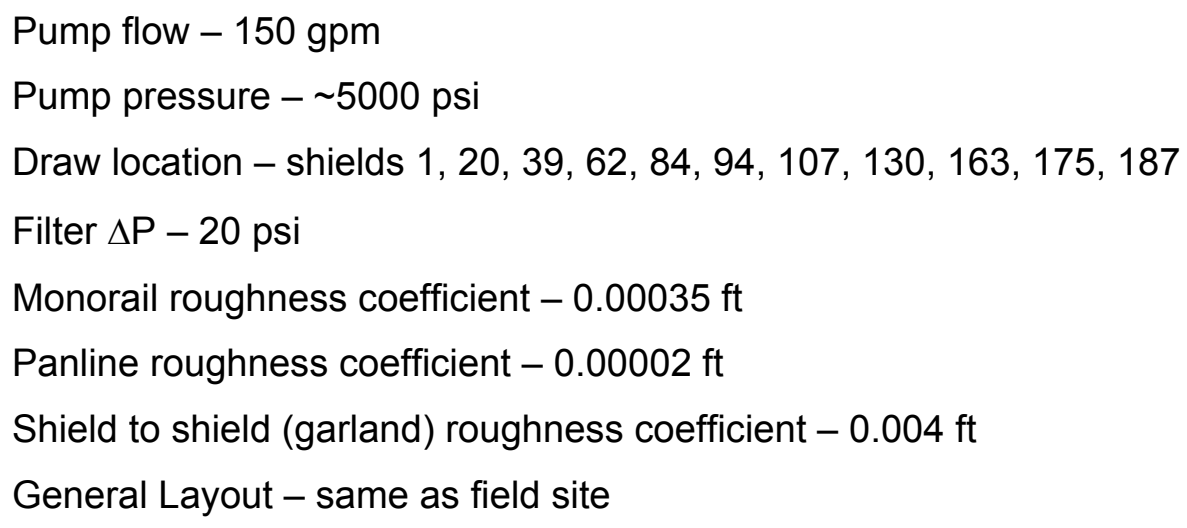

The sensitivity analysis was based on estimated roughness coefficients as shown above from previous research and estimated changes to the system. There are two ways to view the results of the sensitivity analysis. One is through the pressure losses between the pump and a particular location along the face, referred to as pressure losses. The other is by looking at the pressure supplied to the shield during setting, referred to as pressure across face. This allowed for the general patterns of the changes to the hydraulic system to be seen, but did not demonstrate the exact values associated with these changes. The results from the base case can be seen in the following Figures, 6-1 and 6-2: 


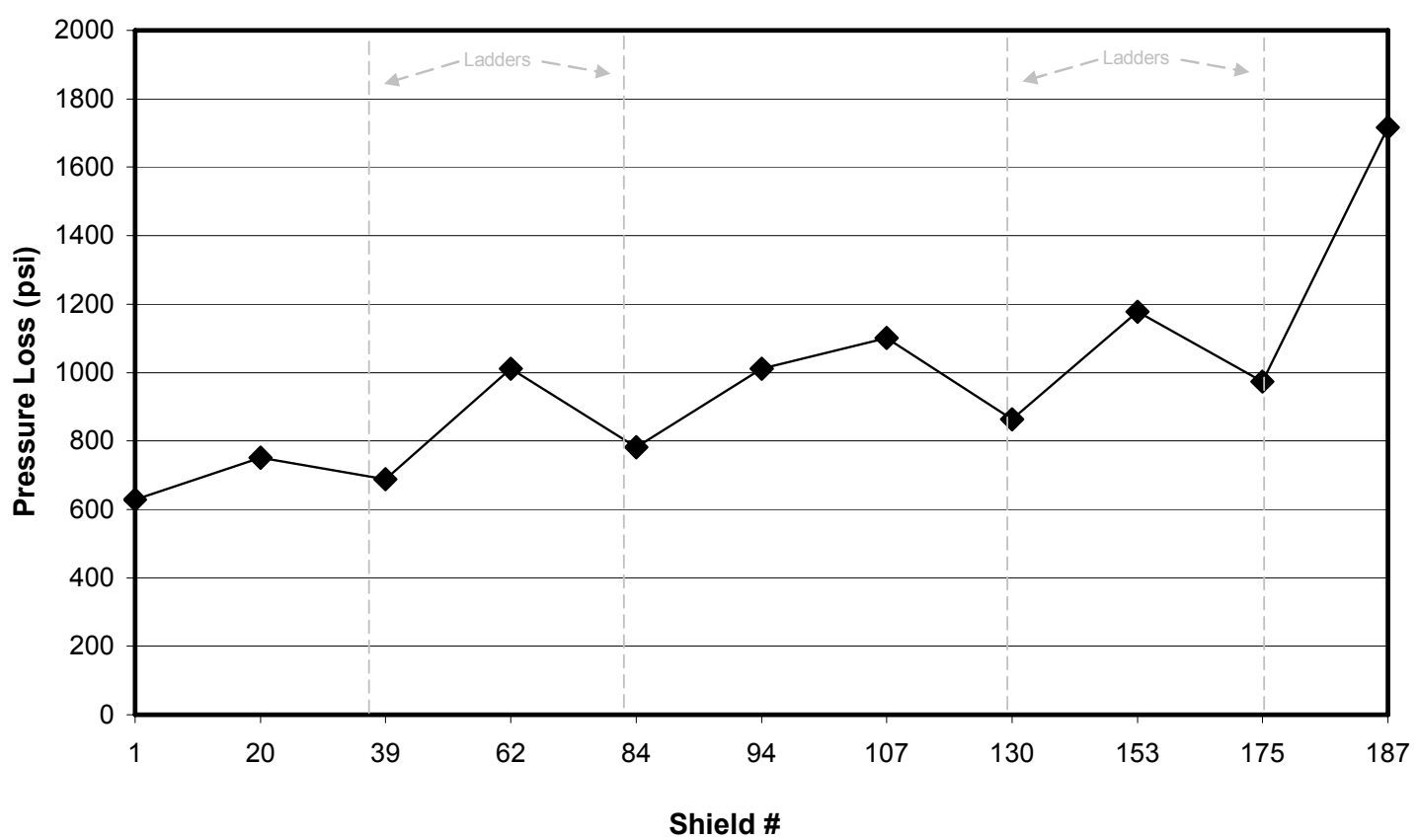

Figure 6-1, Base case, pressure losses 


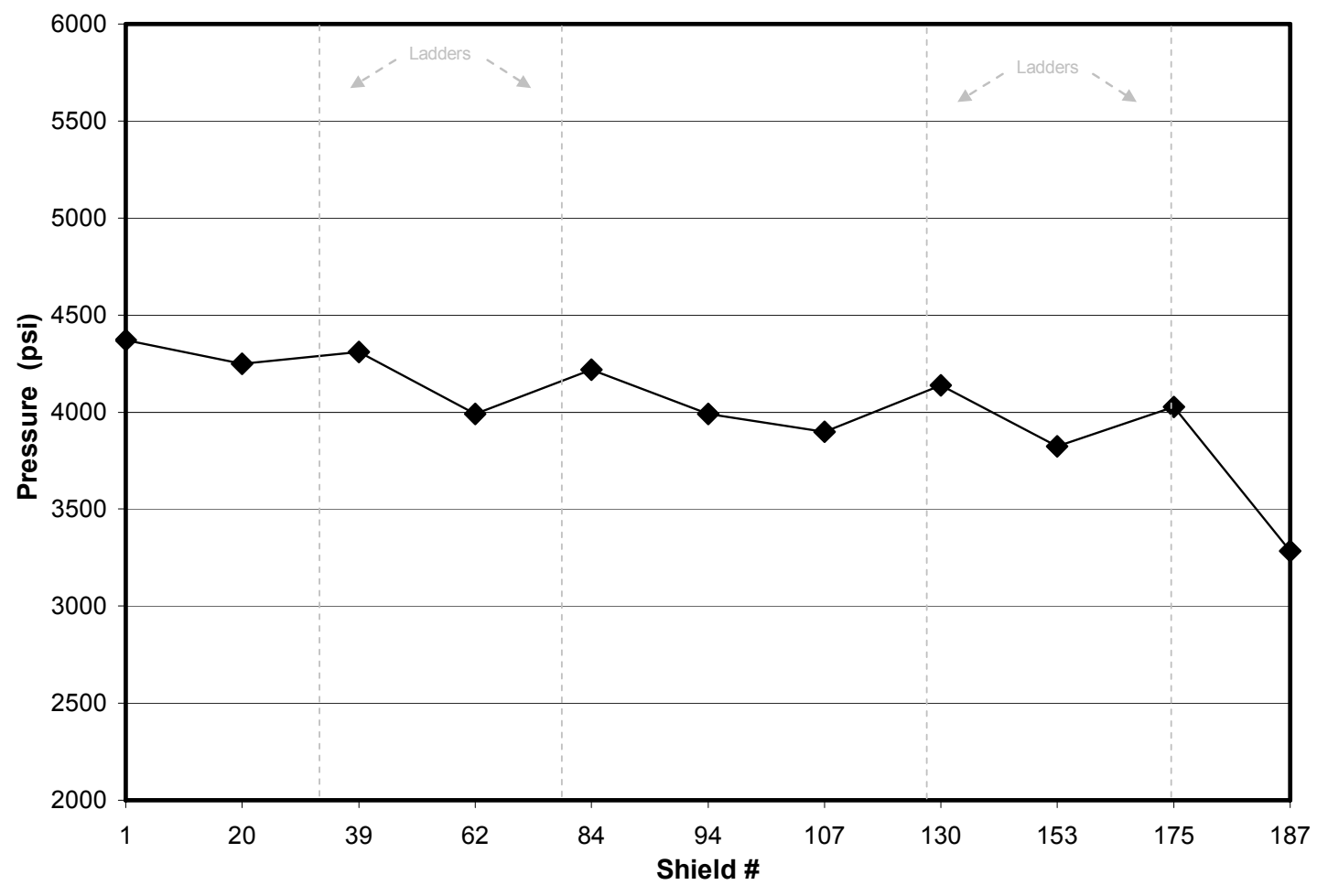

Figure 6-2, Base case, pressure across face

Figures 6-1 and 6-2 showed the base case results across the face for pressure loss and achieved setting pressure at the shields of interest. As seen in these figures, the greatest pressure loss is at shield 187 , the tailgate shield. This is caused by the location of the last ladder and having only one small hose to transport fluid from shield 175 to shield 187. The fact that this shield is the furthest from the pump station leads to it having the greatest pressure loss.

The remainder of the sensitivity analyses brackets the reasonable operating parameters of the hydraulic longwall system. 


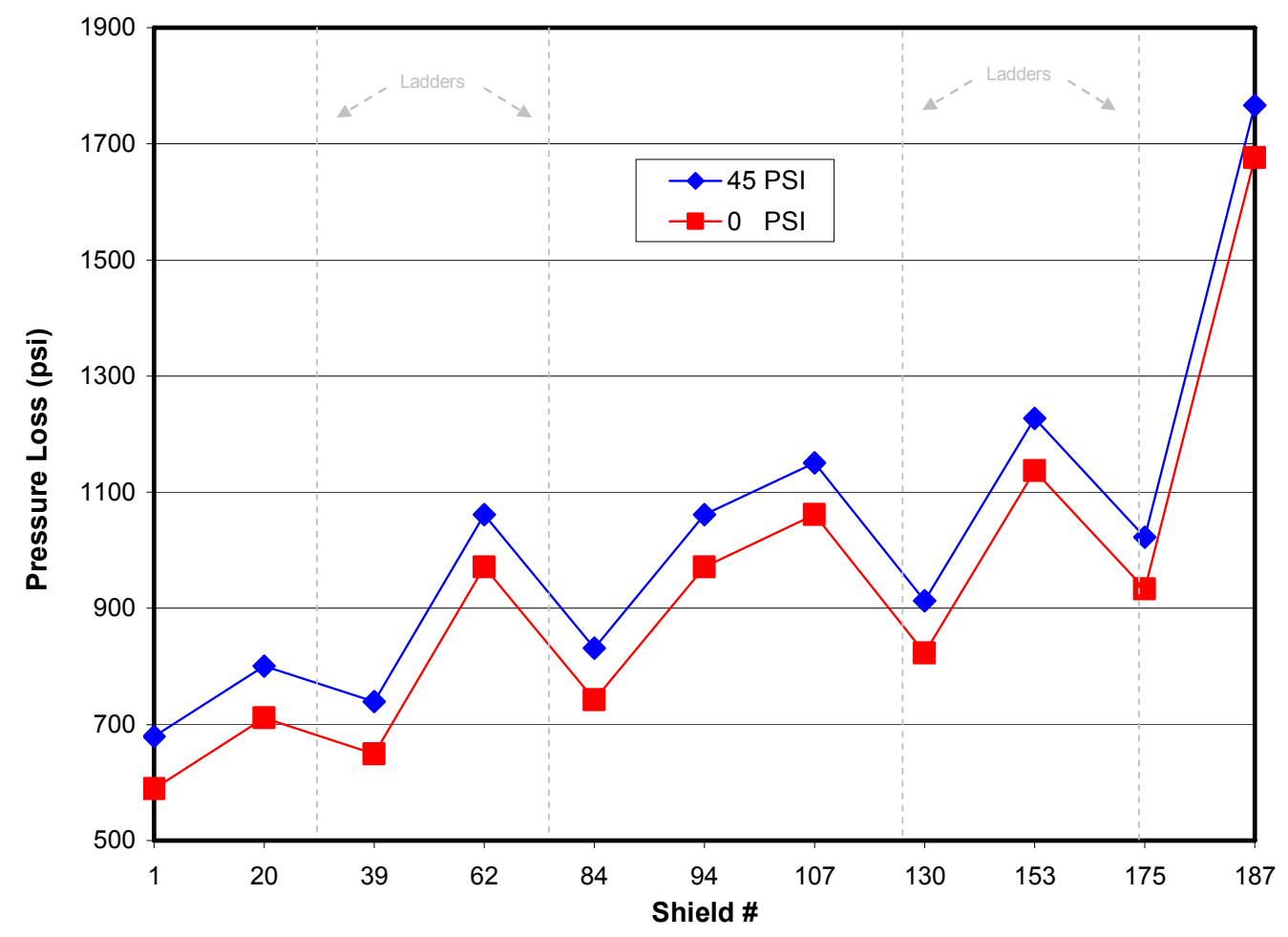

Figure 6-3, Variation of pressure losses due to filter changes

The results for the variation of pressure loss across the filters in the system can be seen in Figure 6-3. It shows that over the life of a filter, the pressure losses across the face vary by about 100 psi at each shield. If the location or number of filters are changed these pressure losses will also change. 


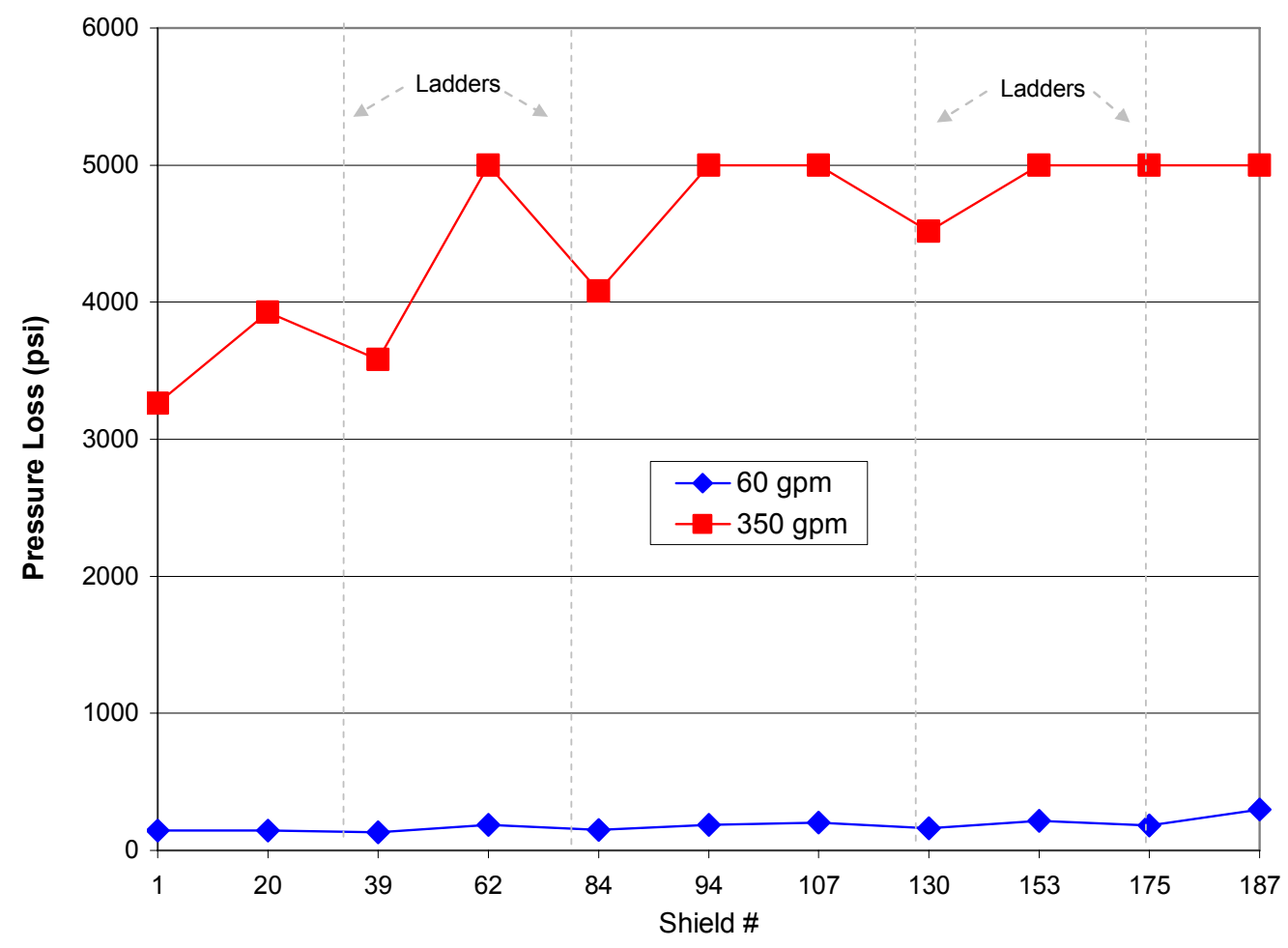

Figure 6-4, Variation of pressure losses due to flow rate

The results from the variation of pump flow rate can be seen in Figure 6-4. From Figure $6-4$, the pressure losses across the face vary greatly with increasing flow rates. This chart also demonstrates the inaccuracy of the estimates from previous research. The system evaluated in this chart should not be able to deliver 4000 psi at $350 \mathrm{gpm}$ across the entire face, but it should be able to deliver pressures greater than zero at $350 \mathrm{gpm}$. The fact that it cannot is a function of the roughness coefficients derived from the prior research. It is improbable that the pressure losses will exceed the pump pressure at a Flow rate of $350 \mathrm{gpm}$. 


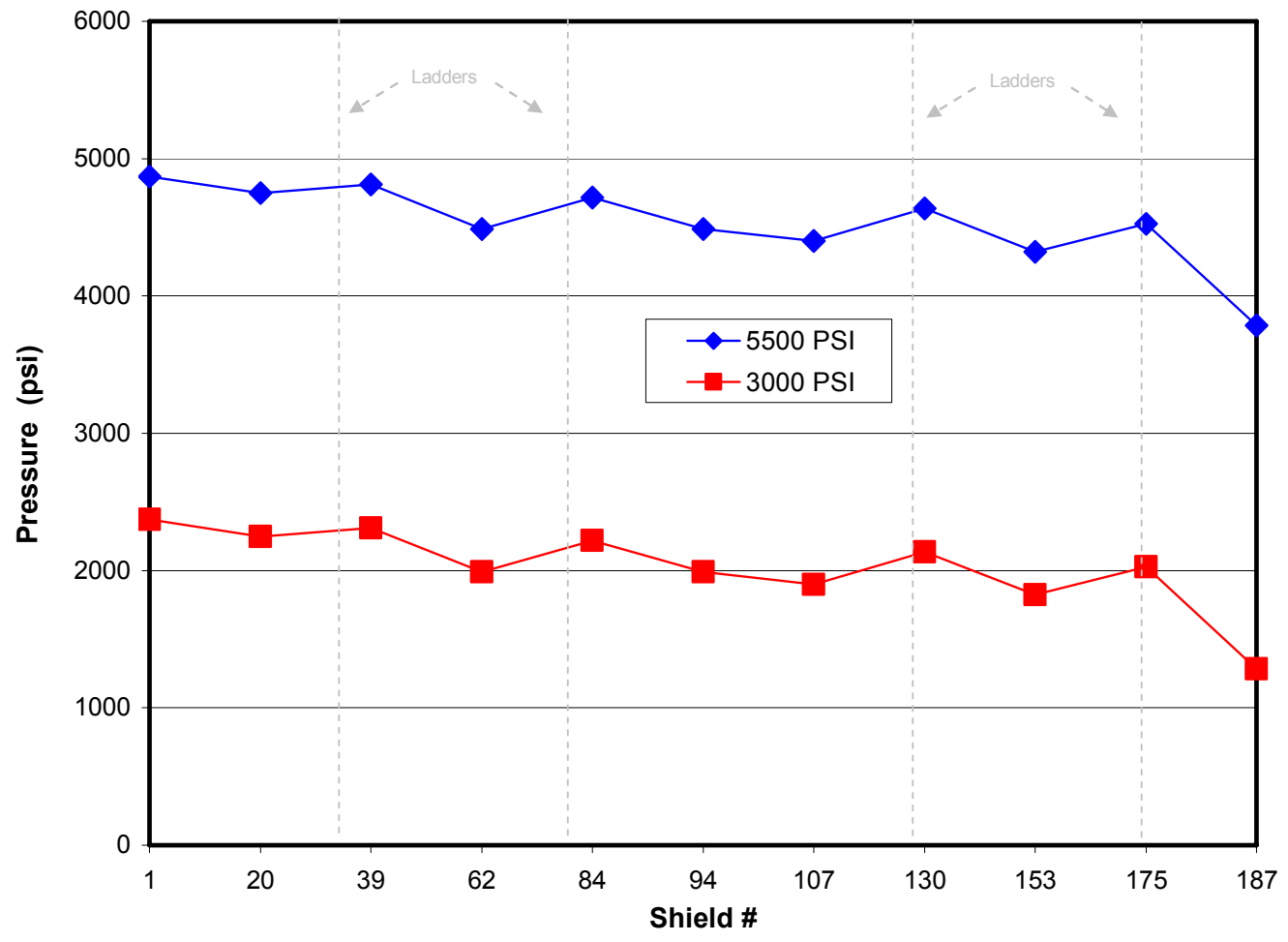

Figure 6-5, Variation of pressure across face due to pump pressure

Figure 6-5 shows the effect of a change in pump pressure. If the pump pressure is increased by a specified amount the pressure at each location along the face will increase by the specified amount. This shows that by increasing the pressure at the pump to $6000 \mathrm{psi}$, the pressure at the face would increase by 1000 psi assuming that the initial pump pressure was $5000 \mathrm{psi}$, and that the hoses or pipes could handle such a pressure. 


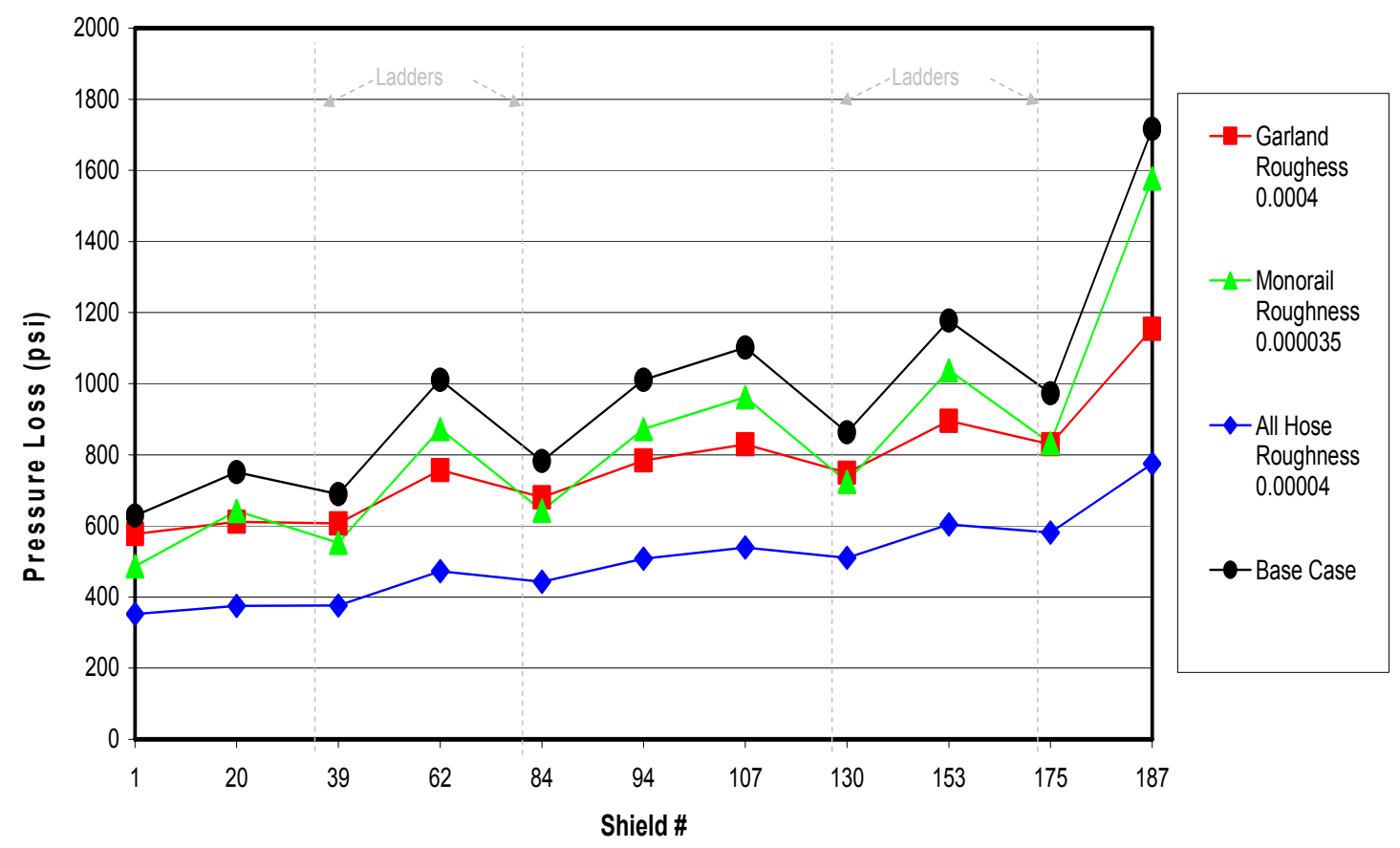

Figure 6-6, Variation of pressure losses due to roughness coefficients

Figure 6-6 shows the effects of varying the roughness coefficients within the hydraulic supply system. If the shield-shield (garland) hose roughness coefficients are lowered by an order of magnitude then there will be a drop at all locations along the face. If the monorail roughness coefficient is lowered by an order of magnitude, then there will be a drop at each location along the face, but due to the already low roughness of the monorail, the benefit is not quite as much as at the shield-shield. If all of the roughness coefficients were lowered to the same value similar to that of the monorail, then the pressure losses across the face would be more similar and lower than the existing system. These order of magnitude changes are in line with the variation of roughness coefficients seen in Table 5-1. 


\section{Scenario Analysis}

The scenarios analyzed were that of a pipe instead of a hose in the monorail, using eight ladders instead of four, and extending the face to 1,650 feet, all other factors were kept identical to the base case. The variance from the base case to the scenarios examined is depicted in Figure 6-7.

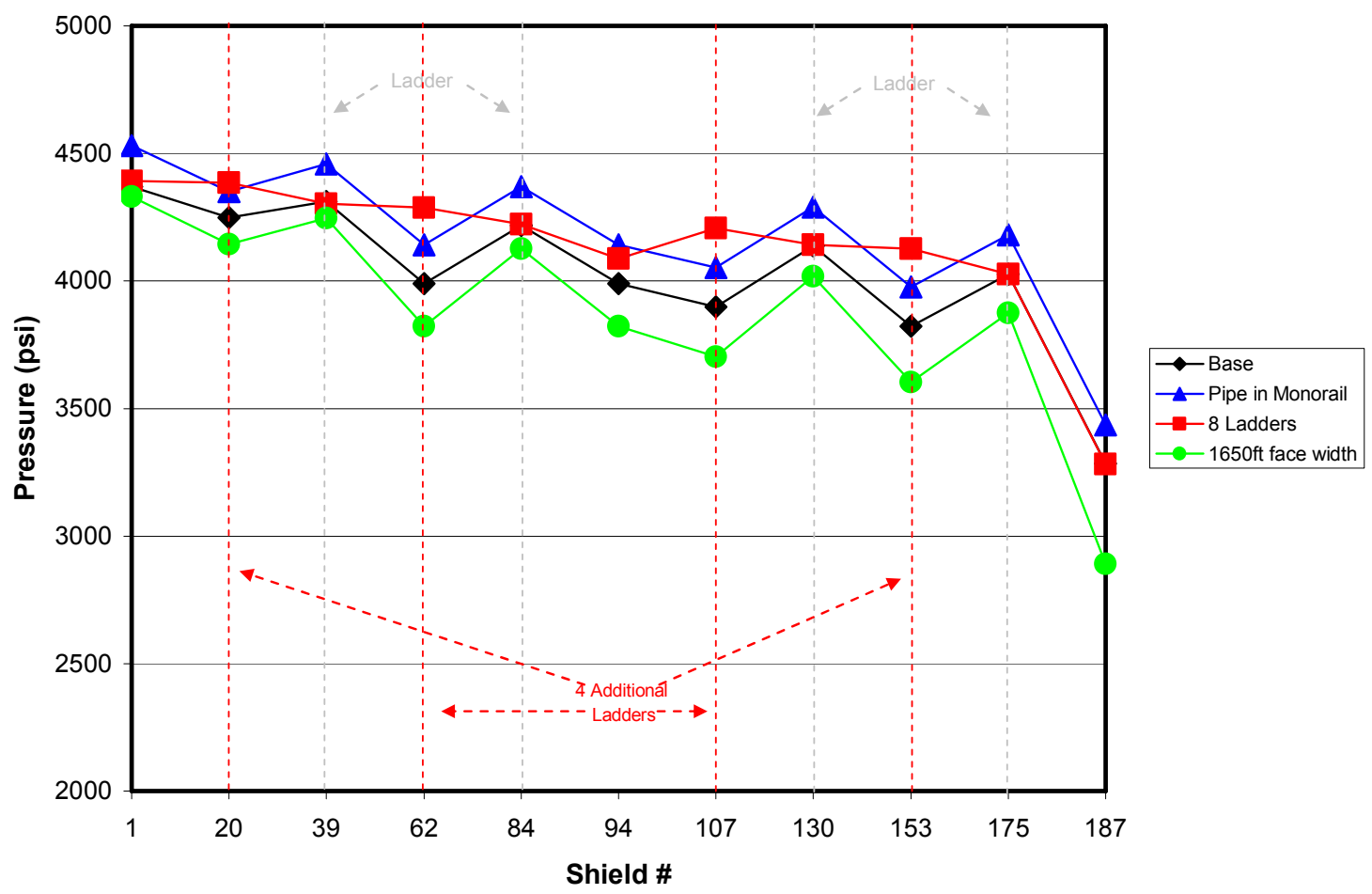

Figure 6-7, Variation of pressure across face due to scenarios 


\subsection{RESULTS OF MODEL CALIBRATION}

This model shows great potential to meet the requirements of modeling the hydraulic supply systems for the longwall face support systems. The following data sets represent points in time that were used in an attempt to calibrate the model.

Table 6-5, Calibration input information

\begin{tabular}{|c|c|c|c|c|c|c|c|c|c|}
\hline \multirow{2}{*}{ Time } & \multicolumn{4}{|c|}{ Pump parameters } & \multicolumn{4}{c|}{ Face position } & $\begin{array}{c}\text { Location } \\
\text { of } \\
\text { Activity }\end{array}$ \\
\cline { 2 - 10 } & Flow1 & Flow2 & Flow Total & Pressure & $\mathbf{3 9}$ & $\mathbf{8 4}$ & $\mathbf{1 3 0}$ & $\mathbf{1 7 5}$ & psi \\
\cline { 2 - 10 } & $\mathbf{g p m}$ & $\mathbf{g p m}$ & $\mathbf{g p m}$ & psi & psi & psi & psi & psi & Shield \# \\
\hline $3: 36: 03$ & 106 & 82 & 188 & 4672 & 4300 & 4100 & 3900 & 3600 & 130 \\
\hline 4:38:18 & 108 & 69 & 177 & 2907 & 2500 & 2400 & 2200 & 2100 & 170 \\
\hline $5: 57: 04$ & 64 & 48 & 112 & 4735 & 4500 & 4400 & 4300 & 4200 & 95 \\
\hline
\end{tabular}

Input of each of the individual data points resulted in substantial divergence from expected roughness coefficients, which needed to be recalculated in order to replicate the varying conditions presented in Table 6-5. Several other points in time were also evaluated with no more success. Thus, the model calibration could not be determined with the current field results, but the model was able to independently replicate each of the individual points in time. Since the model was able to reproduce the varying results available with this data set, it suggests that it is capable of performing the task at hand.

Upon close inspection of the results from the field study, the rate at which the pressure changed in the system was alarmingly fast. This could have led to some of the difficulty in accurately calibrating the model. Table 6-6 shows the pressure changes which occurred within a one second interval. This is representative of the normal behavior. The values that are highlighted are those where the change in pressure over the one 
second interval exceeded 500 psi. The highest pressure change was approximately 1,000 psi.

Table 6-6, Measured pressure changes in the face hoses

\begin{tabular}{|c|c|c|c|c|c|c|c|c|}
\hline \multirow[b]{2}{*}{ Time } & \multirow{2}{*}{$\begin{array}{c}\text { Shield } \\
39\end{array}$} & \multirow{2}{*}{$\begin{array}{c}\text { Shield } \\
84\end{array}$} & \multirow{2}{*}{$\begin{array}{c}\text { Shield } \\
130\end{array}$} & \multirow{2}{*}{$\begin{array}{c}\text { Shield } \\
175\end{array}$} & \multicolumn{4}{|c|}{ Change in pressure over 1 second } \\
\hline & & & & & $\begin{array}{c}\text { Shield } \\
39 \\
\end{array}$ & $\begin{array}{c}\text { Shield } \\
84 \\
\end{array}$ & $\begin{array}{c}\text { Shield } \\
130 \\
\end{array}$ & $\begin{array}{c}\text { Shield } \\
175 \\
\end{array}$ \\
\hline $7: 51: 58$ & 4830 & 4554 & 3960 & 4119 & & & & \\
\hline 7:51:59 & 4830 & 4772 & 3887 & 4119 & 0 & -218 & 73 & 0 \\
\hline $7: 52: 00$ & 4598 & 4946 & 4337 & 4119 & 232 & -174 & -450 & 0 \\
\hline 7:52:01 & 4308 & 4888 & 4685 & 3858 & 290 & 58 & -348 & 261 \\
\hline $7: 52: 02$ & 4192 & 4728 & 4931 & 4366 & 116 & 160 & -247 & -508 \\
\hline $7: 52: 03$ & 4192 & 4308 & 4757 & 4699 & 0 & 421 & 174 & -334 \\
\hline $7: 52: 04$ & 4337 & 4221 & 4888 & 4917 & -145 & 87 & -131 & -218 \\
\hline 7:52:05 & 3742 & 4221 & 4525 & 4917 & 595 & 0 & 363 & 0 \\
\hline 7:52:06 & 3350 & 4221 & 4525 & 4917 & 392 & 0 & 0 & 0 \\
\hline $7: 52: 07$ & 3176 & 4221 & 4163 & 4801 & 174 & 0 & 363 & 116 \\
\hline 7:52:08 & 3031 & 3582 & 4163 & 4801 & 145 & 638 & 0 & 0 \\
\hline $7: 52: 09$ & 3031 & 3437 & 4163 & 4235 & 0 & 145 & 0 & 566 \\
\hline $7: 52: 10$ & 3234 & 3104 & 3960 & 4235 & -203 & 334 & 203 & 0 \\
\hline $7: 52: 11$ & 3162 & 2915 & 3394 & 4032 & 73 & 189 & 566 & 203 \\
\hline $7: 52: 12$ & 3684 & 2901 & 3249 & 4206 & -522 & 15 & 145 & -174 \\
\hline $7: 52: 13$ & 3945 & 3104 & 2872 & 4206 & -261 & -203 & 377 & 0 \\
\hline $7: 52: 14$ & 4380 & 3118 & 2683 & 3263 & -435 & -15 & 189 & 943 \\
\hline $7: 52: 15$ & 4583 & 3626 & 2683 & 2770 & -203 & -508 & 0 & 493 \\
\hline $7: 52: 16$ & 4757 & 4076 & 2944 & 2596 & -174 & -450 & -261 & 174 \\
\hline $7: 52: 17$ & 4757 & 4250 & 3814 & 2915 & 0 & -174 & -870 & -319 \\
\hline $7: 52: 18$ & 4467 & 4641 & 3814 & 2915 & 290 & -392 & 0 & 0 \\
\hline $7: 52: 19$ & 4583 & 4815 & 4076 & 3205 & -116 & -174 & -261 & -290 \\
\hline $7: 52: 20$ & 4656 & 4888 & 4583 & 3423 & -73 & -73 & -508 & -218 \\
\hline $7: 52: 21$ & 4511 & 4351 & 4583 & 3423 & 145 & 537 & 0 & 0 \\
\hline
\end{tabular}

Note: the units for all values except time are psi

The following three figures are 2-4 minute sections of the field study data set. They contain the pump pressure and the four inline pressure measurements. Each of the charts has a slightly different look to them, thus capturing several different occurrences at the face. 


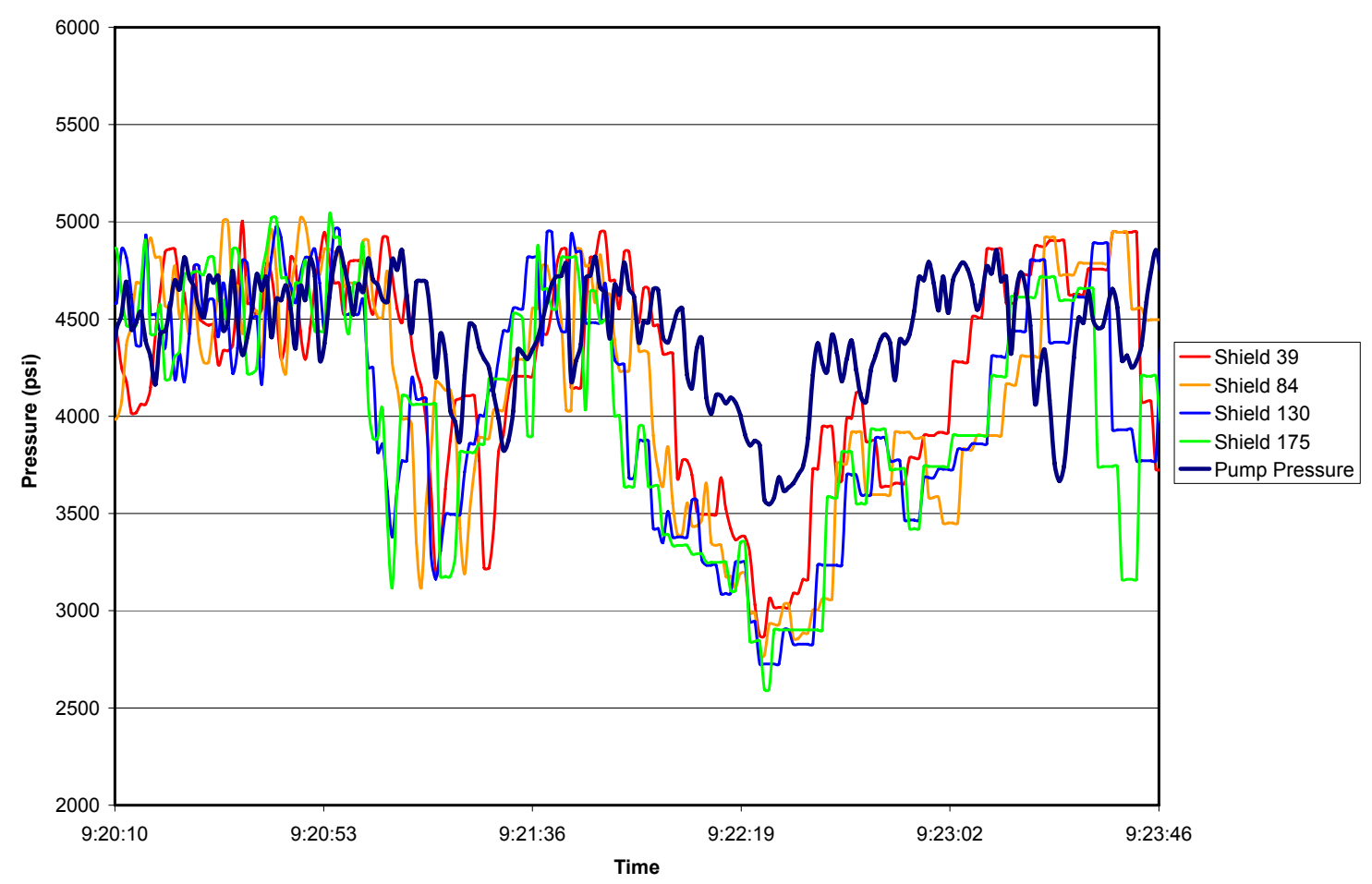

Figure 6-8, Pressure data from field study

The preceding figure shows the relationship of the pump pressure to the pressure at the four locations in the main pressure line along the face. In this figure, there are a few distinct pressure drops in the system. During one of these, the pump pressure is distinctly above the rest of the pressure readings as expected. The rest of the chart shows numerous points where at least one of the mainline pressures is above the pump pressure, about $50 \%$ of the time. This excursion is not physically possible and can only be explained as an error in the monitoring system. This error could be related to the time delays between the two data logging systems. It could also be associated with the sampling rate. 


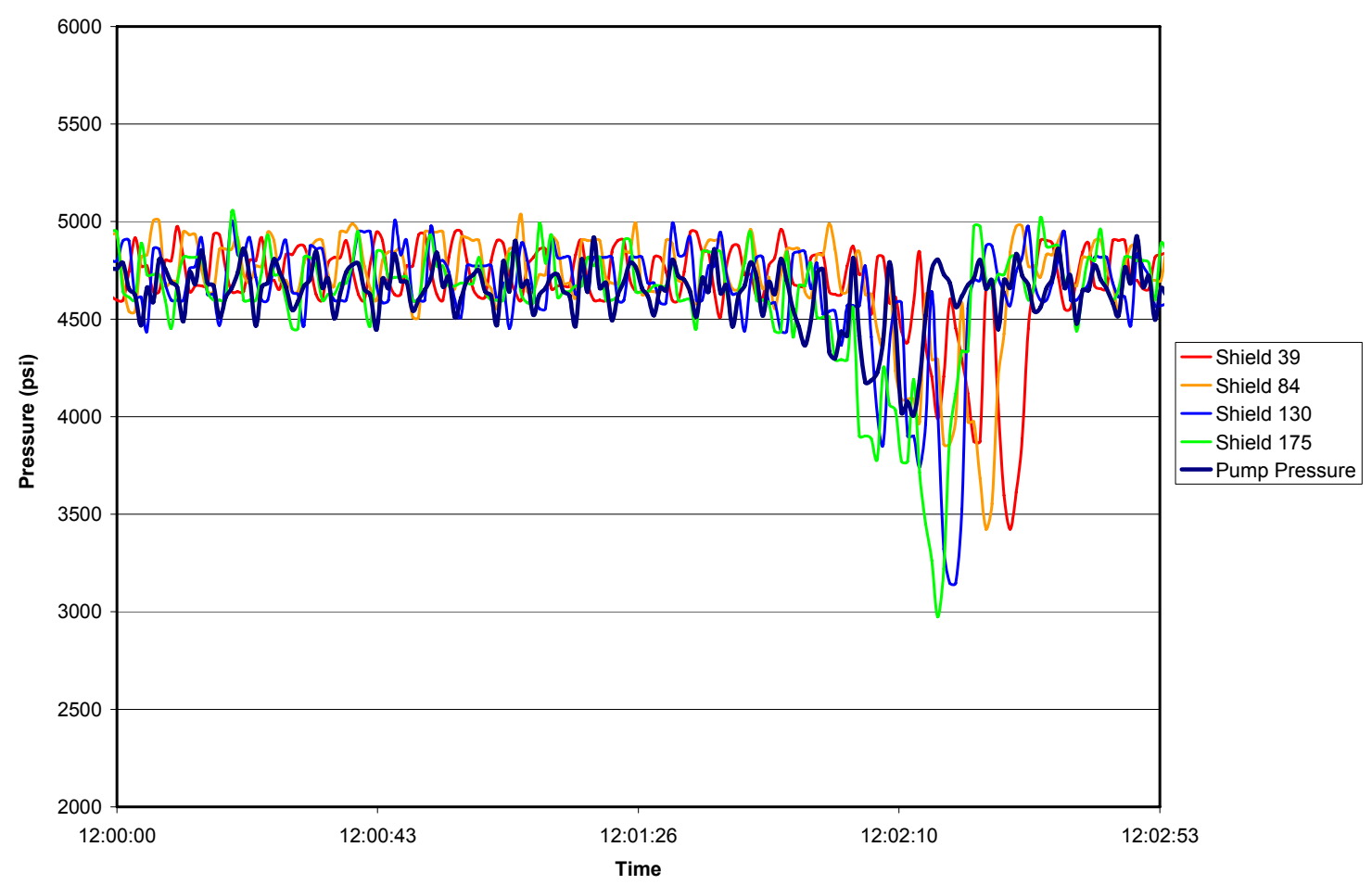

Figure 6-9, Pressure data from field study, second sample

Figure 6-9 is the second of three sections of data from the field study. Figure 6-9 is much more representative of a divergence from expected values and generally presents data points that are physically unlikely or impossible. In this chart there appear to be only a few instances when the pump pressure actually exceeds all the mainline pressure measurements. 


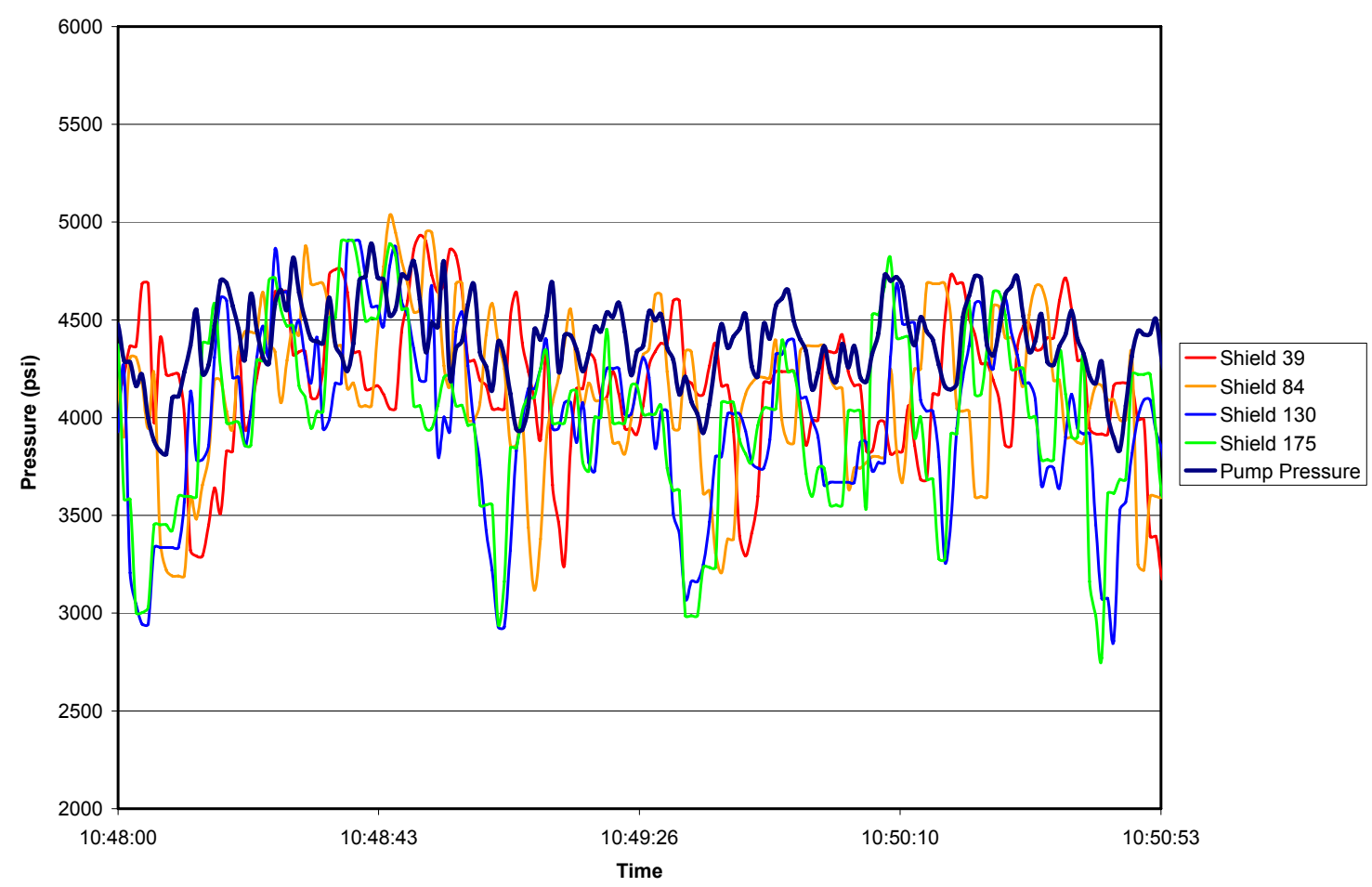

Figure 6-10, Pressure data from field study, third sample

The preceding figure is the last of three sections of data extracted from the field study. Once again, there are numerous occasions when the pump pressure is lower than the mainline pressure measurements. This particular figure appears to have higher pump pressure measurements about $50 \%$ of the time. This again represents a highly problematic data set. 


\section{CHAPTER 7: CONCLUSIONS}

This section discusses the implication of the results from the previous sections, including the initial model design, the field study, and the model calibration. The limitations of the study are also presented. Lastly, the future research needed in this area will be discussed.

\subsection{DISCUSSION}

\subsubsection{Initial Model Design}

The initial model design was straight forward and represented the results found in previous research quite well. Through continued use of the model, additional techniques will be discovered allowing for much faster hydraulic system evaluations. It was also discovered that the model lacked the ability to fully represent the complexity of the pump station in that the pump station is designed to be a dynamic system whereas the model is a static system.

\subsubsection{Field Study}

There were a number of issues that caused the data collection to be less than optimal. The problems associated with the data collection are as follows:

1. Too few flow meters
a. No flow meters along face
b. No flow meters in panline
c. No flow meters in ladders 
2. Too few mainline pressure transducers

a. No pressure transducers in panline

b. No pressure transducers in monorail

3. Time lag of data logging system along the face

a. Approximately a 6 second delay

4. Multiple data logging systems

a. Different time stamping between two systems

b. Potentially different sampling scheme

5. Sampling rate too slow

a. Sampling once per second

6. Pressure transducers low accuracy $\pm 5 \%$

7. Too many variables for points collected

a. Different connection types

b. Filters

C. Pump station components

Although data collection was less than optimal, the field study showed numerous interesting results. They all were related to the operation of the hydraulic supply system, but did not allow for the primary research objective to be completed. One of the more interesting outcomes of the field study is that the hydraulic supply system has leaks at about $70 \%$ of the shields. Also, the setting load on the shields drops upon each adjacent shield setting. This load shedding also occurs up to three shields away.

An accurate setting pressure determination was also quite elusive in the field study data, in that the resolution of the data was not such that an exact setting pressure could be measured. 
The field study also showed the speed that the system changes. Pressure changes in excess of 900 psi were observed within a one second sampling interval. This leads to the necessity of increasing the frequency of data collection. These pressure changes are illustrated in Table 4-30.

\subsubsection{Model Calibration}

The model calibration demonstrated the complexity of an operational longwall hydraulic supply system, showing the necessity of an initial laboratory study as well as a much more dynamic field study. The calibration proved to be difficult even when using a small number of measurement points along the face. There were several points in time where the pressure along the face actually exceeded that of the pump station, which is either physically impossible or demonstrates the extreme dynamic nature of an operating longwall hydraulic supply system. At other times, there were pressures higher than reasonably expected at varying positions along the face.

Further complications associated with this study centered on the dynamic nature of the complex network. The following is a list of the system components and operational procedures that cause that dynamic nature:

1. Positive set scheme

a. Shield may be setting multiple times

2. Expansion/contraction of hoses

a. Hoses can expand with increasing pressure slightly damping flow changes

3. Positive displacement pumps

a. Delayed shut off and start up

b. Pulsating pressure output 
$\begin{array}{ll}\text { 4. } & \text { Accumulators } \\ \text { 5. Leakage }\end{array}$

a. Flow at unknown locations

6. Resetting of shields

7. Pan pushes while shield setting

8. Changing flow rates over the shield cycling

9. Filters

a. Pressure loss across filters changes with time and flow rate

\subsection{LIMITATIONS OF THE STUDY}

Some of the most noteworthy results led to shortcomings of this study. These limitations span from the equipment to the methods. For example, the instrumentation used does not have the necessary resolution or accuracy to determine the roughness coefficients from the field study. Although the instrumentation lacked resolution and accuracy, it showed the necessity of a laboratory study to determine the roughness coefficients. The hydraulic supply system is extremely dynamic and has several components that cause ideal calculations to be very difficult to complete in a producing longwall environment. These components were listed in the previous section.

The active longwall environment caused several other discrepancies which are realistic, but are too disruptive at this stage of the project. The variations in shield setting times, order, number, and the concurrent pan advances led to extremely fast variations in pressure and flow requirements for the hydraulic supply system.

One of the initial goals of this thesis was to have a working model capable of evaluating changes to an existing longwall hydraulic supply system. Due to the fact that the model 
calibration could not be completed with the data available at this time, the effects of various changes to the system can only be evaluated on a limited scale. In order to even attempt to determine the effects of varying design conditions, several assumptions had to be made. One of these is that the previous research performed by Peter Migenda and Bernd Fusser (2006) is deemed correct. Based on their findings, an increase in longwall width would be best accommodated by replacing the hoses in the monorail and on the panline with pipes of similar dimensions. Also, increasing the size of the shield-shield, garland hoses, and adding additional ladders would allow for lower pressure losses with higher flow rates. Regardless of the cause of the higher flow rates, the changes mentioned above can be used to limit the effects of higher flow rates.

From the results of the scenario analysis, replacing the monorail hose with a pipe lowers the pressure losses across the whole face. The scenario analysis also showed that utilizing a pipe in the panline will lower the pressure losses along most of the face. The pressure losses closest to the headgate were impacted the least by replacing the panline hose with a pipe. The last result demonstrated by the scenario analysis is the impact of adding additional ladders to the hydraulic supply system. By adding additional ladders, the pressure losses between the previously existing systems ladders are lowered, but the pressure losses closest to the previously installed ladders remains almost constant. 


\subsection{FUTURE RESEARCH AND MODEL ENHANCEMENTS}

To further this research, there are two additional steps that should be considered. These two steps include a laboratory study, to determine the roughness coefficients, and a field study with instrumentation with greater accuracy and data logging at a higher resolution or sampling rate. The laboratory study is the first step in advancing this research. The laboratory study should involve collecting sample hoses of the various sizes used in the longwall hydraulic supply system. Then a simple test will be setup using pressure transducers, flow meters, data acquisition system, and a pump, as illustrated in Figure 7-1.

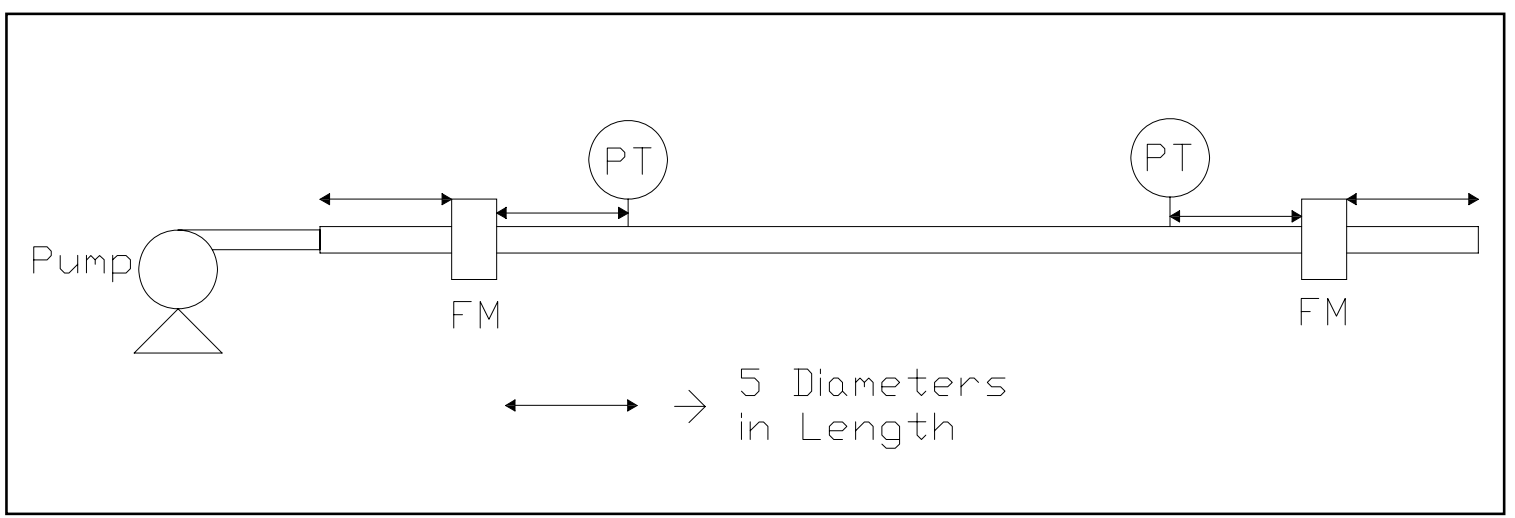

Figure 7-1, Laboratory test setup, straight hose

It would be beneficial to use as long a section of hose as possible to most accurately determine the roughness coefficient. Several different configurations of the hose should be evaluated to simulate the different conditions in the longwall mine. For example, a scenario with the hose fully coiled and with the hose fully extended, as shown in Figure 7-2, should be evaluated. 


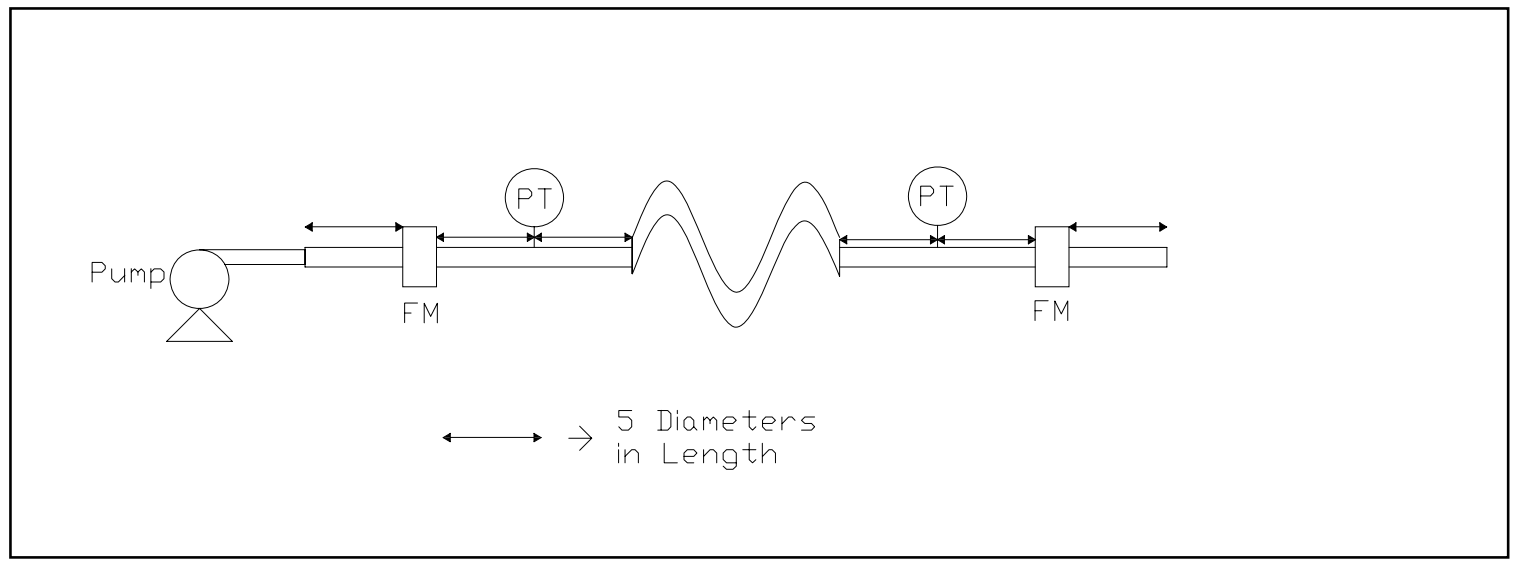

\section{Figure 7-2, Laboratory test setup, snaked hose}

The test setup should include a flow meter at the beginning and end of the hose section, but at least 5 diameters away from any flow changing component. Pressure transducers must also be placed within the flow meter with the same diameter distance from flow changing components. The pump should be at one end of the hose section and a collection tank should be at the other.

The test sequence should include various pressures and flows, depending on the available pump, but should include realistic flow rates and pressures. It may be necessary to divert some of the flow in order to lower the flow rates and/or connect an adjustable nozzle to the exit side of the hose.

The next step would be to perform a modified field study. The modified field study should include many of the same measurements as performed in this thesis. The measurement equipment must be more accurate and the data logging system must have a higher resolution. The details of the collection method could be adopted from those found in the field study description in the methods chapter. 
The instrumentation required for this modified field study is similar to that of the laboratory study. The pressure transducers need to have less than a $1 \%$ error in order to see the variation of flow and pressure at low flow rates. The flow meters must also have a similar error. The data acquisition system must be capable of sampling at a frequency of $100 \mathrm{~Hz}$ and recording these measurements for at least a full shift. 


\section{BIBLIOGRAPHY}

Ashwin, D.P., S.G. Campbell, J.D. Kible, J.D. Haskayne, J.F.A. Moorte, and R. Shepherd. "Some fundamental aspects of face powered support design," The Mining Engineer, August 1970, 659-675.

Bader, S., R. Mendoza, S. Kieffer, M. Salamon, and U. Ozbay. "Numerical modeling of longwalls in deep coal mines," Proceedings: $22^{\text {nd }}$ International Conference on Ground Control in Mining, August 2003, 37-43.

Barczak, T.M. "A retrospective assessment of longwall roof support with a focus on challenging accepted roof support concepts and design premises," Proceedings: $25^{\text {th }}$ International Conference on Ground Control in Mining, August 2006.

Barczak, T.M. and D.Conover. "The NIOSH shield hydraulics inspection and evaluation of leg data (shield) computer program," Proceedings: $21^{\text {st }}$ Conference on Ground Control in Mining, August 2002, 27-38.

Barczak, T.M. "Modern shield technology: Better than ever but still not perfect," Proceedings: $18^{\text {th }}$ Conference on Ground Control in Mining, August 1999, 149-163.

Barczak, T.M. and D. Gearhart. "Performance and safety considerations of hydraulic support systems," Proceedings: $17^{\text {th }}$ Conference on Ground Control in Mining, August 1998, 176186.

Barczak, T.M. "Design and operation of powered roof support systems for longwall mining," U.S. Department of Interior, Bureau of Mines, IC 9320, 1992, 14p.

Barczak, T.M. "The history and future of longwall mining in the United States," U.S.

Department of Interior, Bureau of Mines, IC 9316, 1992, 26pp.

Barczak, T.M. and D.E. Schwemmer. "Stiffness characteristics of longwall shields," U.S. Department of Interior, Bureau of Mines, RI 9154, 1988, 14pp.

Bassier, R. and P. Migenda. "Planning of shield hydraulic systems for high performance longwalls," presentation provided by Dr. Syd Peng, West Virginia University, October 2006.

Bates, J. "An analysis of powered support behavior," The Mining Engineer, June 1978, 681694.

Benedict, R.P. Fundamentals of Pipe Flow, John Wiley \& Sons, New York, 1980, 531pp.

Chen, J., M. Mishra, E. Zahl, J. Dunford, and R. Thompson. "Longwall mining-induced abatement loads and their impacts on pillar and entry stability," Proceedings: $21^{\text {st }}$ International Conference on Ground Control in Mining, August 2002, 11-17.

Crane Company. "Flow of fluids through valves, fittings, and pipe" Technical Paper 410, Crane Company, 1981.

Cross, H. "Analysis of flow in networks of conduits and conductors," Univ. III. Eng. Exp. Stn. Bull. 286, November 1936

Das, S.K. "Observations and classification of roof strata behaviour over longwall coal mining panels in India," International Journal of Rock Mechanics and Mining Sciences, Vol. 37, 2000, 585-597. 
Fusser, B. "Requirements for an optimum hydraulic system resulting from the productivity increase in longwall faces," presentation provided by Dr. Syd Peng, West Virginia University, October 2006.

Gupta, R.N. and I.W. Farmer. "Relations between strata deformation and support performance on longwall faces," Strata Mechanics: Developments in Geotechnical Engineering, Vol. 32, 1982, 74-81.

Gupta, R.N. and I.W. Farmer. "Interaction between roof and support on longwall faces with particular reference to support resistance," Proceedings: $4^{\text {th }}$ Conference on Ground Control in Mining, July 1985, 58-77.

Graham, J.J. "A review of some recent powered support developments," The Mining Engineer, June 1978, 665-679.

Graham, J.M. "Control valve systems," Colliery Guardian Coal International, July 1980, 4146.

Green, A.R. "Safety in mines research," Proceedings: $21^{\text {st }}$ International Conference of Safety in Mines Research Institutes, October 1985, 33-38

Hart, W.M. and S.S. Peng. "Longwall production, maintenance, and roof control system," Proceedings: $13^{\text {th }}$ Conference on Ground Control in Mining, August 1994, 136-147.

Heasley, K., P. Worley, and Y. Zhang. "Stress analysis and support design for longwall mine-through entries (a case study)," Proceedings:22 ${ }^{\text {nd }}$ International Conference on Ground Control in Mining, August 2003, 11-18.

Hebblewhite, B.K., and T. Lu. "Geomechanical behaviour of laminated, weak coal mine roof strata and the implications for a ground reinforcement strategy," International Journal of Rock Mechanics and Mining Sciences, Vol. 41, 2004, 147-157.

Holla, L. "Ground movement due to longwall mining in high relief areas in New South Wales, Australia," International Journal of Rock Mechanics and Mining Sciences, Vol. 34 No.5, 1997, 775-787.

Hydraulic Institute, Engineering Data Book, Hydraulic Institute, Second Edition, New Jersey, 1990

Jacobi, O. "The increase of roof flaking in longwall faces as a result of working under pillar edges and of abutment pressure of adjacent workings," International Journal of Rock Mechanics and Mining Sciences, Vol. 3, 1966, 221-230.

Keim, K.S. and M.S. Miller. "Case study evaluation of geological influences impacting mining conditions at a West Virginia longwall mine," International Journal of Coal Geology, Vol. 44, 1999, 51-71.

Kelly, M., X. Luo, and S. Craig. "Integrating tools for longwall geomechanics assessment," International Journal of Rock Mechanics and Mining Sciences, Vol. 39, 2002, 661-676.

Kim, J-M., R.R. Parizek, and D. Elsworth. "Evaluation of fully-coupled strata deformation and groundwater flow in response to longwall mining," International Journal of Rock Mechanics and Mining Sciences, Vol. 34 No. 8, 1997, 1187-1199.

Massey, C.T. "Changes in roof support equipment," Colliery Guardian Annual Review, August 1980, 343-347. 
Opolony, K. and W. Holger. "Comparison of multiple and single entry roadways for highly stressed longwalls," Proceedings:22 ${ }^{\text {nd }}$ International Conference on Ground Control in Mining, August 2003, 33-36.

Peng, S.S. Longwall Mining, West Virginia University, Second Edition, West Virginia, 2006, $621 \mathrm{pp}$.

Peng, S.S. "Design of active horizontal force for shield supports for controlling roof falls," The Mining Engineer, June 1990, 457-461.

Peng, S.S. and H.S. Chiang. Longwall Mining, John Wiley and Sons, 1984, 708pp.

Peng, S.S. and H.S. Chiang. "Roof stability in longwall coal faces," Proceedings: $1^{\text {st }}$ International Conference on Stability in Underground Mining, 1982, 295-335.

Peng, S.S. and H.S. Chiang. "Support resistance and roof behavior of a longwall face with 4-leg shields." Proceedings: $2^{\text {nd }}$ Conference on Ground Control in Mining, July 1982, 53-63.

Price, R.J. and M.H.B. Pickering. "Application of higher setting loads to powered supports in South Notts area," The Mining Engineer, May 1981, 841-848.

Reddish, D.J., L. R. Stace, and D.N. Whittles. "The utilization of numerical modeling to predict water and gas flows around longwall panels; two case studies from the UK coal mining industry," Proceedings: $22^{\text {nd }}$ International Conference on Ground Control in Mining. August 2003, 19-26.

Shepherd, R. and D.P. Ashwin. "Measurement and interpretation of strata behavior on mechanized faces," Colliery Guardian, December 1968, 795-804.

Singh, K.B. and T.N. Singh. "Ground movements over longwall workings in the Kamptee coalfield, India," Engineering Geology, Vol. 50, 1998, 125-139.

Singh, M.M. and F.S. Kendorski. "Strata disturbance prediction for mining beneath surface water and waste impoundments," Proceedings: $1^{\text {st }}$ Conference on Ground Control in Mining, July 1981, 76-89.

Streeter, V.L. (ed) Handbook of fluid dynamics, McGraw-Hill, New York, 1961.

Su, D., T.J. Morris, and J. McCaffrey. "Influence of structural stress concentration and structural irregularity on longwall gateroad roof control," Proceedings: $21^{\text {st }}$ International Conference on Ground Control in Mining, August 2002, 18-26.

Su, D.W.H., D.J. Draskovich, and E.P. Thomas. "Pillar design and roof support for controlling longwall headgate subject to high horizontal stresses," $22^{\text {nd }}$ International Conference on Ground Control in Mining, August 2003, 1-9.

Su, W.H. and S.S. Peng. "Cutter roof and its causes," Mining Science and Technology, Vol. 4, 1987, 113-132.

Tadolini, S., Y. Zhang, and S. Peng. "Pre-driven experimental longwall recovery room under weak roof conditions- design, implementation, and evaluation," $21^{\text {st }}$ International Conference on Ground Control in Mining, August 2002, 1-10.

Trueman, R., G. Lyman, M. Callan, and B. Robertson. "Assessing longwall support-roof interaction from shield leg pressure data," Mining Technology, Vol. 114, September 2005, A176-A184. 
Unver, B. and N.E. Yasitli. "Modelling of strata movement with a special reference to caving mechanism in thick seam coal mining," International Journal of Coal Geology, (66) 2006, 227-252.

Wilson, A.H. "Conclusions from recent strata control measurements made by the Mining Research Establishment," The Mining Engineer, April 1964, 367-380.

Wilson, A.H. "Support load requirements on longwall faces," The Mining Engineer, June 1975, 480-491.

$\mathrm{Xu}, \mathrm{J} ., \mathrm{M}$. Gian, and H. Yu. "The characteristics of mining-induced fractures in overlying strata," $22^{\text {nd }}$ International Conference on Ground Control in Mining, August 2003, 44-47.

Yavuz, $\mathrm{H}$. "An estimation method for cover pressure re-establishment distance and pressure distribution in the goaf of longwall coal mines," International Journal of Rock Mechanics and Mining Sciences, Vol. 41, 2004, 193-205.

Young, D.F., B. Munson, and T. Okiishi. A brief introduction to fluid mechanics John Wiley and Sons, New York, 2001, 500pp. 
APPENDIX A: Distributions of Field Study Results 
Table A-1, Pressure distribution of Shield 175, May 112007 12:00 a.m. to May 12 2007 8:00 a.m.

\begin{tabular}{|c|c|c|c|c|}
\hline \multicolumn{2}{|c|}{ Pressure (psi) } & Frequency & Percent & Cumulative Percent \\
\hline Minimum & Maximum & 2692 & 2.34 & 2.34 \\
3000.01 & 3000 & 2186 & 1.90 & 4.24 \\
3500.01 & 3500 & 974 & 0.85 & 5.08 \\
3600.01 & 3600 & 1144 & 0.99 & 6.08 \\
3700.01 & 3700 & 1558 & 1.35 & 7.43 \\
3800.01 & 3800 & 1823 & 1.58 & 9.01 \\
3900.01 & 3900 & 2980 & 2.59 & 11.60 \\
4000.01 & 4000 & 3330 & 2.89 & 14.49 \\
4100.01 & 4100 & 3826 & 3.32 & 17.82 \\
4200.01 & 4200 & 4807 & 4.17 & 21.99 \\
4300.01 & 4300 & 5786 & 5.03 & 27.01 \\
4400.01 & 4400 & 8291 & 7.20 & 34.22 \\
4500.01 & 4500 & 15109 & 13.12 & 47.34 \\
4600.01 & 4600 & 18678 & 16.22 & 63.56 \\
4700.01 & 4700 & 11876 & 10.31 & 73.87 \\
4800.01 & 4800 & 15281 & 13.27 & 87.14 \\
4900.01 & 4900 & 13290 & 11.54 & 98.69 \\
5000.01 & 5000 & 1512 & 1.31 & 100.00 \\
5100.01 & 5100 & 1 & 0.00 & 100.00 \\
\hline
\end{tabular}

Table A-2, Pressure distribution of Shield 130, May 112007 12:00 a.m. to May 12 2007 8:00 a.m.

\begin{tabular}{|c|c|c|c|c|}
\hline \multicolumn{2}{|c|}{ Pressure (psi) } & \multirow{2}{*}{ Frequency } & Percent & Cumulative Percent \\
\hline Minimum & Maximum & 2460 & 2.14 & 2.14 \\
3000.01 & 3000 & 2179 & 1.89 & 4.03 \\
3500.01 & 3500 & 996 & 0.87 & 4.90 \\
3600.01 & 3600 & 1187 & 1.03 & 5.93 \\
3700.01 & 3700 & 1722 & 1.50 & 7.42 \\
3800.01 & 3800 & 1867 & 1.62 & 9.05 \\
3900.01 & 3900 & 3020 & 2.62 & 11.67 \\
4000.01 & 4000 & 3283 & 2.85 & 14.52 \\
4100.01 & 4100 & 3863 & 3.36 & 17.88 \\
4200.01 & 4200 & 4897 & 4.26 & 22.14 \\
4300.01 & 4300 & 5493 & 4.77 & 26.91 \\
4400.01 & 4400 & 9484 & 8.24 & 35.15 \\
4500.01 & 4500 & 15962 & 13.87 & 49.02 \\
4600.01 & 4600 & 17592 & 15.29 & 64.31 \\
4700.01 & 4700 & 15915 & 13.83 & 78.13 \\
4800.01 & 4800 & 16429 & 14.28 & 92.41 \\
4900.01 & 4900 & 8468 & 7.36 & 99.77 \\
5000.01 & 5000 & 266 & 0.23 & 100.00 \\
5100.01 & 5100 & 0 & 0.00 & 100.00 \\
\hline
\end{tabular}


Table A-3, Pressure distribution of Shield 84, May 112007 12:00 a.m. to May 12 2007 8:00 a.m.

\begin{tabular}{|c|c|c|c|c|}
\hline \multicolumn{2}{|c|}{ Pressure (psi) } & \multirow{2}{*}{ Frequency } & Percent & Cumulative Percent \\
\hline Minimum & Maximum & 2317 & 2.01 & 2.01 \\
3000.01 & 3000 & 1604 & 1.39 & 3.41 \\
3500.01 & 3500 & 852 & 0.74 & 4.15 \\
3600.01 & 3600 & 875 & 0.76 & 4.91 \\
3700.01 & 3700 & 1300 & 1.13 & 6.03 \\
3800.01 & 3800 & 1508 & 1.31 & 7.34 \\
3900.01 & 3900 & 2556 & 2.22 & 9.56 \\
4000.01 & 4000 & 2989 & 2.60 & 12.16 \\
4100.01 & 4100 & 3556 & 3.09 & 15.25 \\
4200.01 & 4200 & 4808 & 4.18 & 19.42 \\
4300.01 & 4300 & 4711 & 4.09 & 23.51 \\
4400.01 & 4400 & 5574 & 4.84 & 28.36 \\
4500.01 & 4500 & 12129 & 10.53 & 38.89 \\
4600.01 & 4600 & 19004 & 16.50 & 55.39 \\
4700.01 & 4700 & 14013 & 12.17 & 67.56 \\
4800.01 & 4800 & 20729 & 18.00 & 85.57 \\
4900.01 & 4900 & 14489 & 12.58 & 98.15 \\
5000.01 & 5000 & 2129 & 1.85 & 100.00 \\
5100.01 & 5100 & 1 & 0.00 & 100.00 \\
\hline
\end{tabular}

Table A-4, Pressure distribution of Shield 39, May 112007 12:00 a.m. to May 12 2007 8:00 a.m.

\begin{tabular}{|c|c|c|c|c|}
\hline \multicolumn{2}{|c|}{ Pressure (psi) } & Frequency & Percent & Cumulative Percent \\
\hline Minimum & Maximum & 2223 & 1.93 & 1.93 \\
3000.01 & 3000 & 1395 & 1.21 & 3.14 \\
3500.01 & 3500 & 730 & 0.63 & 3.78 \\
3600.01 & 3600 & 881 & 0.77 & 4.54 \\
3700.01 & 3700 & 1161 & 1.01 & 5.55 \\
3800.01 & 3800 & 1512 & 1.31 & 6.86 \\
3900.01 & 3900 & 2597 & 2.26 & 9.12 \\
4000.01 & 4000 & 3005 & 2.61 & 11.73 \\
4100.01 & 4100 & 3742 & 3.25 & 14.98 \\
4200.01 & 4200 & 5247 & 4.56 & 19.53 \\
4300.01 & 4300 & 5140 & 4.46 & 24.00 \\
4400.01 & 4400 & 5865 & 5.09 & 29.09 \\
4500.01 & 4500 & 14437 & 12.54 & 41.63 \\
4600.01 & 4600 & 22670 & 19.69 & 61.32 \\
4700.01 & 4700 & 13126 & 11.40 & 72.72 \\
4800.01 & 4800 & 23053 & 20.02 & 92.74 \\
4900.01 & 4900 & 8302 & 7.21 & 99.95 \\
5000.01 & 5000 & 58 & 0.05 & 100.00 \\
5100.01 & 5100 & 0 & 0.00 & 100.00 \\
\hline
\end{tabular}


Table A-5, Pump Pressure distribution, May 112007 12:00 a.m. to May 12 2007 8:00 a.m.

\begin{tabular}{|c|c|c|c|c|}
\hline \multicolumn{2}{|c|}{ Pressure (psi) } & \multirow{2}{*}{ Frequency } & \multirow{2}{*}{ Percent } & \multirow{2}{*}{ Cumulative Percent } \\
\hline Minimum & Maximum & & & \\
\hline-1000 & 3000 & 6013 & 5.23 & 5.23 \\
\hline 3000.01 & 3500 & 171 & 0.15 & 5.38 \\
\hline 3500.01 & 3600 & 82 & 0.07 & 5.45 \\
\hline 3600.01 & 3700 & 139 & 0.12 & 5.57 \\
\hline 3700.01 & 3800 & 174 & 0.15 & 5.72 \\
\hline 3800.01 & 3900 & 343 & 0.30 & 6.02 \\
\hline 3900.01 & 4000 & 548 & 0.48 & 6.50 \\
\hline 4000.01 & 4100 & 1050 & 0.91 & 7.41 \\
\hline 4100.01 & 4200 & 2904 & 2.53 & 9.94 \\
\hline 4200.01 & 4300 & 5017 & 4.36 & 14.30 \\
\hline 4300.01 & 4400 & 6755 & 5.88 & 20.18 \\
\hline 4400.01 & 4500 & 14205 & 12.36 & 32.53 \\
\hline 4500.01 & 4600 & 16938 & 14.73 & 47.26 \\
\hline 4600.01 & 4700 & 30003 & 26.10 & 73.36 \\
\hline 4700.01 & 4800 & 21256 & 18.49 & 91.85 \\
\hline 4800.01 & 4900 & 8724 & 7.59 & 99.44 \\
\hline 4900.01 & 5000 & 647 & 0.56 & 100.00 \\
\hline 5000.01 & 5100 & 0 & 0.00 & 100.00 \\
\hline 5100.01 & 5200 & 0 & 0.00 & 100.00 \\
\hline 5200.01 & 5300 & 1 & 0.00 & 100.00 \\
\hline 5300.01 & 5400 & 0 & 0.00 & 100.00 \\
\hline 5400.01 & 5500 & 0 & 0.00 & 100.00 \\
\hline 5500.01 & 5600 & 0 & 0.00 & 100.00 \\
\hline
\end{tabular}


Table A-6, Flow distribution Flow 2, May 112007 12:00 a.m. to May 122007 8:00 a.m.

\begin{tabular}{|c|c|c|c|c|}
\hline \multicolumn{2}{|c|}{ Flow (gpm) } & \multirow{2}{*}{ Frequency } & Percent & Cumulative Percent \\
\cline { 1 - 2 } Minimum & Maximum & & 8.17 & 8.17 \\
10.01 & 10 & 9397 & 23.45 & 31.62 \\
20.01 & 20 & 26961 & 28.61 & 60.23 \\
30.01 & 30 & 6500 & 5.72 & 65.96 \\
40.01 & 40 & 6287 & 5.47 & 71.42 \\
50.01 & 50 & 6594 & 5.73 & 77.16 \\
60.01 & 60 & 7593 & 6.60 & 83.76 \\
70.01 & 70 & 7309 & 6.36 & 90.12 \\
80.01 & 80 & 4818 & 4.19 & 94.31 \\
90.01 & 90 & 2791 & 2.43 & 96.74 \\
100.01 & 100 & 1934 & 1.68 & 98.42 \\
110.01 & 110 & 1146 & 1.00 & 99.42 \\
120.01 & 120 & 364 & 0.32 & 99.73 \\
130.01 & 130 & 181 & 0.16 & 99.89 \\
140.01 & 140 & 82 & 0.07 & 99.96 \\
150.01 & 150 & 45 & 0.04 & 100.00 \\
\hline
\end{tabular}

Table A-7, Flow distribution Flow 1, May 112007 12:00 a.m. to May 122007 8:00 a.m.

\begin{tabular}{|c|c|c|c|c|}
\hline \multicolumn{2}{|c|}{ Flow (gpm) } & \multirow{2}{*}{ Frequency } & Percent & Cumulative Percent \\
\cline { 1 - 2 } Minimum & Maximum & & 5.14 & 5.14 \\
10.01 & 10 & 5934 & 12.89 & 18.04 \\
20.01 & 20 & 14872 & 36.83 & 54.87 \\
30.01 & 30 & 42482 & 5.94 & 60.81 \\
40.01 & 40 & 4850 & 4.25 & 65.06 \\
50.01 & 50 & 4898 & 4.24 & 69.29 \\
60.01 & 60 & 4769 & 4.13 & 73.43 \\
70.01 & 70 & 5061 & 4.39 & 77.82 \\
80.01 & 80 & 5574 & 4.83 & 82.65 \\
90.01 & 90 & 5711 & 4.95 & 87.60 \\
100.01 & 100 & 4924 & 4.27 & 91.87 \\
110.01 & 110 & 3142 & 2.72 & 94.59 \\
120.01 & 120 & 2046 & 1.77 & 96.37 \\
130.01 & 130 & 1501 & 1.30 & 97.67 \\
140.01 & 140 & 1162 & 1.01 & 98.68 \\
150.01 & 150 & 1527 & 1.32 & 100.00 \\
\hline
\end{tabular}


Table A-8, Pressure distribution of Shield 175, May 122007 4:00 p.m. to May 13 2007 11:59 p.m.

\begin{tabular}{|c|c|c|c|c|}
\hline \multicolumn{2}{|c|}{ Pressure (psi) } & \multirow{2}{*}{ Frequency } & Percent & Cumulative Percent \\
\cline { 1 - 2 } Minimum & Maximum & 9066 & 7.88 & 7.88 \\
3000.01 & 3000 & 1439 & 1.25 & 9.13 \\
3500.01 & 3500 & 572 & 0.50 & 9.63 \\
3600.01 & 3600 & 755 & 0.66 & 10.28 \\
3700.01 & 3700 & 1027 & 0.89 & 11.17 \\
3800.01 & 3800 & 1252 & 1.09 & 12.26 \\
3900.01 & 3900 & 2106 & 1.83 & 14.09 \\
4000.01 & 4000 & 2760 & 2.40 & 16.49 \\
4100.01 & 4100 & 3290 & 2.86 & 19.35 \\
4200.01 & 4200 & 4276 & 3.72 & 23.06 \\
4300.01 & 4300 & 4847 & 4.21 & 27.28 \\
4400.01 & 4400 & 7704 & 6.69 & 33.97 \\
4500.01 & 4500 & 14116 & 12.27 & 46.24 \\
4600.01 & 4600 & 20581 & 17.88 & 64.12 \\
4700.01 & 4700 & 13114 & 11.40 & 75.51 \\
4800.01 & 4800 & 18029 & 15.67 & 91.18 \\
4900.01 & 4900 & 8487 & 7.37 & 98.55 \\
5000.01 & 5000 & 1659 & 1.44 & 100.00 \\
5100.01 & 5100 & 4 & 0.00 & 100.00 \\
\hline
\end{tabular}

Table A-9, Pressure distribution of Shield 130, May 122007 4:00 p.m. to May 13 11:59 p.m.

\begin{tabular}{|c|c|c|c|c|}
\hline \multicolumn{2}{|c|}{ Pressure (psi) } & \multirow{2}{*}{ Frequency } & Percent & Cumulative Percent \\
\cline { 1 - 2 } Minimum & Maximum & 8332 & 7.24 & 7.24 \\
3000.01 & 3000 & 1441 & 1.25 & 8.49 \\
3500.01 & 3500 & 650 & 0.56 & 9.06 \\
3600.01 & 3600 & 731 & 0.64 & 9.69 \\
3700.01 & 3700 & 1078 & 0.94 & 10.63 \\
3800.01 & 3800 & 1283 & 1.11 & 11.74 \\
3900.01 & 3900 & 2213 & 1.92 & 13.67 \\
4000.01 & 4000 & 2629 & 2.28 & 15.95 \\
4100.01 & 4100 & 3350 & 2.91 & 18.86 \\
4200.01 & 4200 & 4414 & 3.84 & 22.70 \\
4300.01 & 4300 & 4450 & 3.87 & 26.56 \\
4400.01 & 8491 & 7.38 & 33.94 \\
4500.01 & 4400 & 15356 & 13.34 & 47.29 \\
4600.01 & 4500 & 20508 & 17.82 & 65.11 \\
4700.01 & 4600 & 12902 & 11.21 & 76.32 \\
4800.01 & 4700 & 18871 & 16.40 & 92.71 \\
4900.01 & 4800 & 8038 & 6.98 & 99.70 \\
5000.01 & 4900 & 346 & 0.30 & 100.00 \\
5100.01 & 5000 & 1 & 0.00 & 100.00 \\
\hline
\end{tabular}


Table A-10, Pressure distribution of Shield 84, May 122007 4:00 p.m. to May 13 2007 11:59 p.m.

\begin{tabular}{|c|c|c|c|c|}
\hline \multicolumn{2}{|c|}{ Pressure (psi) } & Frequency & Percent & Cumulative Percent \\
\hline Minimum & Maximum & 8184 & 7.11 & 7.11 \\
3000.01 & 3000 & 1131 & 0.98 & 8.09 \\
3500.01 & 3500 & 479 & 0.42 & 8.51 \\
3600.01 & 3600 & 611 & 0.53 & 9.04 \\
3700.01 & 3700 & 837 & 0.73 & 9.77 \\
3800.01 & 3800 & 988 & 0.86 & 10.63 \\
3900.01 & 3900 & 1687 & 1.47 & 12.09 \\
4000.01 & 4000 & 2179 & 1.89 & 13.99 \\
4100.01 & 4100 & 2861 & 2.49 & 16.47 \\
4200.01 & 4200 & 4184 & 3.64 & 20.11 \\
4300.01 & 4300 & 4167 & 3.62 & 23.73 \\
4400.01 & 4400 & 4628 & 4.02 & 27.75 \\
4500.01 & 4500 & 11161 & 9.70 & 37.45 \\
4600.01 & 4600 & 19024 & 16.53 & 53.98 \\
4700.01 & 4700 & 16433 & 14.28 & 68.26 \\
4800.01 & 4800 & 18650 & 16.21 & 84.46 \\
4900.01 & 4900 & 16029 & 13.93 & 98.39 \\
5000.01 & 5000 & 1843 & 1.60 & 99.99 \\
5100.01 & 5100 & 7 & 0.01 & 100.00 \\
\hline
\end{tabular}

Table A-11, Pressure distribution of Shield 39, May 122007 4:00 p.m. to May 13 2007 11:59 p.m.

\begin{tabular}{|c|c|c|c|c|}
\hline \multicolumn{2}{|c|}{ Pressure (psi) } & \multirow{2}{*}{ Frequency } & Percent & Cumulative Percent \\
\hline Minimum & Maximum & 8226 & 7.15 & 7.15 \\
3000.01 & 3000 & 1255 & 1.09 & 8.24 \\
3500.01 & 3500 & 571 & 0.50 & 8.74 \\
3600.01 & 3600 & 721 & 0.63 & 9.37 \\
3700.01 & 3700 & 872 & 0.76 & 10.12 \\
3800.01 & 3800 & 1198 & 1.04 & 11.17 \\
3900.01 & 3900 & 2090 & 1.82 & 12.98 \\
4000.01 & 4000 & 2786 & 2.42 & 15.40 \\
4100.01 & 4100 & 3800 & 3.30 & 18.71 \\
4200.01 & 4200 & 5104 & 4.44 & 23.15 \\
4300.01 & 4300 & 5290 & 4.60 & 27.74 \\
4400.01 & 4400 & 5918 & 5.15 & 32.89 \\
4500.01 & 4500 & 11558 & 10.05 & 42.94 \\
4600.01 & 4600 & 23681 & 20.59 & 63.53 \\
4700.01 & 4700 & 13146 & 11.43 & 74.95 \\
4800.01 & 4800 & 20649 & 17.95 & 92.91 \\
4900.01 & 4900 & 7703 & 6.70 & 99.60 \\
5000.01 & 5000 & 456 & 0.40 & 100.00 \\
5100.01 & 5100 & 0 & 0.00 & 100.00 \\
\hline
\end{tabular}


Table A-12, Pump Pressure distribution, May 122007 4:00 p.m. to May 132007 11:59 p.m.

\begin{tabular}{|c|c|c|c|c|}
\hline \multicolumn{2}{|c|}{ Pump Pressure (psi) } & \multirow{2}{*}{ Frequency } & Percent & Cumulative Percent \\
\cline { 1 - 2 } Minimum & Maximum & 8183 & 7.12 & 7.12 \\
-1000 & 3000 & 279 & 0.24 & 7.36 \\
3000.01 & 3500 & 108 & 0.09 & 7.45 \\
3500.01 & 3600 & 128 & 0.11 & 7.57 \\
3600.01 & 3700 & 188 & 0.16 & 7.73 \\
3700.01 & 3800 & 263 & 0.23 & 7.96 \\
3800.01 & 3900 & 412 & 0.36 & 8.32 \\
3900.01 & 4000 & 690 & 0.60 & 8.92 \\
4000.01 & 4100 & 1792 & 1.56 & 10.47 \\
4100.01 & 4200 & 3503 & 3.05 & 13.52 \\
4200.01 & 4300 & 5455 & 4.74 & 18.27 \\
4300.01 & 4400 & 13425 & 11.68 & 29.94 \\
4400.01 & 4500 & 17434 & 15.16 & 45.11 \\
4500.01 & 4600 & 30918 & 26.89 & 72.00 \\
4600.01 & 4700 & 22028 & 19.16 & 91.16 \\
4700.01 & 4800 & 8642 & 7.52 & 98.68 \\
4800.01 & 4900 & 1492 & 1.30 & 99.97 \\
4900.01 & 5000 & 27 & 0.02 & 100.00 \\
5000.01 & 5100 & 0 & 0.00 & 100.00 \\
5100.01 & 5200 & 0 & 0.00 & 100.00 \\
5200.01 & 5300 & 0 & 0.00 & 100.00 \\
5300.01 & 5400 & 1 & 0.00 & 100.00 \\
5400.01 & 5500 & 1 & 0.00 & 100.00 \\
5500.01 & 5600 & & & \\
\hline
\end{tabular}


Table A-13, Flow distribution Flow 2, May 122007 4:00 p.m. to May 132007 11:59 p.m.

\begin{tabular}{|c|c|c|c|c|}
\hline \multicolumn{2}{|c|}{ Flow (gpm) } & \multirow{2}{*}{ Frequency } & Percent & Cumulative Percent \\
\cline { 1 - 2 } Minimum & Maximum & & 7.02 & 7.02 \\
10.01 & 10 & 8069 & 22.09 & 29.11 \\
20.01 & 20 & 25398 & 36.13 & 65.24 \\
30.01 & 30 & 41536 & 5.37 & 70.61 \\
40.01 & 40 & 6172 & 4.85 & 75.46 \\
50.01 & 50 & 5578 & 5.17 & 80.63 \\
60.01 & 60 & 7942 & 6.10 & 86.73 \\
70.01 & 70 & 6926 & 6.02 & 92.75 \\
80.01 & 80 & 3627 & 3.15 & 95.91 \\
90.01 & 90 & 2096 & 1.82 & 97.73 \\
100.01 & 100 & 1345 & 1.17 & 98.90 \\
110.01 & 110 & 744 & 0.65 & 99.55 \\
120.01 & 120 & 276 & 0.24 & 99.79 \\
130.01 & 130 & 146 & 0.13 & 99.91 \\
140.01 & 140 & 70 & 0.06 & 99.98 \\
150.01 & 150 & 28 & 0.02 & 100.00 \\
\hline
\end{tabular}

Table A-14, Flow distribution Flow 1, May 122007 4:00 p.m. to May 132007 11:59 p.m.

\begin{tabular}{|c|c|c|c|c|}
\hline \multicolumn{2}{|c|}{ Flow (gpm) } & \multirow{2}{*}{ Frequency } & Percent & Cumulative Percent \\
\cline { 1 - 2 } Minimum & Maximum & & 7.05 & 7.05 \\
-10 & 10 & 8103 & 0.83 & 7.88 \\
10.01 & 20 & 956 & 48.51 & 56.38 \\
20.01 & 30 & 11532 & 10.03 & 66.42 \\
30.01 & 40 & 4546 & 3.95 & 70.37 \\
40.01 & 50 & 4398 & 3.83 & 74.19 \\
50.01 & 60 & 4554 & 3.96 & 78.16 \\
60.01 & 70 & 4512 & 3.92 & 82.08 \\
70.01 & 80 & 4969 & 4.32 & 86.40 \\
80.01 & 90 & 5101 & 4.44 & 90.84 \\
90.01 & 100 & 3845 & 3.34 & 94.18 \\
100.01 & 110 & 2289 & 1.99 & 96.17 \\
110.01 & 120 & 1537 & 1.34 & 97.51 \\
120.01 & 130 & 1150 & 1.00 & 98.51 \\
130.01 & 140 & 814 & 0.71 & 99.22 \\
140.01 & 150 & 897 & 0.78 & 100.00 \\
150.01 & 160 & & & \\
\hline
\end{tabular}




\section{APPENDIX B: Field Study Pump Data}


Table B-1, Central Tendency of Pump Flow \& Pump Pressure, May 11, 2007, 12:00 a.m. to 8:00 a.m.

\begin{tabular}{|l|l|l|l|l|l|l|l|}
\hline & \multicolumn{7}{|c|}{ 12:00a.m.-8:00a.m. } \\
\cline { 2 - 8 } & $\begin{array}{l}\text { Flow1 } \\
\text { (gpm) }\end{array}$ & $\begin{array}{l}\text { Flow2 } \\
\text { (gpm) }\end{array}$ & $\begin{array}{l}\text { Pump } \\
\text { Pressure } \\
\text { (psi) }\end{array}$ & $\begin{array}{l}\text { Shield 39 } \\
\text { Pressure } \\
\text { (psi) }\end{array}$ & $\begin{array}{l}\text { Shield 84 } \\
\text { Pressure } \\
\text { (psi) }\end{array}$ & $\begin{array}{l}\text { Shield } \\
\text { 130 } \\
\text { Pressure } \\
\text { (psi) }\end{array}$ & $\begin{array}{l}\text { Shield } \\
\text { 175 } \\
\text { Pressure } \\
\text { (psi) }\end{array}$ \\
\hline Minimum & 0.00 & 0.00 & 0 & 0 & 0 & 0 & 0 \\
Maximum & 155.46 & 155.46 & 5214 & 5033 & 5091 & 5062 & 5076 \\
Mean & 47.70 & 37.78 & 4020 & 4317 & 4342 & 4276 & 4302 \\
Median & 28.71 & 23.02 & 4594 & 4641 & 4685 & 4612 & 4627 \\
\hline
\end{tabular}

Table B-2, Central Tendency of Pump Flow \& Pump Pressure, May 11, 2007, 8:00 a.m. to 4:00 p.m.

\begin{tabular}{|l|l|l|l|l|l|l|l|}
\hline & \multicolumn{9}{|c|}{ 8:00a.m.-4:00p.m. } \\
\cline { 2 - 8 } & $\begin{array}{l}\text { Flow1 } \\
\text { (gpm) }\end{array}$ & $\begin{array}{l}\text { Flow2 } \\
\text { (gpm) }\end{array}$ & $\begin{array}{l}\text { Pump } \\
\text { Pressure } \\
\text { (psi) }\end{array}$ & $\begin{array}{l}\text { Shield 39 } \\
\text { Pressure } \\
\text { (psi) }\end{array}$ & $\begin{array}{l}\text { Shield 84 } \\
\text { Pressure } \\
\text { (psi) }\end{array}$ & $\begin{array}{l}\text { Shield } \\
\text { 130 } \\
\text { Pressure } \\
\text { (psi) }\end{array}$ & $\begin{array}{l}\text { Shield } \\
\text { 175 } \\
\text { Pressure } \\
\text { (psi) }\end{array}$ \\
\hline Minimum & 0.00 & 0.00 & 0 & 165 & 140 & 146 & 0 \\
Maximum & 155.46 & 155.46 & 4957 & 346 & 349 & 348 & 350 \\
Mean & 48.06 & 36.83 & 4258 & 316 & 317 & 312 & 311 \\
Median & 26.89 & 22.10 & 4631 & 323 & 326 & 321 & 321 \\
\hline
\end{tabular}

Table B-3, Central Tendency of Pump Flow \& Pump Pressure, May 11, 2007, 4:00 p.m. to 12:00 a.m.

\begin{tabular}{|l|l|l|l|l|l|l|l|}
\hline & \multicolumn{7}{|c|}{ 4:00p.m.-12:00a.m. } \\
\cline { 2 - 8 } & $\begin{array}{l}\text { Flow1 } \\
\text { (gpm) }\end{array}$ & $\begin{array}{l}\text { Flow2 } \\
\text { (gpm) }\end{array}$ & $\begin{array}{l}\text { Pump } \\
\text { Pressure } \\
\text { (psi) }\end{array}$ & $\begin{array}{l}\text { Shield 39 } \\
\text { Pressure } \\
\text { (psi) }\end{array}$ & $\begin{array}{l}\text { Shield 84 } \\
\text { Pressure } \\
\text { (psi) }\end{array}$ & $\begin{array}{l}\text { Shield } \\
\text { 130 } \\
\text { Pressure } \\
\text { (psi) }\end{array}$ & $\begin{array}{l}\text { Shield } \\
\text { 175 } \\
\text { Pressure } \\
\text { (psi) }\end{array}$ \\
\hline Minimum & 0.14 & 0.00 & 37 & 1 & 1 & 1 & 1 \\
Maximum & 155.46 & 155.46 & 4957 & 5033 & 5105 & 5047 & 5120 \\
Mean & 54.09 & 42.36 & 4501 & 4469 & 4489 & 4430 & 4435 \\
Median & 34.68 & 27.30 & 4618 & 4641 & 4656 & 4598 & 4598 \\
\hline
\end{tabular}


Table B-4, Central Tendency of Pump Flow \& Pump Pressure, May 12, 2007, 12:00 a.m. to 8:00 a.m.

\begin{tabular}{|l|r|r|l|l|l|l|l|}
\hline & \multicolumn{7}{|c|}{ 12:00a.m.-8:00a.m. } \\
\cline { 2 - 8 } & $\begin{array}{l}\text { Flow1 } \\
\text { (gpm) }\end{array}$ & $\begin{array}{l}\text { Flow2 } \\
\text { (gpm) }\end{array}$ & $\begin{array}{l}\text { Pump } \\
\text { Pressure } \\
\text { (psi) }\end{array}$ & $\begin{array}{l}\text { Shield 39 } \\
\text { Pressure } \\
\text { (psi) }\end{array}$ & $\begin{array}{l}\text { Shield 84 } \\
\text { Pressure } \\
\text { (psi) }\end{array}$ & $\begin{array}{l}\text { Shield } \\
\text { 130 } \\
\text { Pressure } \\
\text { (psi) }\end{array}$ & $\begin{array}{l}\text { Shield } \\
\text { 175 } \\
\text { Pressure } \\
\text { (psi) }\end{array}$ \\
\hline Minimum & 19.99 & 16.11 & 2574 & 2422 & 2509 & 2422 & 2437 \\
Maximum & 155.46 & 155.46 & 4984 & 5033 & 5076 & 5047 & 5062 \\
Mean & 49.11 & 38.11 & 4583 & 4575 & 4597 & 4529 & 4544 \\
Median & 29.46 & 23.21 & 4621 & 4641 & 4656 & 4598 & 4612 \\
\hline
\end{tabular}

Table B-5, Central Tendency of Pump Flow \& Pump Pressure, May 12, 2007, 8:00 a.m. to 4:00 p.m.

\begin{tabular}{|l|l|l|l|l|l|l|l|}
\hline \multirow{2}{*}{} & \multicolumn{7}{|c|}{ 8:00a.m.-4:00p.m. } \\
\cline { 2 - 7 } & $\begin{array}{l}\text { Flow1 } \\
\text { (gpm) }\end{array}$ & $\begin{array}{l}\text { Flow2 } \\
\text { (gpm) }\end{array}$ & $\begin{array}{l}\text { Pump } \\
\text { Pressure } \\
\text { (psi) }\end{array}$ & $\begin{array}{l}\text { Shield 39 } \\
\text { Pressure } \\
\text { (psi) }\end{array}$ & $\begin{array}{l}\text { Shield 84 } \\
\text { Pressure } \\
\text { (psi) }\end{array}$ & $\begin{array}{l}\text { Shield } \\
130 \\
\text { Pressure } \\
\text { (psi) }\end{array}$ & $\begin{array}{l}\text { Shield } \\
\text { 175 } \\
\text { Pressure } \\
\text { (psi) }\end{array}$ \\
\hline $\begin{array}{l}\text { Minimum } \\
\text { Maximum } \\
\begin{array}{l}\text { Mean } \\
\text { Median }\end{array}\end{array}$ & \multicolumn{7}{|c|}{ Power Station Move } \\
\hline
\end{tabular}

Table B-6, Central Tendency of Pump Flow \& Pump Pressure, May 12, 2007, 4:00 p.m. to 12:00 a.m.

\begin{tabular}{|l|l|l|l|l|l|l|l|}
\hline & \multicolumn{7}{|c|}{ 4:00p.m.-12:00a.m. } \\
\cline { 2 - 8 } & $\begin{array}{l}\text { Flow1 } \\
\text { (gpm) }\end{array}$ & $\begin{array}{l}\text { Flow2 } \\
\text { (gpm) }\end{array}$ & $\begin{array}{l}\text { Pump } \\
\text { Pressure } \\
\text { (psi) }\end{array}$ & $\begin{array}{l}\text { Shield 39 } \\
\text { Pressure } \\
\text { (psi) }\end{array}$ & $\begin{array}{l}\text { Shield 84 } \\
\text { Pressure } \\
\text { (psi) }\end{array}$ & $\begin{array}{l}\text { Shield } \\
\text { 130 } \\
\text { Pressure } \\
\text { (psi) }\end{array}$ & $\begin{array}{l}\text { Shield } \\
\text { 175 } \\
\text { Pressure } \\
\text { (psi) }\end{array}$ \\
\hline Minimum & 0.14 & 0.00 & 37 & 1 & 1 & 1 & 1 \\
Maximum & 155.46 & 155.46 & 5410 & 5047 & 5105 & 5047 & 5076 \\
Mean & 55.66 & 44.01 & 4521 & 4490 & 4519 & 4449 & 4455 \\
Median & 35.87 & 29.80 & 4611 & 4627 & 4656 & 4598 & 4598 \\
\hline
\end{tabular}


Table B-7, Central Tendency of Pump Flow \& Pump Pressure, May 13, 2007, 12:00 a.m. to 8:00 a.m.

\begin{tabular}{|l|l|l|l|l|l|l|l|}
\hline & \multicolumn{7}{|c|}{ 12:00a.m.-8:00a.m. } \\
\cline { 2 - 8 } & $\begin{array}{l}\text { Flow1 } \\
\text { (gpm) }\end{array}$ & $\begin{array}{l}\text { Flow2 } \\
\text { (gpm) }\end{array}$ & $\begin{array}{l}\text { Pump } \\
\text { Pressure } \\
\text { (psi) }\end{array}$ & $\begin{array}{l}\text { Shield 39 } \\
\text { Pressure } \\
\text { (psi) }\end{array}$ & $\begin{array}{l}\text { Shield 84 } \\
\text { Pressure } \\
\text { (psi) }\end{array}$ & $\begin{array}{l}\text { Shield } \\
\text { 130 } \\
\text { Pressure } \\
\text { (psi) }\end{array}$ & $\begin{array}{l}\text { Shield } \\
\text { 175 } \\
\text { Pressure } \\
\text { (psi) }\end{array}$ \\
\hline Minimum & & & & 1 & 1 & 1 & 5 \\
Maximum & 155.46 & 155.46 & 5016 & 5047 & 5265 & 5076 & 5091 \\
Mean & 45.71 & 35.56 & 4515 & 4555 & 4576 & 4515 & 4521 \\
Median & 29.79 & 23.03 & 4609 & 4656 & 4670 & 4598 & 4612 \\
\hline
\end{tabular}

Table B-8, Central Tendency of Pump Flow \& Pump Pressure, May 13, 2007, 8:00 a.m. to 4:00 p.m.

\begin{tabular}{|l|l|l|l|l|l|l|l|}
\hline & \multicolumn{7}{|c|}{ 8:00a.m.-4:00p.m. } \\
\cline { 2 - 8 } & $\begin{array}{l}\text { Flow1 } \\
\text { (gpm) }\end{array}$ & $\begin{array}{l}\text { Flow2 } \\
\text { (gpm) }\end{array}$ & $\begin{array}{l}\text { Pump } \\
\text { Pressure } \\
\text { (psi) }\end{array}$ & $\begin{array}{l}\text { Shield 39 } \\
\text { Pressure } \\
\text { (psi) }\end{array}$ & $\begin{array}{l}\text { Shield 84 } \\
\text { Pressure } \\
\text { (psi) }\end{array}$ & $\begin{array}{l}\text { Shield } \\
\text { 130 } \\
\text { Pressure } \\
\text { (psi) }\end{array}$ & $\begin{array}{l}\text { Shield } \\
\text { 175 } \\
\text { Pressure } \\
\text { (psi) }\end{array}$ \\
\hline Minimum & 0.00 & 0.00 & 0 & 1 & 1 & 1 & 1 \\
Maximum & 155.46 & 155.46 & 5038 & 5033 & 5076 & 5091 & 5091 \\
Mean & 30.25 & 21.52 & 3786 & 3814 & 3838 & 3791 & 3709 \\
Median & 25.72 & 16.54 & 4638 & 4685 & 4699 & 4641 & 4641 \\
\hline
\end{tabular}

Table B-9, Central Tendency of Pump Flow \& Pump Pressure, May 13, 2007, 4:00 p.m. to $12: 00$ a.m.

\begin{tabular}{|l|l|r|l|l|l|l|l|}
\hline & \multicolumn{7}{|c|}{ 4:00p.m.-12:00a.m. } \\
\cline { 2 - 8 } & $\begin{array}{l}\text { Flow1 } \\
\text { (gpm) }\end{array}$ & $\begin{array}{l}\text { Flow2 } \\
\text { (gpm) }\end{array}$ & $\begin{array}{l}\text { Pump } \\
\text { Pressure } \\
\text { (psi) }\end{array}$ & $\begin{array}{l}\text { Shield 39 } \\
\text { Pressure } \\
\text { (psi) }\end{array}$ & $\begin{array}{l}\text { Shield 84 } \\
\text { Pressure } \\
\text { (psi) }\end{array}$ & $\begin{array}{l}\text { Shield } \\
\text { 130 } \\
\text { Pressure } \\
\text { (psi) }\end{array}$ & $\begin{array}{l}\text { Shield } \\
\text { 175 } \\
\text { Pressure } \\
\text { (psi) }\end{array}$ \\
\hline Minimum & 0.13 & 0.00 & 31 & 1 & 1 & 1 & 1 \\
Maximum & 155.46 & 155.46 & 5016 & 5076 & 5163 & 5105 & 5134 \\
Mean & 45.71 & 35.56 & 4515 & 4313 & 4335 & 4274 & 4262 \\
Median & 29.79 & 23.03 & 4609 & 4670 & 4699 & 4641 & 4641 \\
\hline
\end{tabular}

